\title{
DEVELOPMENT OF AN ON-LINE COAL WASHABILITY ANALYZER
}

DOE Award No.:

DE-FG22-96PC96215

$\underline{\text { Submitted to: }}$

United States Department of Energy

Federal Energy Technology Center

Principal Investigator:

J. D. Miller, Professor

Department of Metallurgical Engineering

University of Utah

Co-Principal Investigators:

C. L. Lin, Research Associate Professor

Department of Metallurgical Engineering

University of Utah.

G. H. Luttrell, Professor, and G.T. Adel, Professor

Department of Mining and Minerals Engineering

Virginia Polytechnic Institute and State University

Barbara Marin, Geologist

Terra Tek, Inc.

Salt Lake City, Utah

Submission Date:

June 26, 2001 


\section{TABLE OF CONTENTS}

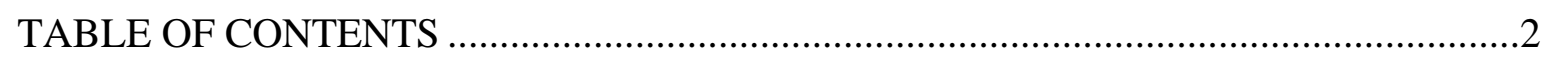

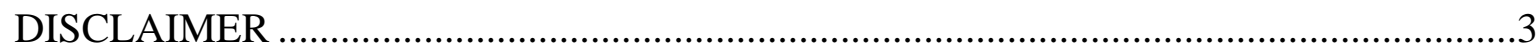

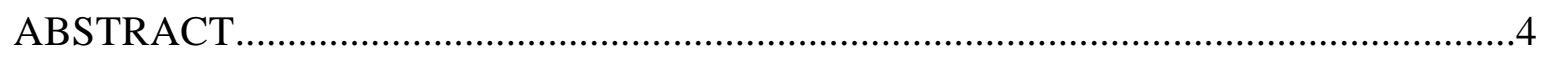

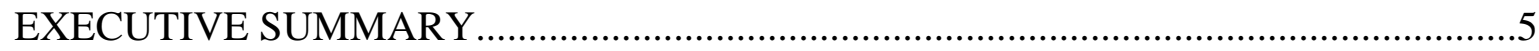

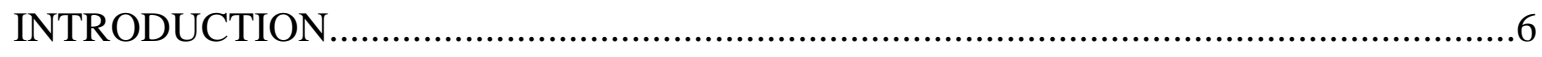

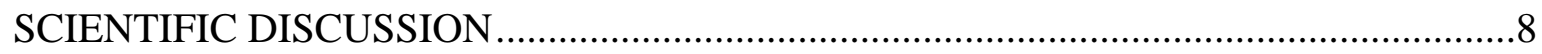

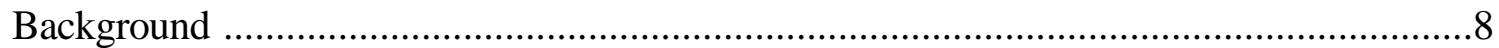

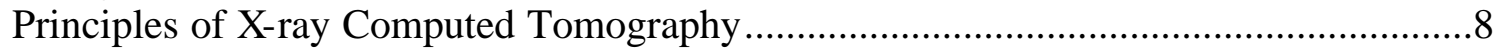

Quantitative Coal Washability Analysis Using X-Ray CT .............................................10

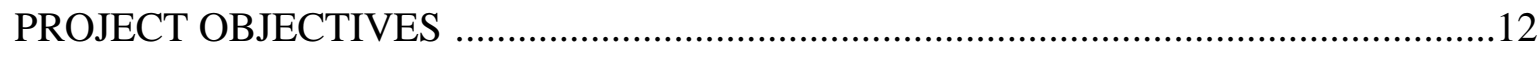

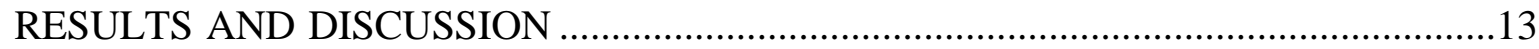

Part I: Development of CT-Based On-Line Coal Washability Analyzer.........................13

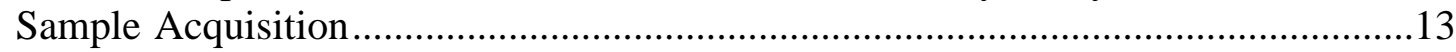

Gravity/Size Partitioning .......................................................................................13

X-Ray CT Equipment and Calibration..................................................................14

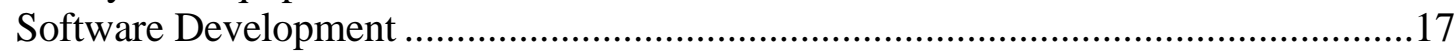

Statistical Analysis of Finite Mixture Distributions from Tomographic Data.........17

Particle Segmentation, Classification and Mass Density Analysis ............................25

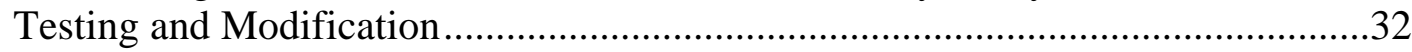

Summary of Development Work ..........................................................................36

Part II: Evaluation Under Simulated On-Line Conditions ................................................37

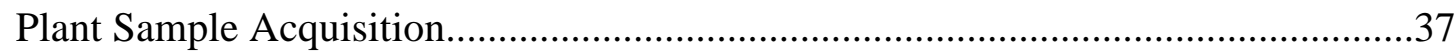

On-line Considerations for Segmentation, Classification and Density Analysis..........38

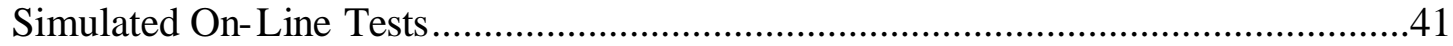

Plant Sampling for System Evaluation.....................................................................51

Technical Justification for On-Line Washability Analysis ..........................................57

Economic Justification for On-Line Washability Analysis ...........................................61

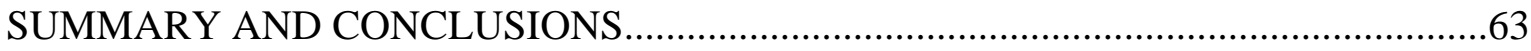

Part I: Development of CT-Based On-Line Coal Washability Analyzer.........................63

Part II: Evaluation Under Simulated On-Line Conditions ..............................................64

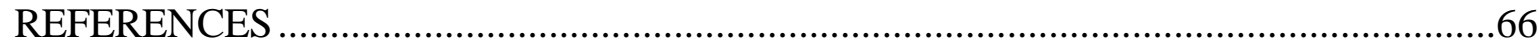




\section{DISCLAIMER}

This report was prepared as an account to work sponsored by an agency of the United States Government. Neither the United States Government nor any agency thereof, nor any of their employees, makes any warranty, express or implied, or assumes any legal liability or responsibility for the accuracy, completeness, or usefulness of any information, apparatus, product, or process disclosed, or represents that its use would not infringe privately owned rights. Reference herein to any specific commercial product, process, or service by trade name, trademark, manufacturer, or otherwise does not necessarily constitute or imply its endorsement, recommendation, or favoring by the United States Government or any agency thereof. The views and opinions of authors expressed herein do not necessarily state or reflect those of the United States Government or any agency thereof. 


\begin{abstract}
Washability analysis is the basis for nearly all coal preparation plant separations. Unfortunately, there are no on-line techniques for determining this most fundamental of all coal cleaning information. In light of recent successes at the University of Utah, it now appears possible to determine coal washability on-line through the use of x-ray computed tomography (CT) analysis. The successful development of such a device is critical to the establishment of process control and automated coal blending systems. In this regard, Virginia Tech, Terra Tek Inc., and U.S. coal producers have joined with the University of Utah and to undertake the development of an X-ray CT-based on-line coal washability analyzer with financial assistance from DOE. Each project participant brought special expertise to the project in order to create a new dimension in coal cleaning technology. The project involves development of appropriate software and extensive testing/evaluation of well-characterized coal samples from operating coal preparation plants. Data collected to date suggest that this new technology is capable of serving as a universal analyzer that can not only provide washability analysis, but also particle size distribution analysis, ash analysis, and perhaps pyritic sulfur analysis.
\end{abstract}




\section{EXECUTIVE SUMMARY}

The primary objective of the proposed research program was to develop a CTbased on-line coal washability analyzer. A secondary objective was be to demonstrate the capabilities of the analyzer by comparing efficiency data from traditional float-sink tests conducted at preparation plant site with efficiency data generated by the washability analyzer. The scope of the proposed research program involved several tasks including (i) acquisition and preparation of test samples for use in testing and calibrating the analyzer, (ii) development of appropriate hardware and software necessary to adapt a CT analyzer for use in determining coal washability, (iii) testing and modification of the analyzer using well-characterized coal samples, (iv) evaluation of the analyzer's performance under simulated plant conditions, and (v) evaluation of the technical and economic feasibility of implementing the CT-based washability analyzer on a commercial basis. Researchers from the University of Utah and Terra Tek Inc. performed tasks related to the development, calibration and testing the analyzer, while technical personnel from Virginia Tech and Coal companies provided the required coal samples, evaluated the industrial capabilities of the analyzer, and promoted system commercialization. 


\section{INTRODUCTION}

The determination of the washability characteristics of various coal streams is an essential step in the evaluation of preparation plant performance. Conventional washability data are generally obtained in the laboratory by tedious sink-float analysis (particle fractionation by specific gravity) using large quantities of hazardous halogenated organic compounds [1]. The cost of a single washability analysis is about $\$ 1,000$ and requires at least one day of laboratory testing when performed on a rush basis. A complete evaluation of plant performance, including sampling and washability analysis, normally requires several weeks of effort and generally costs in excess of $\$ 20,000$. Despite this high cost, plant-wide washability analyses can us ually be justified due to the tremendous impact of misplaced material on the profitability of a mining operation.

The impact of preparation plant performance on corporate profitability has been studied in detail by Norton-Hambleton Consultants [2]. Their sudies indicate that an unfavorable change in plant efficiency is second only to coal transportation in terms of its impact on corporate profitability, while an unfavorable change in the cost of underground mining is a distance third. Their findings are supported by recent field studies conducted at Virginia Tech that show that even minor operating problems can easily reduce the organic efficiency of a preparation plant by 1 percentage point. Over a three-week period, this seemingly small decline in organic efficiency corresponds to $\$ 84,000$ in lost clean coal production for a 1,000 tph operation (assuming a \$25/ton clean coal price and operation for 2 shifts/day). Larger losses of recoverable coal associated with equipment failures, poorly designed circuits and poor operating practices have a significantly larger impact, exceeding $\$ 2$ million annually for some eastern U.S. plants.

Losses due to misplaced material could be greatly minimized by providing plant operators with "on-line" efficiency data that can be used for process control and day-to-day plant optimization. Up to now, this capability has been hampered by the lack of any instrumental method for the rapid determination of coal washability. However, with advancements of computer technology, software development, and improved image

processing technology, new instrumental techniques for material analysis and testing are being developed to analyze the properties of materials in a fast, automatic and 
nondestructive fashion. One of the most promising of these is the technique of $\mathrm{x}$-ray computed tomography (CT).

X-ray CT had its origin in the medical service [3] and has now been applied to a wide variety of non-medical and industrial applications [4]. CT techniques have an inherent advantage in providing very detailed images of the internal structures of opaque materials in a nondestructive manner. Applications of CT techniques in coal technology have been reported since the mid-1980s. Coal microtomography was first studied by Flannery et al. [5,6] and coal structure was investigated by Maylotte et al. [7] and Spiro et al.[8] For quantitative analysis of particulate systems, such as coal washability analysis, a previous study [9] conducted at the University of Utah indicates that X-ray CT can provide sufficient information to construct the washability curve within minutes of sample collection. A step-by-step procedure for the determination of coal particle density using $\mathrm{x}$ ray CT was developed in this preliminary investigation. In addition, with the use of an appropriate algorithm, the successful construction of coal washability curves using xray CT analysis has been demonstrated. It is evident that the coal washability curve derived from the CT-based technique is in good agreement with the results obtained by the conventional sink-float analysis. 


\section{SCIENTIFIC DISCUSSION}

\section{Background}

The washability curve for coal is the basic indicator of the coal quality and its amenability to cleaning. Thus, the washability curve determines whether the coal can be cleaned to meet the necessary product specifications, or whether it needs further processing (e.g., size reduction and separation). The washability curves also provide the basis for the evaluation of the organic efficiency for a given separation process. The washability curves are constructed by a tedious and slow method called sink-float analysis. The principle behind this analytical technique (sink-float) is nothing more than density fractionation. By its very nature and the way it is conducted, the sink-float results cannot be obtained in a reasonable amount of time to provide a satisfactory feedback mechanism for control of various unit operations in a coal preparation plant. On the other hand, the scanned sections produced by x-ray CT are maps of the density variation in the scanned volume that can be determined in a matter of minutes [3]. Reconstruction of the 3-dimensional particle population from the scanned sections should provide sufficient information not only to construct the washability curve for the coal sample in question, but also, should provide information on the particle size and grain size distribution of mineral matter grains present in the coal particles.

\section{Principles of X-ray Computed Tomography}

The basic principles of X-ray CT are well documented [3] and only a short overview is provided herein. Figure 1 shows a schematic diagram of the basic operating principles of a translate-rotate CT machine. Consider an xray beam of intensity of b incident on an object emerging with intensity $\mathrm{I}$. The measurement quantity $\ln \left(\mathrm{I}_{\mathrm{o}} / \mathrm{I}\right)$ is equal to the summation of the xray attenuation coefficients $\left(\mu_{l}\right)$ of the material at each point along the incident line. In CT operation, total attenuation is measured along all rays through an object from several directions around the object, and the image is reconstructed from these intensity data using a reconstruction algorithm. As illustrated in Figure 1, a combination of the translational and rotational motion of the x-ray tube and the use of an appropriate detector allow for the measurement of the x-ray attenuation. The measured 


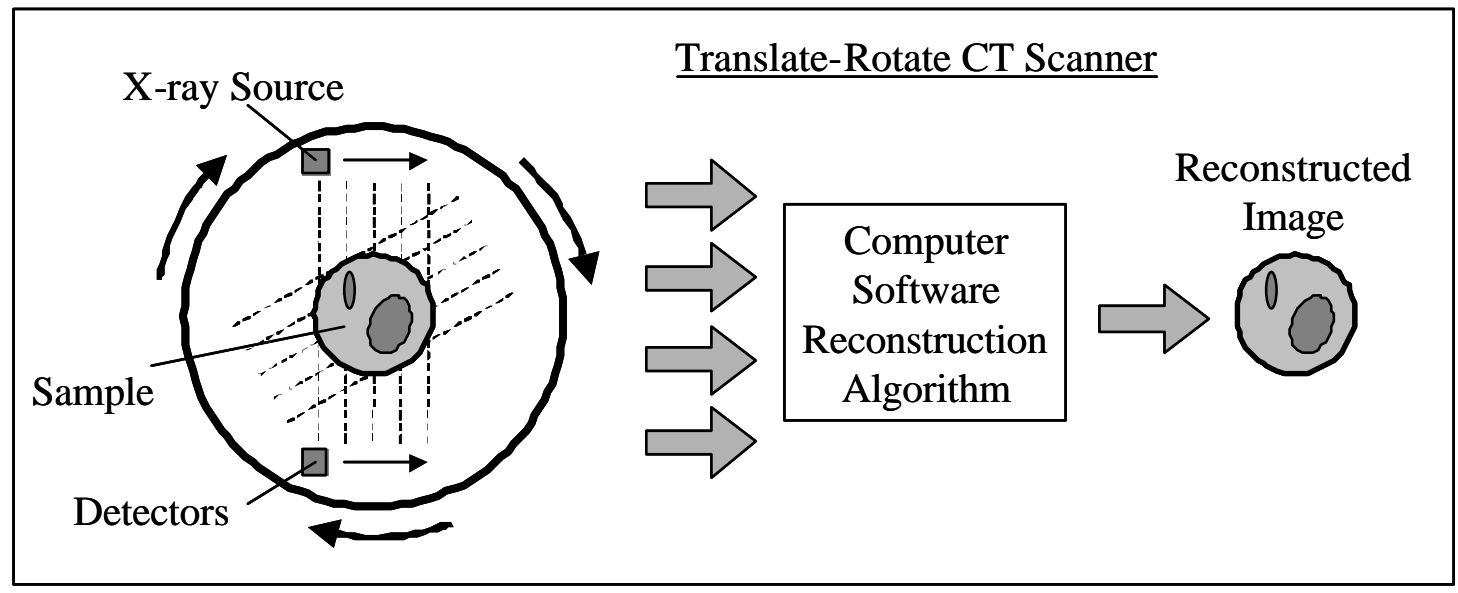

Figure 1. A schematic diagram illustrating the basic operating principles of a translaterotate CT machine.

projections are manipulated by the computer software according to a specific reconstruction algorithm to produce a two-dimensional map of x-ray attenuation coefficients of the irradiated cross sections. Differentiation of features within the sample is possible because $\mu_{l}$ at each point depends directly on the electron density, the effective atomic number $(\mathrm{Z})$ of the material comprising the sample, and the energy of the $\mathrm{x}$-ray beam (E). A simplified equation that illustrates the approximate relationship among these quantities is:

$$
\mu_{l}=\rho\left(a+\frac{b Z^{3.8}}{E^{3.2}}\right)
$$

where $\rho$ is the density of the phase, $a$ is a quantity with a relatively small energy dependence and $b$ is a constant $[10,11]$. When a mixture of atomic species is present, $\mathrm{Z}$ (the effective atomic number) is defined by:

$$
Z^{3.8}=\sum_{i}\left(f_{i}\left[Z_{i}\right]^{3.8}\right)
$$

where $f_{i}$ is the fraction of the total number of electrons contributed by element $i$ with atomic number $\mathrm{Z}_{i}$. For the case of transmission tomography such as $\mathrm{x}$-ray $\mathrm{CT}$, the modern CT scanners are capable of discriminating between values of $\mu_{l}$ that differ by as little as 
$0.1 \%$. In practice, density measurement from x-ray tomographic data can be done either by calibrating the CT machines with objects of known density and obtaining a correlation equation that relates density with attenuation coefficients or using dual energy scanning to determine directly the density of the material. In such a fashion, then, a two-dimensional density map of the object under investigation can be established. Applications of x-ray CT in coal and mineral processing have been demonstrated [4-9, 12].

\section{Quantitative Coal Washability Analysis Using X-Ray CT}

The conventional method for determining the washability curve is based on a series of sink-float separations using heavy organic liquids. The steps that are necessary for this operation are as follows:

1. The coal sample is first sized into different size intervals.

2. For each size class, a suitable amount of sample is taken.

3. Then, dense liquid separations are performed for each size class - a series of binary fractionations based on density.

4. From the weight and analysis of each density fraction in step 3, coal washability curves for each size class are created.

In the case of x-ray CT-based washability calculations [9], the third step of the conventional approach is replaced by a series of steps based on CT scanning of the sample to obtain 3-D information by reconstruction or by transformation of 2-D data. Thus, in a similar fashion, the third step needed in constructing a CT-based washability curve is as follows:

3. Density fractionation by CT analysis:

a. Each sample is loaded into a separate cylindrical container, placed in the CT scanner and properly aligned.

b. CT measurements (sequential scans) are taken as the container passes through the scanner of predetermined scan spacings.

c. Computer analysis of the scan data is completed to determine the 2-D density data. 
d. The 2-D CT images (density data) are then used to provide 3-D information using either 3-D reconstruction or a transformation correction.

e. The particles are isolated and the mass and volume of each particle is calculated.

Figure 2 shows the schematic diagram for the measurement of a CT-based coal washability curve. This report presents the results for the development of a CT-based, on-line coal washability analyzer. The development of appropriate hardware and software necessary to adapt a CT analyzer for use in determining coal washability is discussed. Testing of the analyzer using well-characterized coal samples is also presented.

\section{Schematic Diagram of a Sequential X-Ray CT Scan of a Packed Bed of Coal Particles for Coal Washability Analysis}

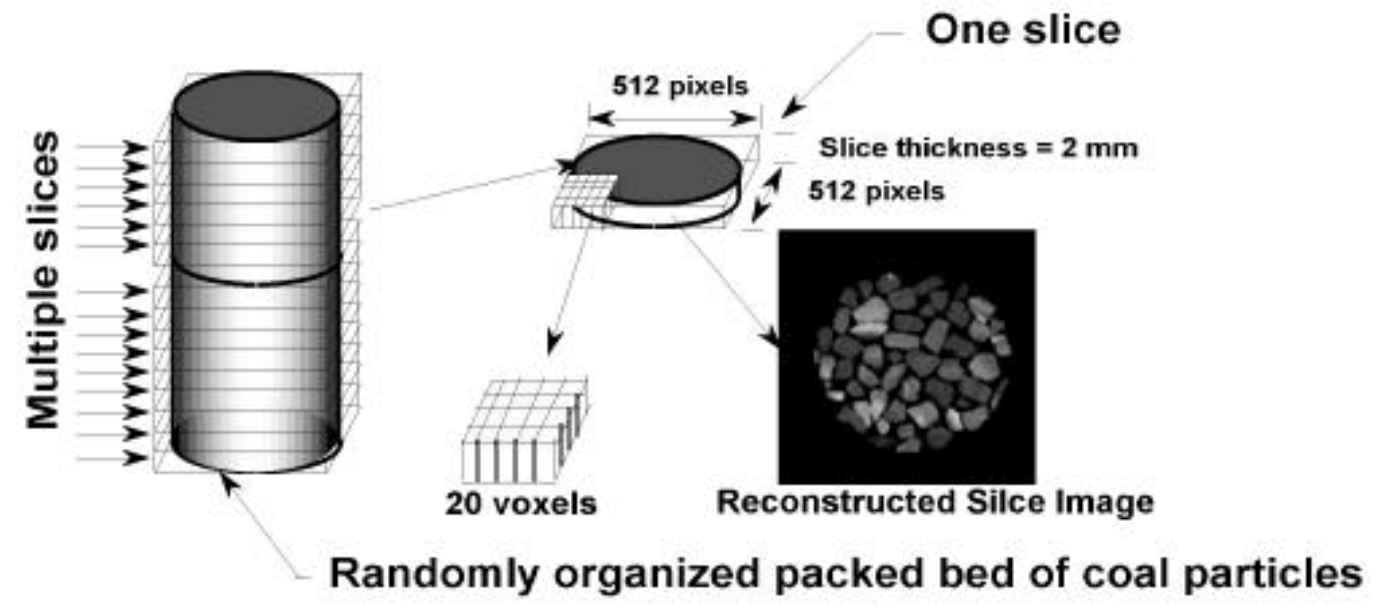

Figure 1. Schematic diagram of sequential x-ray CT scan of coal samples for coal washability analysis. 


\section{PROJECT OBJECTIVES}

The primary objective of this research program is to develop a CT-based, on-line

coal washability analyzer. A secondary objective will be to demonstrate the capabilities of the analyzer by comparing efficiency data from traditional float-sink tests with efficiency data generated by the washability analyzer. The scope of the proposed research program involves several tasks including:

(i) acquisition and preparation of test samples for use in testing and calibrating the analyzer,

(ii) development of appropriate hardware and software necessary to adapt a CT analyzer for use in determining coal washability,

(iii) testing and modification of the analyzer using well-characterized coal samples,

(iv) evaluation of the analyzer's performance under simulated plant conditions, and

(v) evaluation of the technical and economic feasibility of implementing the CT-based washability analyzer on a commercial basis.

Researchers from the University of Utah and Terra Tek Inc. performed tasks related to the development, calibration and testing the analyzer, while technical personnel from Virginia Tech and coal companies provided the required coal samples, evaluated the industrial capabilities of the analyzer, and promoted system commercialization. 


\section{RESULTS AND DISCUSSION}

\section{Part I: Development of CT-Based On-Line Coal Washability Analyzer}

\section{$\underline{\text { Sample Acquisition }}$}

This subtask involves the acquisition of a run-of-mine coal sample to be used in the development, calibration and initial testing of the proposed CT-based washability analyzer. The site selected for the preliminary sampling campaign was the Lady Dunn preparation plant. This newly renovated and recently expanded facility is located in Cannelton, West Virginia, just south of Charleston. The plant is owned and operated by Cyprus Amax Coal Company during the sampling period. The plant was capable of a maximum throughput capacity of approximately $1400 \mathrm{tph}$. The primary feed coal to the plant is the Stockton seam, although feed coal from the No. 5 Block seam is processed on an as-needed basis.

\section{Gravity/Size Partitioning}

The development of the CT-based washability analyzer requires well-characterized test samples for use in calibration and preliminary testing. These samples were prepared by personnel at Virginia Tech in cooperation with a commercial coal testing laboratory located in Beckley, West Virginia. The samples were shipped to the University of Utah after the float-sink tests on the various size fractions had been completed. Each of the size and density fractions generated by this procedure were subjected to coal analysis for the determinations of moisture, volatile matter, ash, fixed carbon and total sulfur content. The sample was screened into six size fractions (+101.6, 101.6x50.8, 50.8x25.4, 25.4x12.7 $12.7 \times 6.3$ and $-6.3 \mathrm{~mm}$ ) and then each size fraction was subjected to detailed washability (sink-float) tests. The gravity classes used for the sink-float tests include: Fbat $\mathrm{x}$ 1.30, $1.30 \times 1.35,1.35 \times 1.40,1.40 \times 1.50,1.50 \times 1.60,1.60 \times 1.80,1.80 \times 2.10$, Sink x 2.10. In total, 40 size/gravity fractions were generated by this procedure. The samples (55 buckets) were shipped to the University of Utah for CT analysis. Washability data for the coal sample from the Stockton seam are provided in Appendix A. 


\section{$\underline{\text { X-Ray CT Equipment and Calibration }}$}

The Philips Tomoscan 60/TX CT scanner (Figure 3) located at Terra Tek Inc. were used for this study. Plastic containers were used for sample chambers. As mentioned previously, to use the CT measurements for coal washability analysis, it is necessary to do a calibration step with known density materials or directly determine the density using dual-energy scans. Both methods were evaluated during this study. In the first experiment, coal particles of known density (measured by He pycnometry) were arranged in a container as a coal phantom for dual-energy CT scans. These dual-energy settings were 100 and 130 $\mathrm{KeV}$.

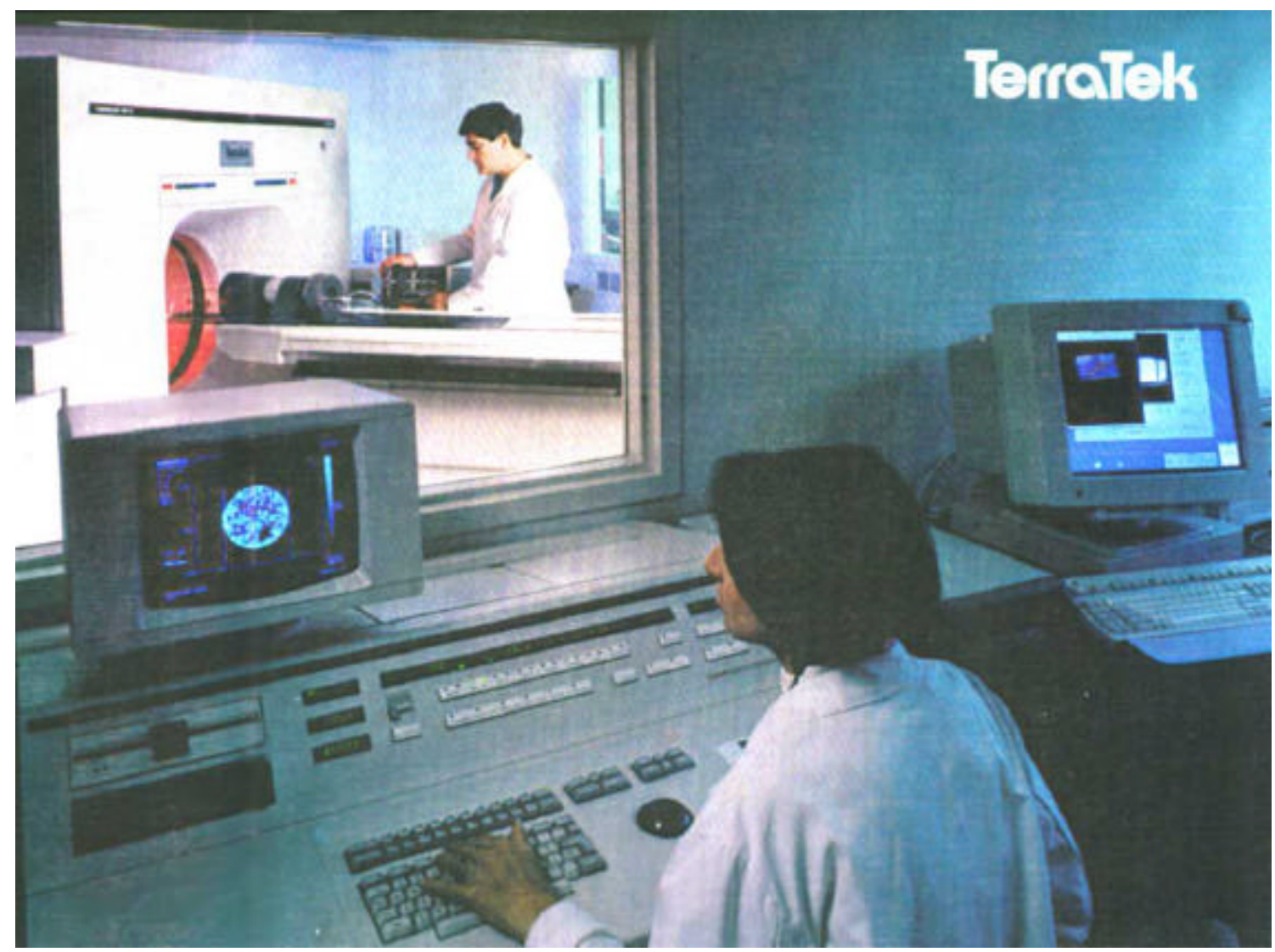

Figure 3. The Philips Tomoscan 60/TX CT scanner used in the current research project. 
Figure 4 shows the 2-D x-ray CT scan of the coal phantom and the corresponding density of the coal particles measured from He pycnometry. The CT machine was calibrated using the coal phantom before and after each scan. Figure 5 presents one of the calibration curves obtained before and after sample scans together with the regression equation from which the actual density scale was established. For particle density measurement, this xray CT scanner is quite stable as indicated by the calibration results for the phantom before and after scanning (approximately 60 scans of a packed bed sample) as shown in Figure 4.

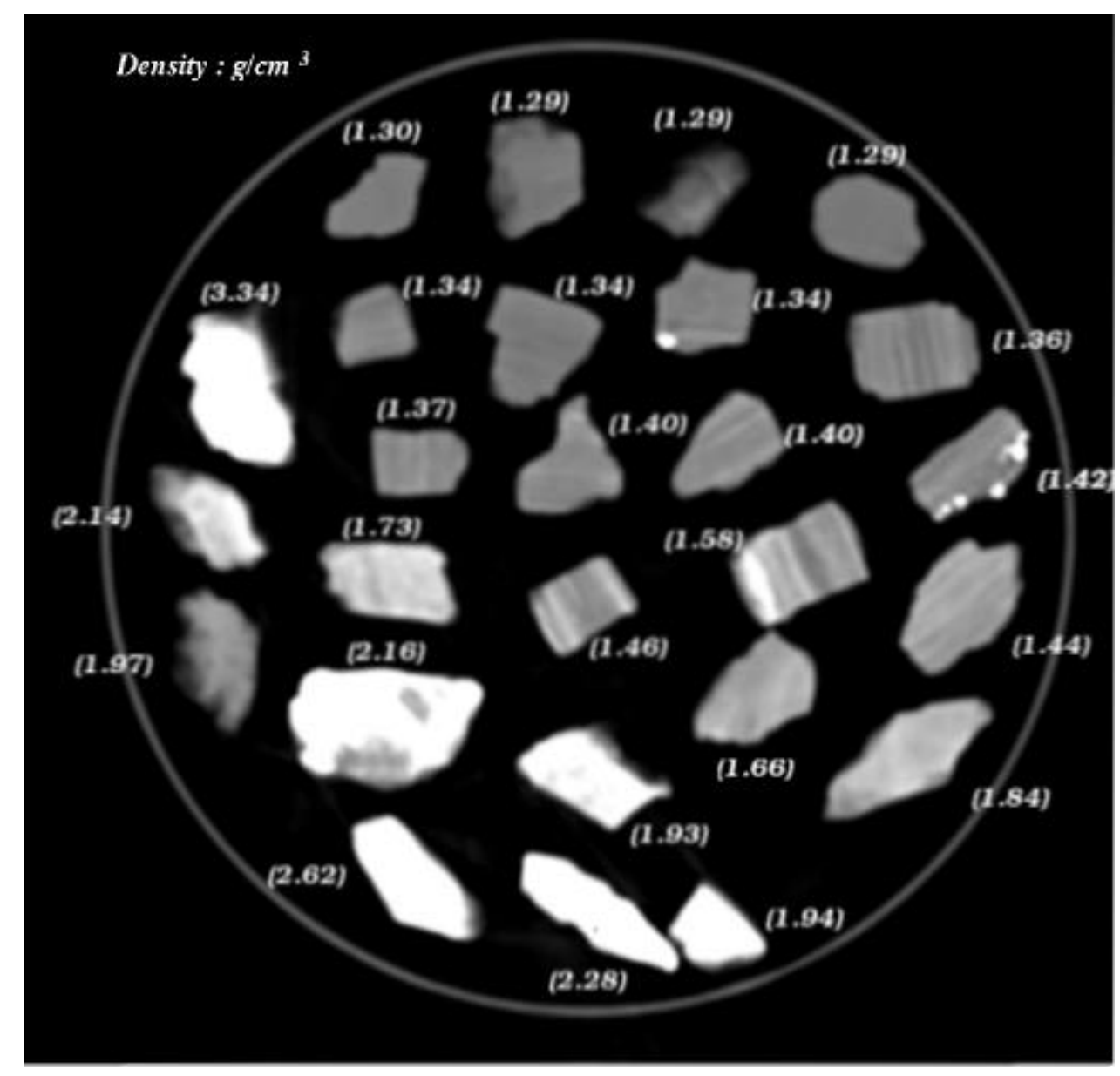

Figure 4. 2-D x-ray CT scan of coal phantom for density calibration. Number indicates the corresponding density of the coal particles measured from $\mathrm{He}$ pycnometry. 


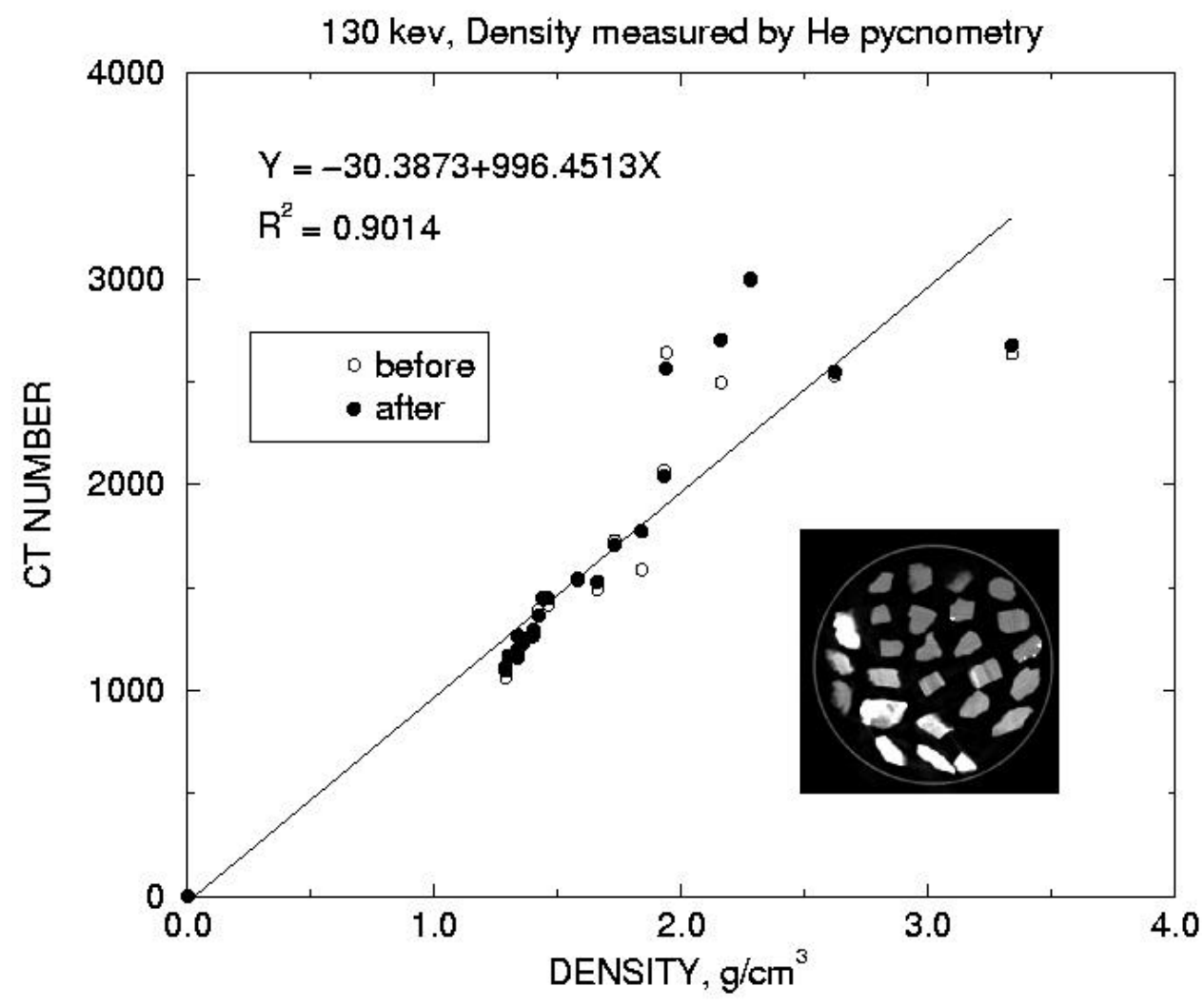

Figure 5. Calibration curve for x-ray CT using coal phantom as shown in Figure 4.

For particle densities below $2.0 \mathrm{~g} / \mathrm{cm}^{3}$, the reproducibility of the density measured with the x-ray CT scanner is very accurate due to the uniformity of the low-density coal particles. However, for densities higher than $2.0 \mathrm{~g} / \mathrm{cm}^{3}$, a large variation is observed. This discrepancy is due to the complex nature of coal and finite volume effects of the tomographic data. Initially, the coal phantom was setup to be used to calibrate the density scale for the coal washability determination. However, an alternative density calibration method was subsequently developed to obtain a more reliable relationship between the density and the attenuation coefficient histogram. Details of this density calibration method are discussed in the next section. Since similar results were obtained for dualenergy scans, $130 \mathrm{KeV}$ was chosen as the energy level for all the remaining scans associated with sample testing. 


\section{$\underline{\text { Software Development }}$}

The x-ray computed tomography equipment being used in this study produces images that are two-dimensional slices of the coal particle bed. For quantitative analysis of the mass density distributions from these tomographic images, a finite mixture model [13] and a special image processing technique was used to determine the coal washability curve. In this approach, physical phenomenon for the construction of coal washability curve can be described from the analysis of multimodal densities. In this regard, the problem is that of decomposing a given attenuation coefficient histogram curve into its components and mixing weights. In this case, the individual components of the curve are based on the 'image segmentation' of the particle surface. The detection of surface boundaries and classification of the particle population is a critical aspect of the algorithm development for the 'image segmentation'. In this section, statistical analysis of the finite mixture distribution, based on the characteristics of tomographic data, is discussed first. Then, methodologies based on the finite mixture model and image processing techniques being developed to facilitate the segmentation and classification of particle images, are discussed in order to determine the density distribution for the packed bed of coal particles.

\section{Statistical Analysis of Finite Mixture Distributions from Tomographic Data}

The reconstructed $\mathrm{CT}$ image consists of a 2-D array of $\mathrm{x}$-ray attenuation coefficients, each associated with a finite-volume cube (voxel) of the sample. As mentioned previously, the attenuation coefficients are a function of the average density and composition of the material in any given voxel. A plot of the attenuation coefficient histogram is a measure of the density variation throughout the sample. Consider a 2-D xray tomographic slice of the packed bed of coal particles (containing single size and single density particles in this case) as shown in Figure 6(a). The distinction between the air and coal phases is not sharp due to finite volume effects and the mature of $x$-ray tomography. The attenuation coefficient histogram corresponding to this CT image consists of an overlapping bivariate distribution as shown in Figure 6(b). The peak with the higher attenuation coefficient value $(\sim 1200)$ is associated with the coal phase having a density 


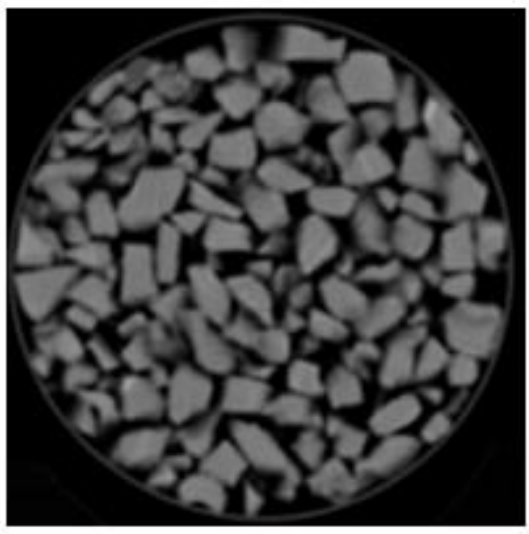

(a)

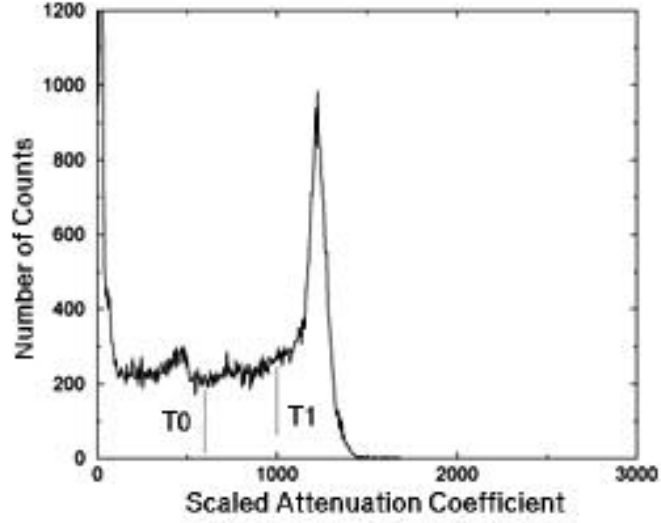

(b)

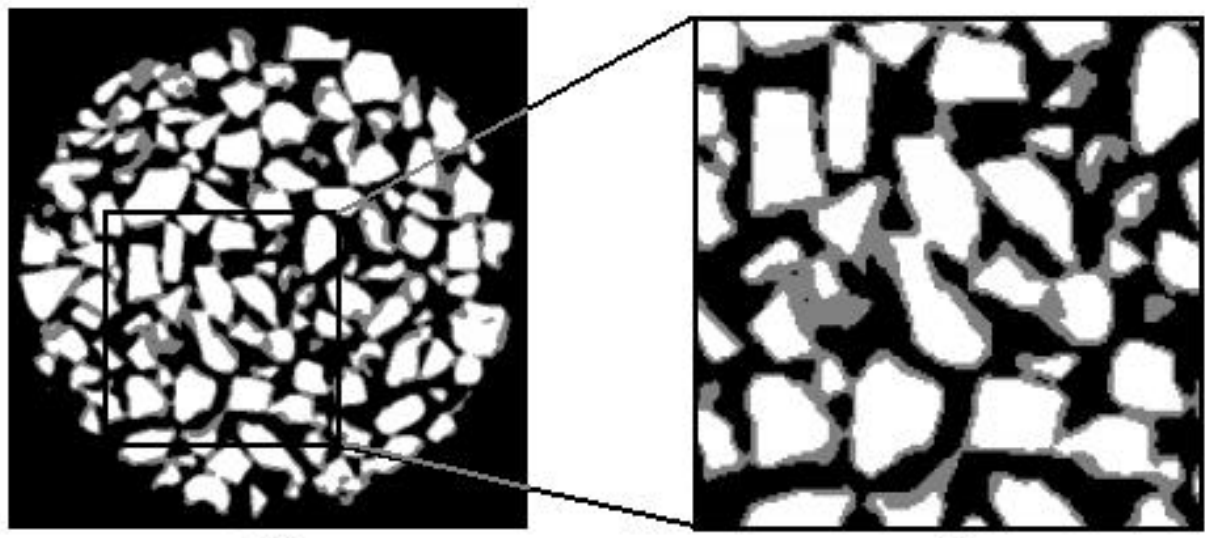

(c)

(d)

Figure 6. (a) A 2-D x-ray CT slice obtained from a packed bed of coal particles. (b) The x-ray attenuation coefficient histogram for the ent ire sample. (c) A priori identification of the image region: coal (white), air (black), particle surface containing both coal and air (gray) based on the thresholds T0 and T1 shown in (b). (d) An enlarged view of the square region identified in the image presented in (c).

between 1.30 and $1.35 \mathrm{~g} / \mathrm{cm}^{3}$. The peak corresponding to the lower attenuation coefficient value $(\sim 0)$ is associated with the external air space surrounding the sample.

Based on the tomographic image information, the finite mixture model can be applied for the construction of the coal washability curve. Usually, the attenuation coefficient histogram obtained the known density of a coal particle bed, is used to provide the underlying component densities, which can then be used as a basis for estimating the mixing weights associated with the set of unknown densities. The objective is that of 
'image segmentation', which seeks to identify the area of contiguous voxels that are associated within some density range. In this regard, for quantitative analysis of the coal washability from tomographic images, it is necessary to have a well-defined, consistent method to identify each voxel as air or coal with different density scales. This approach based on image analysis involves choosing a threshold or cut-off attenuation coefficient value lying somewhere between the peaks for air and the coal phase. Any voxel with an attenuation coefficient value less than the cut-off is identified as air. Now, consider two threshold values T0 and T1 indicated by the gray lines in Figure 6(b). The corresponding regions defined by the two thresholds are shown Figure 6(c). To reveal more details of the resulting image, a selected square region of Figure 6(c) is enlarged as shown in Figure 6(d). The black and white regions are distinguished as air and coal phases, respectively. It is noted that the x-ray beam of the CT scanner has a fixed beam width of about 1 to $2 \mathrm{~mm}$. When the scanning beam hits the edge of the particle, the resulting attenuation coefficient value of that particular voxel is expressed as the average value for the particle and the adjacent air surrounding the particle. This creates an artificially low attenuation coefficient value for the voxels at the edges of a particle. The gray voxels that correspond to the histogram region between threshold values (T0 and T1) illustrate the problem of defining the particle surface.

As shown in Figure 6(b), a single peak for the attenuation coefficient is obtained from the coal particle population having a single size and a single density. In this regard, the attenuation coefficient histogram for the coal particle population would then show a series of spikes that identify the corresponding density scale. As expected, the attenuation coefficient histogram obtained from the packed bed of coal particles (containing one size and six density classes) is shown in Figure 7. In this example, the problem of constructing a washability curve is then to decompose the curve corresponding to the attenuation coefficient histogram into different density fractions and mixing weights. To solve this problem, statistical analysis and modeling for the relationship between the distribution of $\mathrm{x}$-ray linear attenuation coefficients with respect to density and size of the coal particles has been addressed. 


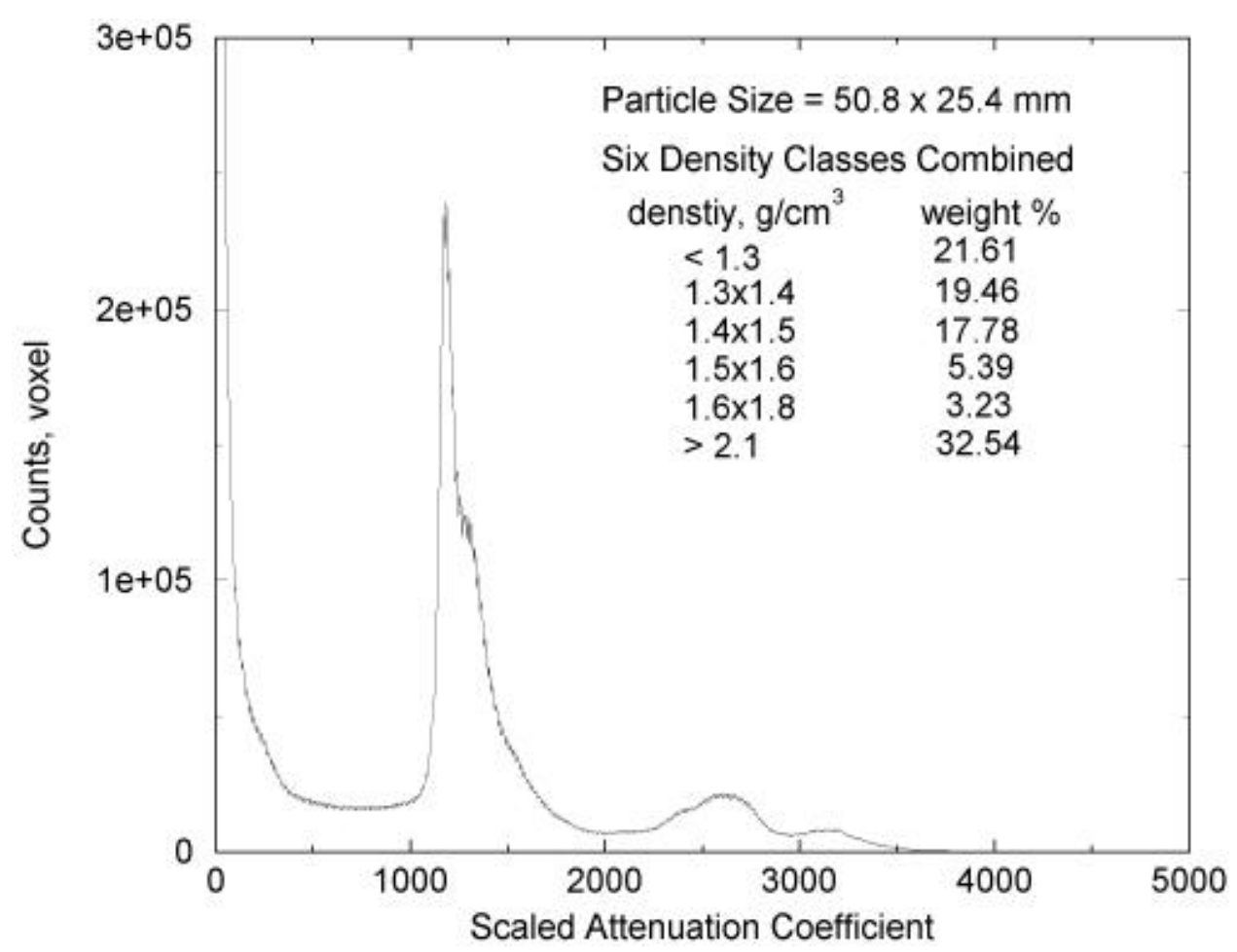

Figure 7. Attenuation coefficient histogram for a coal particle sample (single size/multiple density) showing peaks corresponding to the different density components.

X-ray CT scanning of single-size/single-density coal particle beds is a suitable method to obtain a statistical picture of the overall behavior of the attenuation coefficient with respected to density and size. In fact, Figure $6(\mathrm{~b})$ is one result selected from a sequence of tests. Figure 8 shows the sectional scans of tests for the $12.7 \times 6.3 \mathrm{~mm}(1 / 2 \times 1 / 4$ inch) sample with 8 different densities as indicated on the top of each image. An analysis of the peaks in the coal spectrum for six different density classes suggests that a normal distribution function can be used to model these peaks. In general, the form of the normal distribution function is described as:

$$
f(x)=\frac{1}{\sigma \sqrt{2 \pi}} e^{-(x-\mu)^{2} /\left(2 \sigma^{2}\right)}
$$

where $\mu$ and $\sigma$ represent the mean and variance of the normal distribution, respectively. 


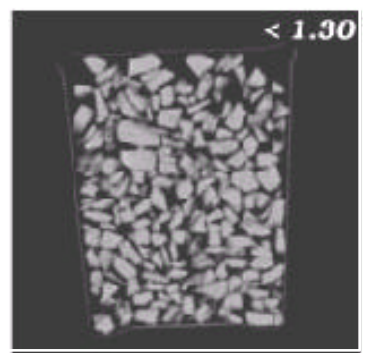

$<1.30$

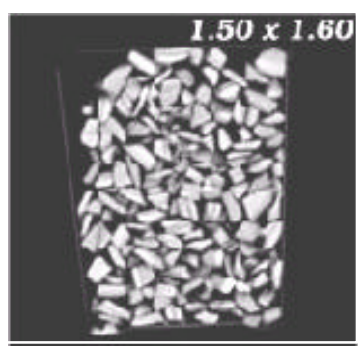

$1.50 \times 1.60$

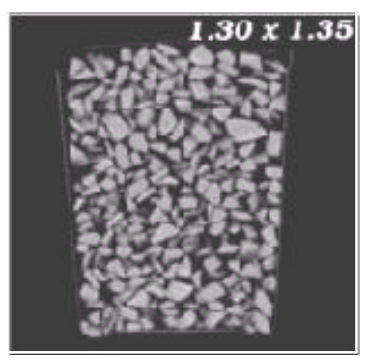

$1.30 \times 1.35$

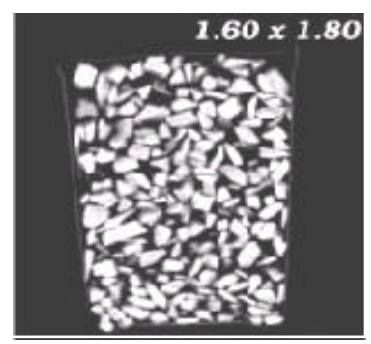

$1.60 \times 1.80$

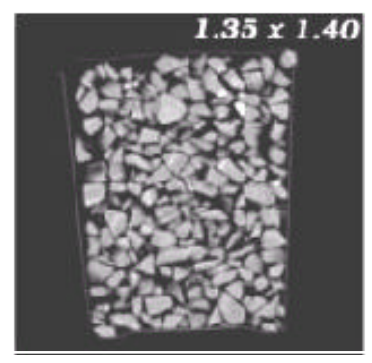

$1.35 \times 1.40$

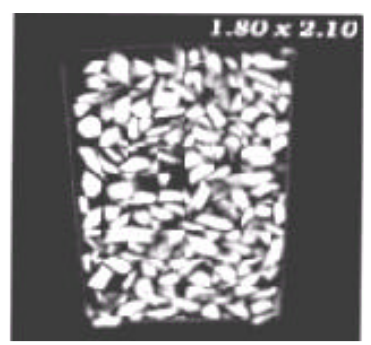

$1.80 \times 2.10$

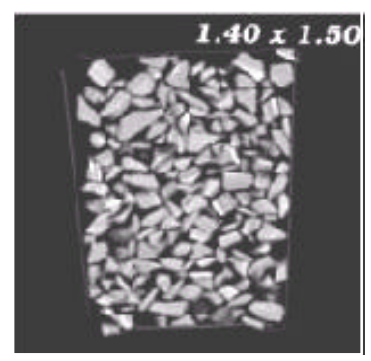

$1.40 \times 1.50$

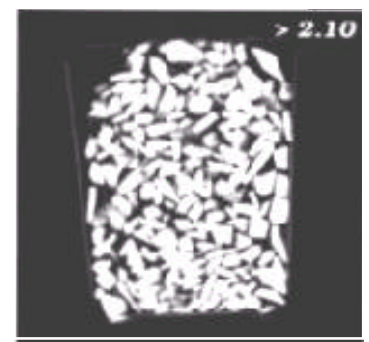

$>2.10$

Figure 8. 2-D x-ray CT scans of $1 / 2 \times 1 / 4$ inch $(12.7 \times 6.3 \mathrm{~mm})$ coal particles of different density.

Figure 9 shows the result of the model fit for a normal distribution function using the data from Figure 6(b) for a individual density class $\left(1.30-1.35 \mathrm{~g} / \mathrm{cm}^{3}\right)$. For this specific sample, the fitted parameters, mean $(\mu)$ and variance $(\sigma)$, of the normal distribution function were found to be 1225 and 0.1 respectively. The region of the histogram related to surface voxels is also shown in this figure as the shaded area.

To evaluate the effect of particle size on the attenuation coefficient histogram, two more coal samples (25.4 x $12.7 \mathrm{~mm}$ and multiple sizes) were prepared and subjected to $\mathrm{X}$ ray CT scanning. Figure 10 illustrates the effect of particle size on the attenuation coefficient histogram. The distribution curves for these three coal samples are identical for this density scale. Of course the surface contribution (the partially filled voxels) is more significant for the sample with smaller size particles, 12.7 x $6.3 \mathrm{~mm}$. 


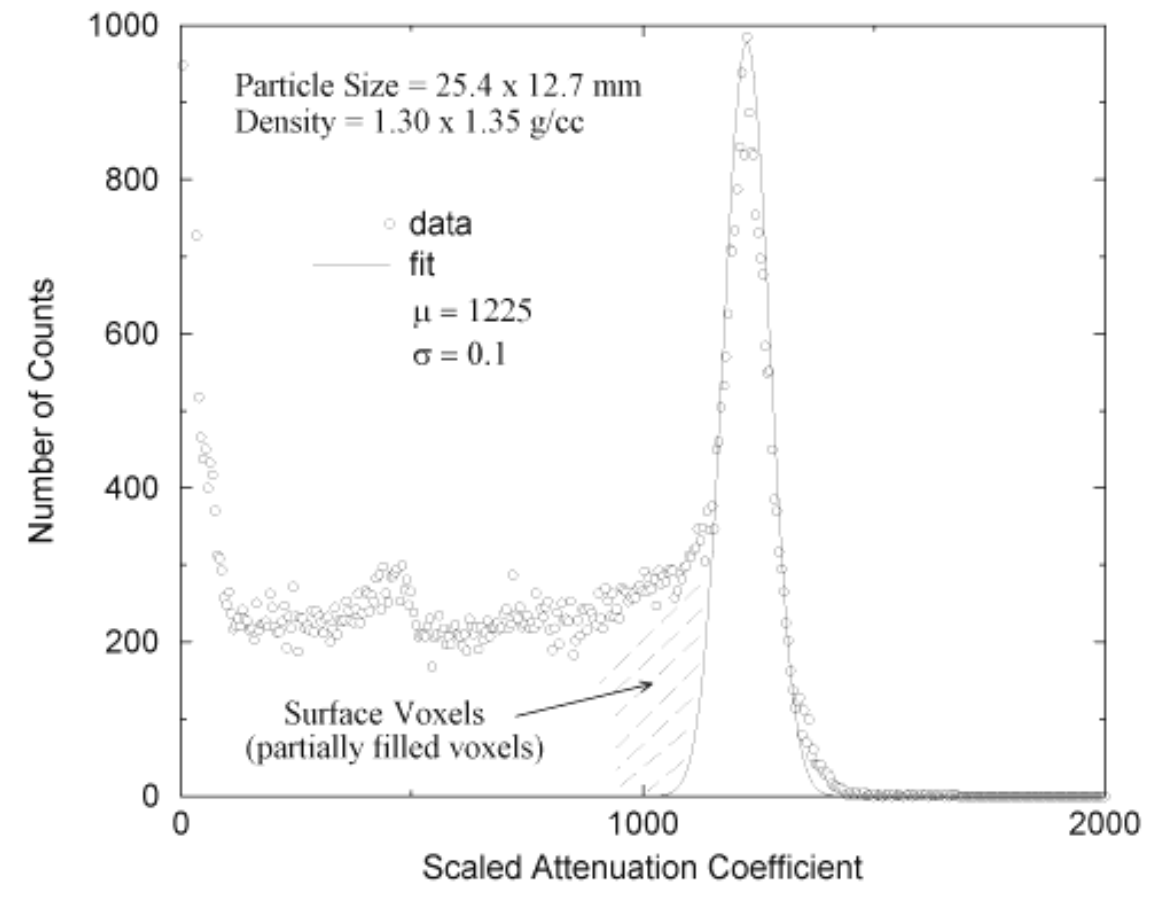

Figure 9. Model fitted normal curve for the attenuation coefficient distribution as obtained for a single-density/single-size sample.

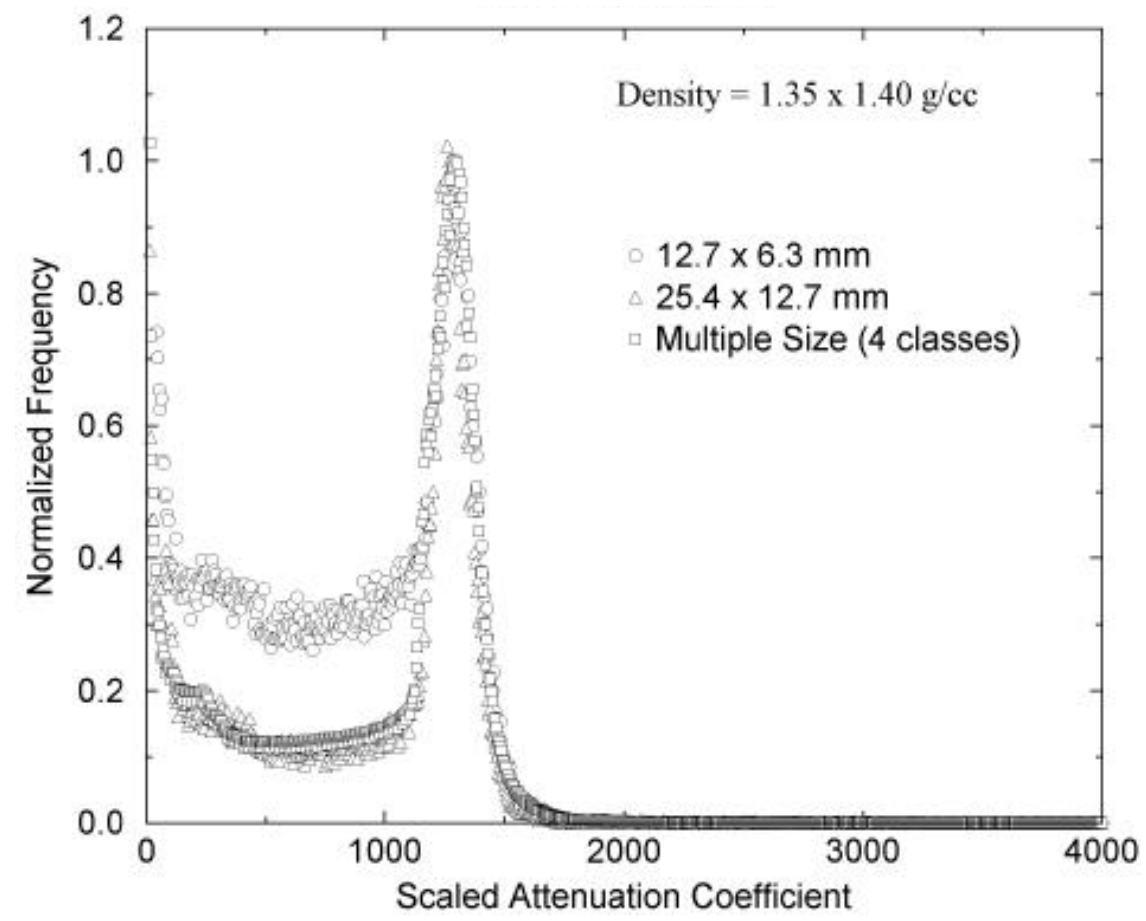

Figure 10. Effect of particle size on model fitted normal curve of attenuation coefficient distribution. 
Table I. Summary of the normal function fit for different density classes.

\begin{tabular}{|c|c|c|}
\hline \multirow{2}{*}{$\begin{array}{c}\text { Density } \\
\left(\mathrm{g} / \mathrm{cm}^{3}\right)\end{array}$} & \multicolumn{2}{|c|}{ Parameters for Fitted Normal Distribution } \\
\cline { 2 - 3 } & $\mu$ & $\sigma$ \\
\hline$<1.30$ & 1220 & 0.08 \\
$1.30 \times 1.35$ & 1225 & 0.10 \\
$1.35 \times 1.40$ & 1295 & 0.20 \\
$1.40 \times 1.50$ & 1380 & 0.25 \\
$1.50 \times 1.60$ & 1500 & 0.40 \\
$1.60 \times 1.80$ & 1740 & 0.40 \\
$1.80 \times 2.10$ & 2090 & 0.40 \\
$>2.10$ & 2560 & 0.50 \\
\hline
\end{tabular}

Additional tests were performed for different density classes, and the data fitted using a normal distribution function. The results are summarized in Table I. The attenuation coefficient histogram based on the model of the fitted normal distribution is displayed in Figure 11. As indicated from the curves shown in Figure 11, the analysis of washability curves based on the overall attenuation coefficient histogram will not be an easy task due to the wide overlap between these curves. However, using an appropriate image processing technique, the area of contiguous voxels belonging to the same particle can be identified. Then, these areas of sectioned particles can be sorted based on density using the attenuation coefficient histogram. In this way, the washability curve can be constructed using tomographic imaging data.

Based on the fitted normal distribution, density calibration can be done considering only completely filled voxels and the actual density determined from sink-float tests. Figure 12 presents a plot of the attenuation coefficient (column 2, $\mu$ of Table I) verses density (column 1 of Table I). For the practical situation, based on image segmentation, usually only one threshold value between the air and coal phase is set to facilitate the particle segmentation. For coal particles within a higher density, the attenuation coefficient of the partially filled surface voxels is considered as coal phase due to the fact that the attenuation coefficient has a higher value than the threshold setting. In this regard, to accurately estimate the density class of a particular coal particle, consideration of the partially filled voxels for density calibration is necessitated. 


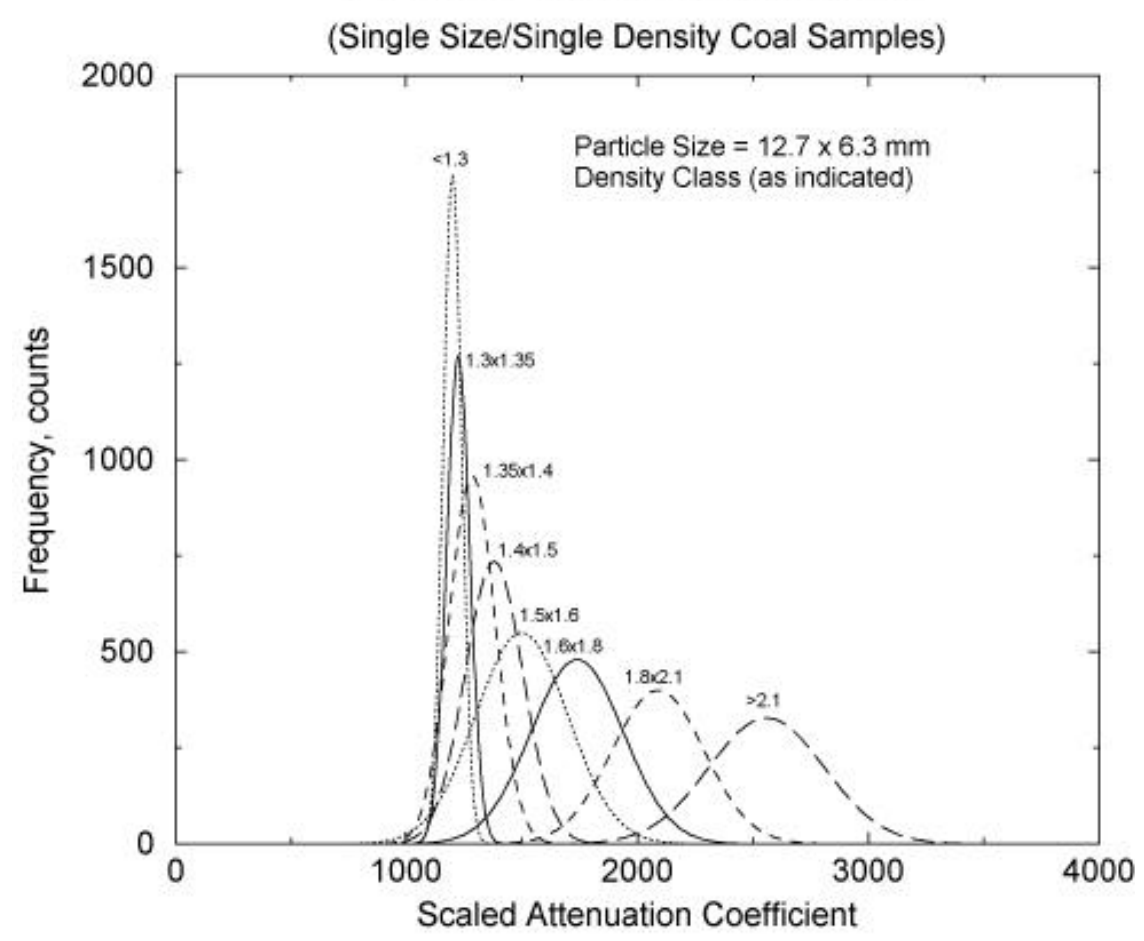

Figure 11. Fitted normal distribution of attenuation coefficients for coal samples of different density classes.

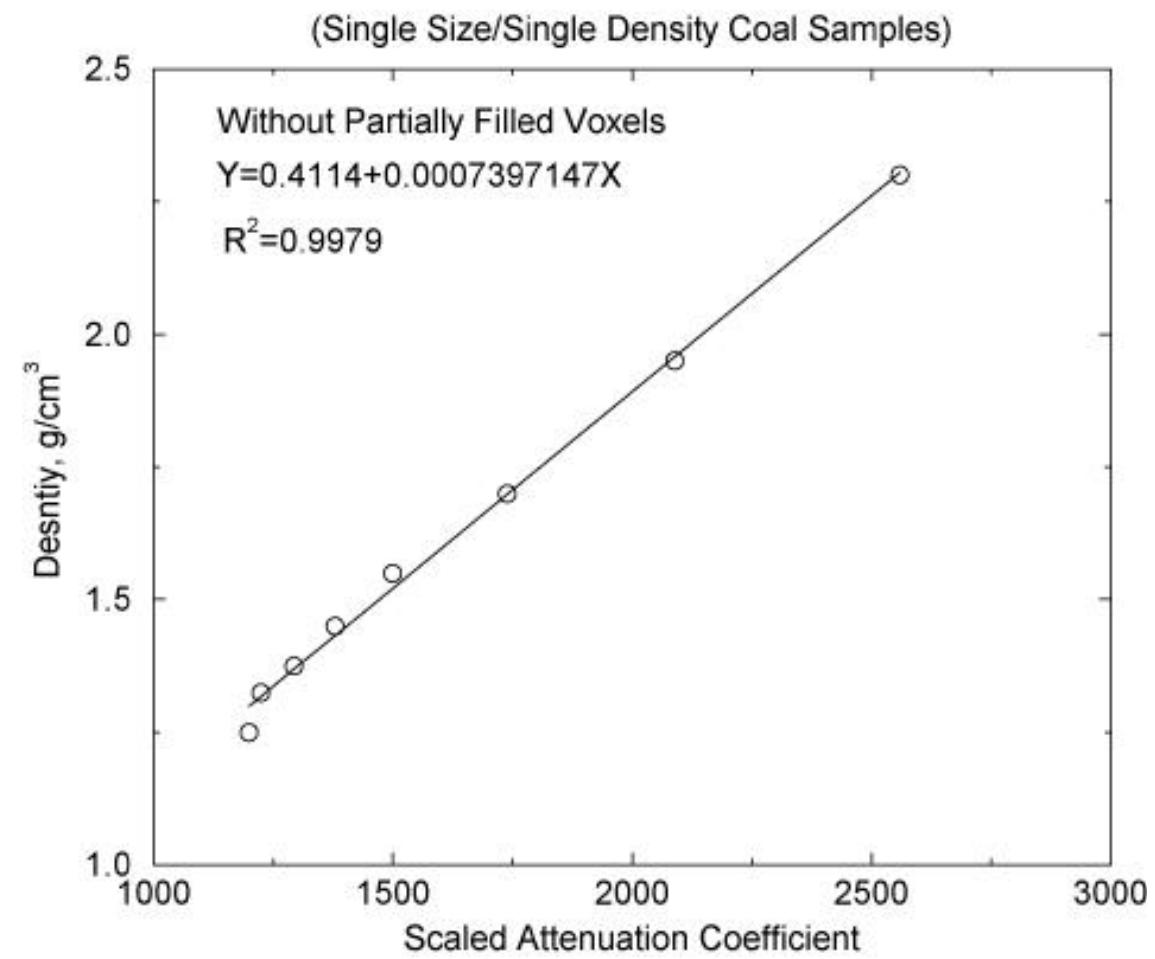

Figure 12. Density calibration curve for x-ray CT based on model fits of the normal distribution for single-size/single-density particles as indicated in Figure 11. 
Figure 13 shows the density calibration curve based on filled and partially filled voxels of coal phase using a threshold value of 1000 . These results were used to calibrate the density scale for determination of the coal washability characteristics.

\section{Particle Segmentation, Classification and Mass Density Analysis}

Since the x-ray CT equipment (Philips Tomoscan 60/TX) being used in this study produces two-dimensional images (slices) of a coal particle bed, two methodologies (namely 3-D and 2-D mass density distribution analyses) are being developed to facilitate the separation and classification of particle images in order to determine the density distribution for the coal particle bed.

The first approach, namely 3-D mass density distribution analysis, involves the procedure of stacking the individual 2D slices and generating a three-dimensional data set

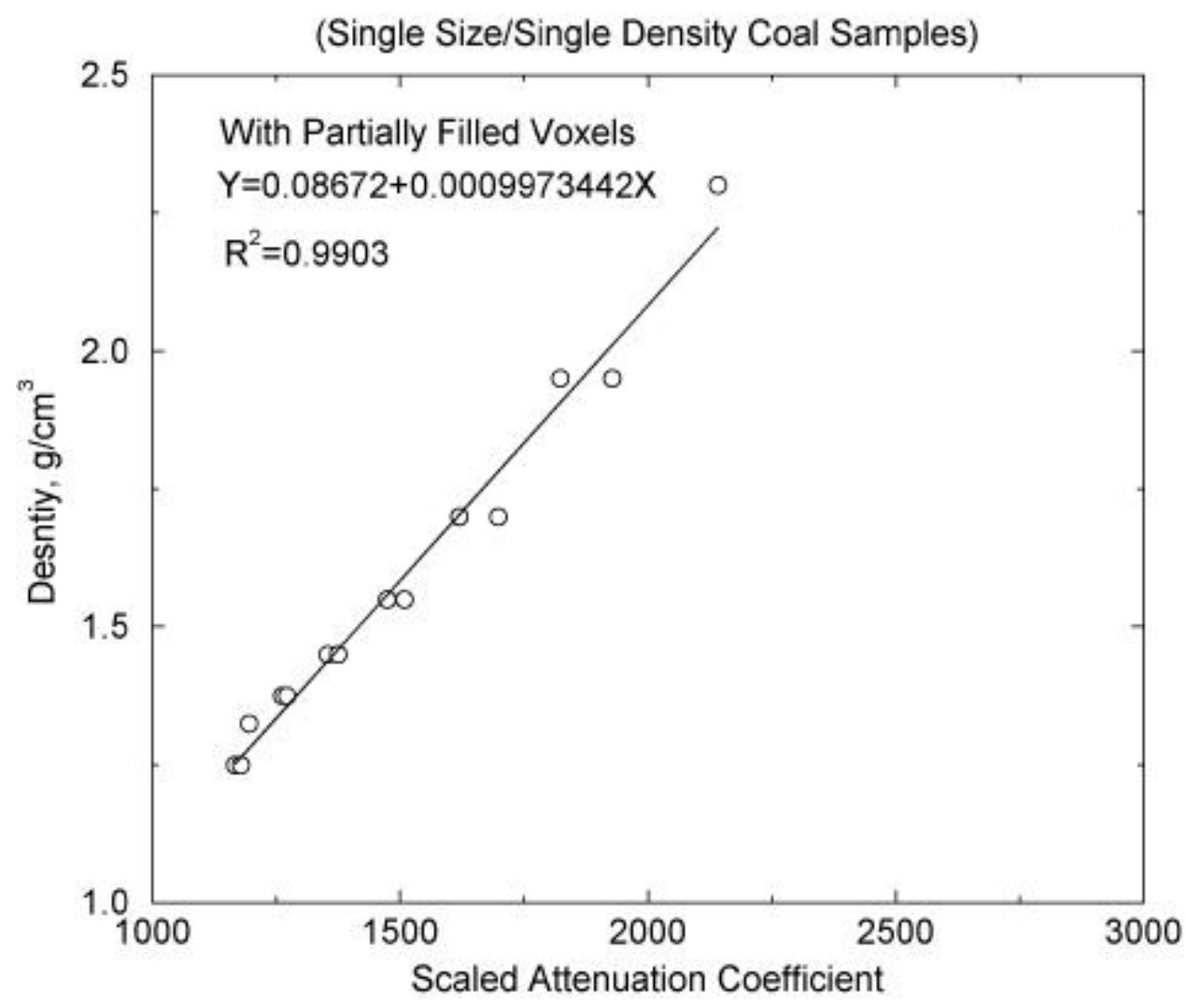

Figure 13. X-ray CT density calibration curve for single-size/single-density coal particles (packed bed) based on filled and partially filled voxels. 
with the assignment of intensity values to small voxels (volume elements) of the particle bed. To illustrate the nature of a packed bed of irregularly shaped coal particles, surface rendering of the three-dimensional images obtained from stacking the 2-D slices is shown in Figure 14. To determine the size and mass density distributions, detection of surface boundaries and classification of the particle population is critical. As shown in Figure 14, particle contact inside the sample chamber is one of the problems that was solved for online coal washability analysis.

The framework for software development to analyze the packed 3-D coal particles has been prepared to construct the corresponding mass-density distribution. The major data processing steps and the corresponding algorithms for mass-density distribution (coal

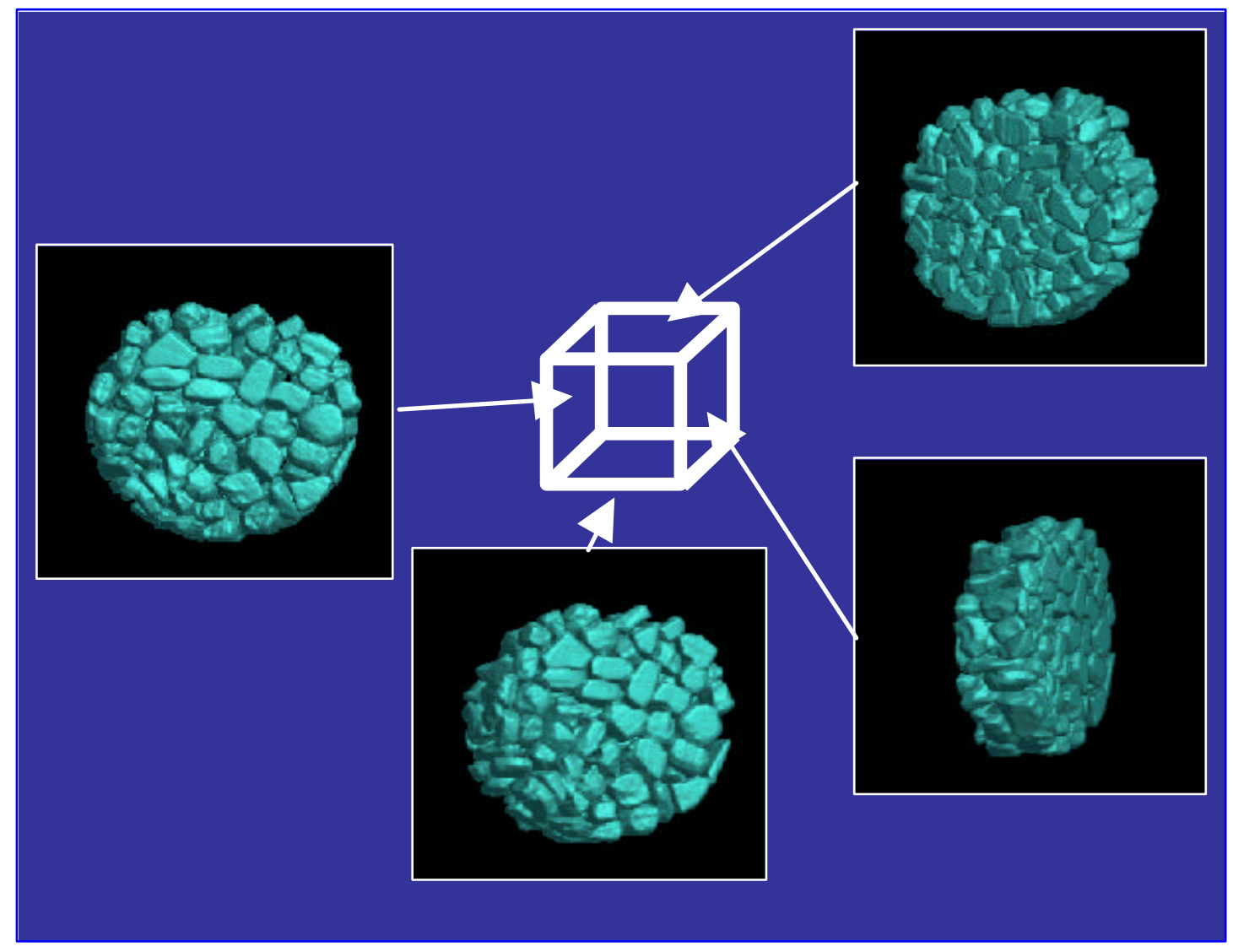

Figure 14. Surface rendering of the three-dimensional image of a packed bed of irregularly shaped coal particles. 
washability curve) are given in Figure 15. The algorithms include phase segmentation for data reduction, surface extraction (watershed algorithm) to separate contacting particles, labeling for particle classification, and volumetric grade classification for the 3-D CT data set. Results indicate that this approach can be used to separate the particles in contact as shown in Figure 16. Three consecutive original x-ray CT images (numbers 6, 7 and 8) are shown in the top of Figure 16. The separated particle images are shown in the bottom of Figure 16.

When dealing with 3-D data, there is always the question of what is the most effective way to display the data in two dimensions so that information is communicated to the viewer without complication or confusion. In this regard, a software package, Volume Slicer (Figure 17), was developed for displaying and managing the 3-D data. Volume Slicer allows the user to download the original sequence of 2-D images and to examine the tomographic plane at different positions and from different view points (angles).

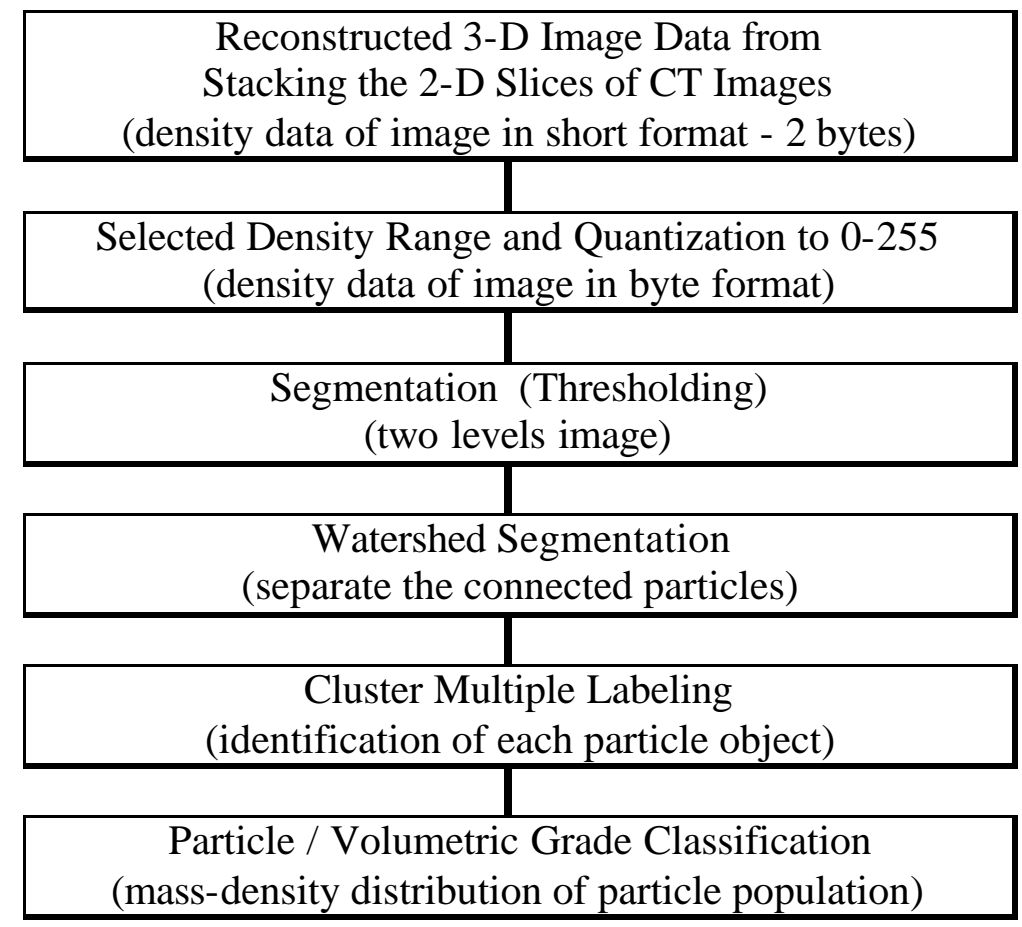

Figure 15. Major steps for the determination of the mass-density distribution of a particle population from 3-D image data collected by stacking 2-D slices generated by x-ray computed tomography. 


\section{Original Images}
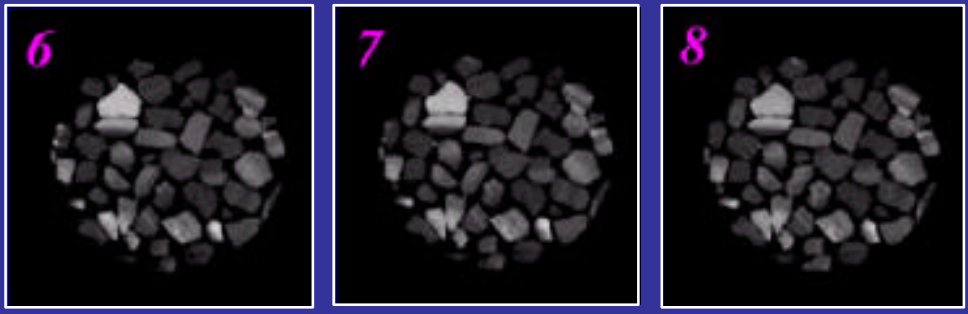

After 3-D Watershed Segmentation
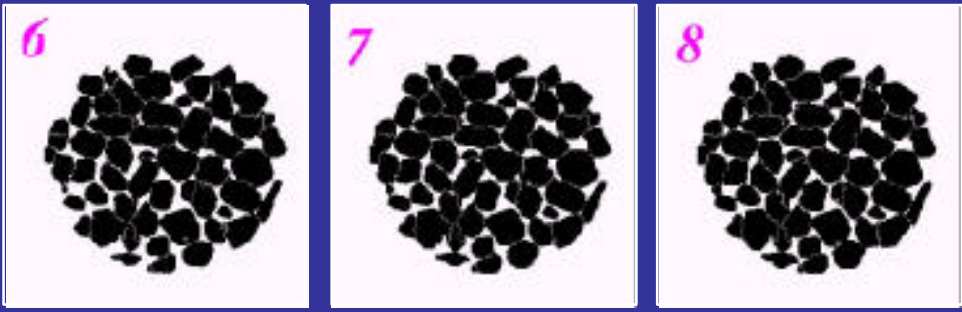

Figure 16. Results for 3-D analysis of packed bed coal particles.

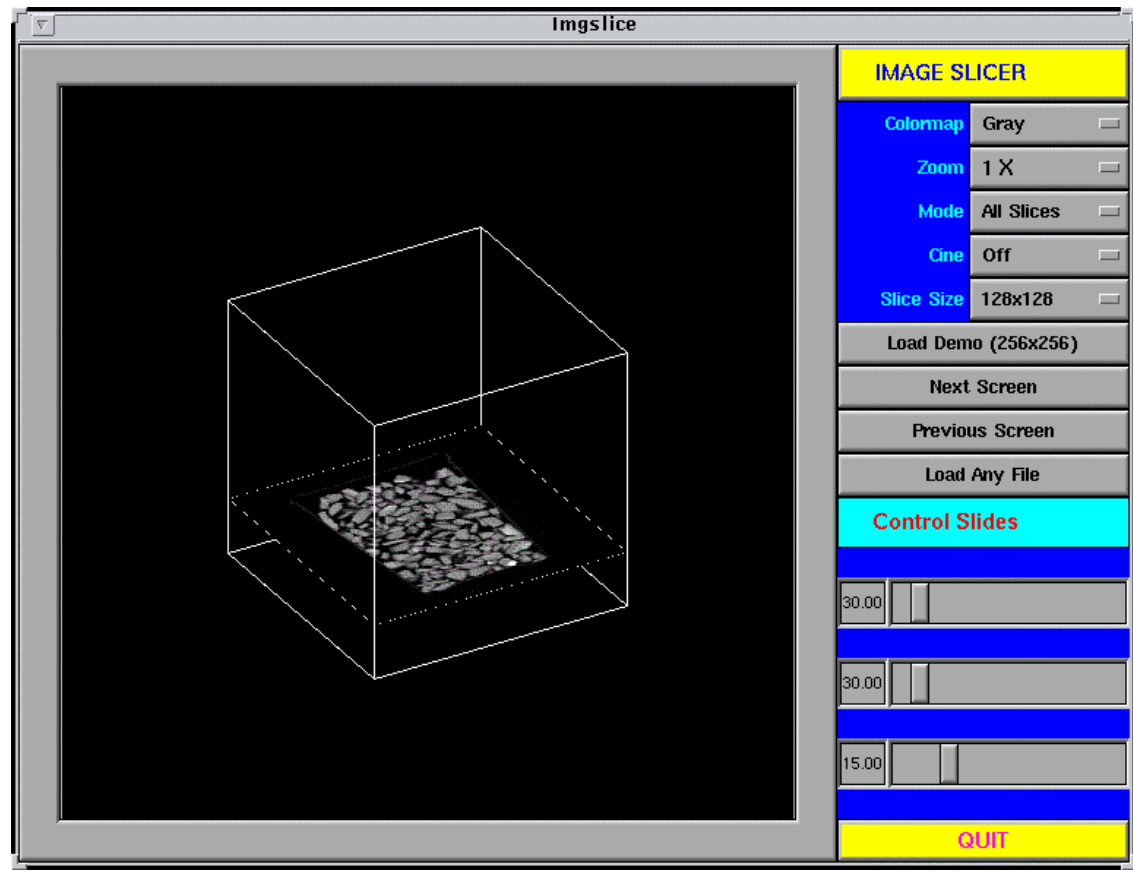

Figure 17. Volume Slicer for displaying and managing 3-D volumetric data sets. 
The response time for the x-ray CT system will be significantly reduced if a large CT sampling interval is used, but still can provide accurate information for coal washability analysis. In this regard, it was essential to develop an algorithm based on image processing techniques to identify the area of contiguous voxels that belong to the same coal particle of a given density. The second approach involves the development of an algorithm such as the polygonal approximation and classification of concavities, based on polygons, to enhance the robustness for the separation of particles in contact [14]. A flow chart for the mass density analysis algorithm is presented in Figure 18. An example of the

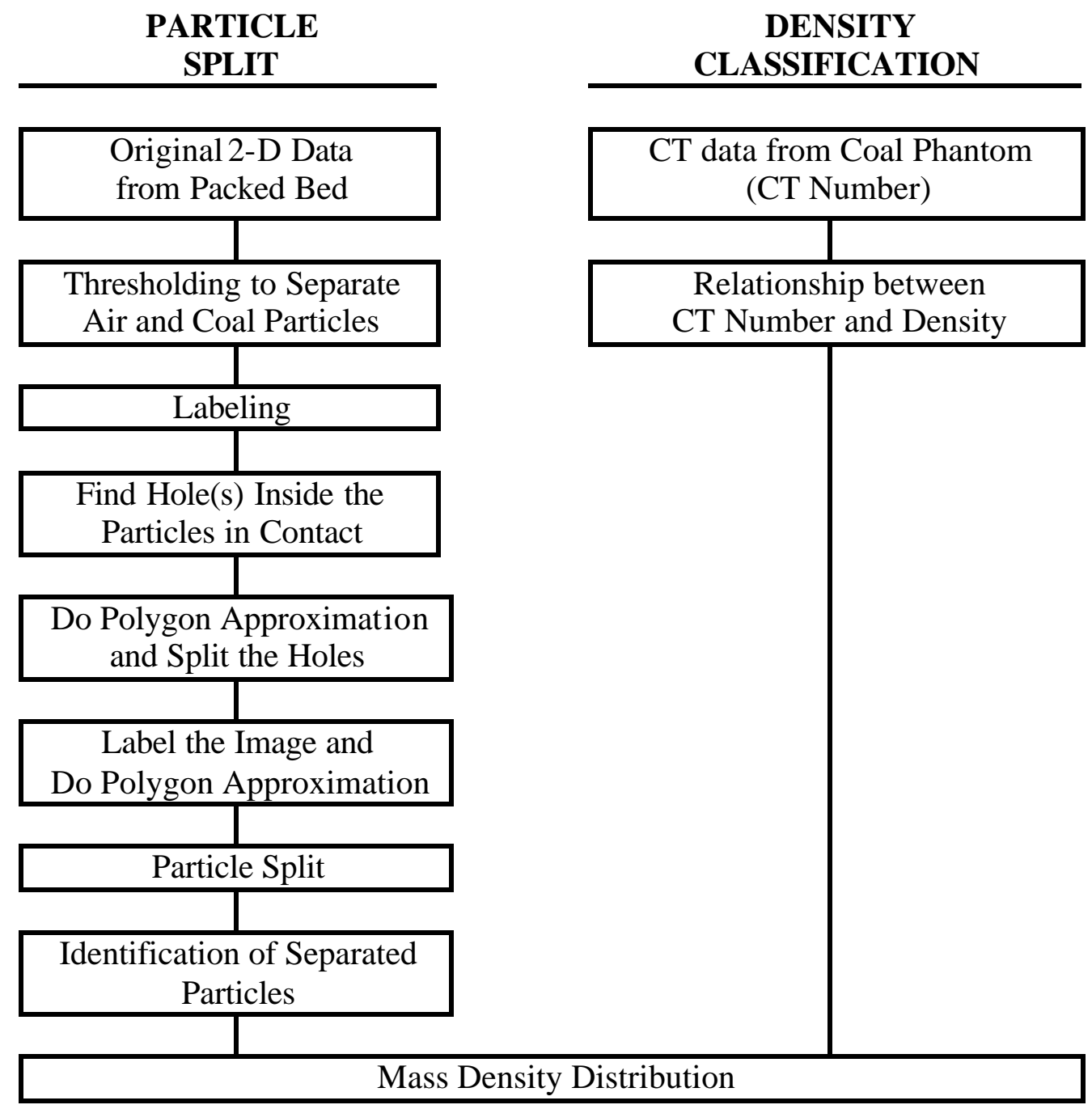

Figure 18. Flow chart for the mass density analysis algorithm. 
resulting images at different processing steps for the separation of the coal particles in contact is shown in Figure 19.

When dealing with large 2-D x-ray CT data sets, a software system designed with a graphical user interface (GUI) will allow the user to handle the coal washability analysis easily. In this regard, an integrated software system was developed which allows the user to download the sequence of the original 2-D CT x-ray data sets (2-byte format). The system facilitates the separation and classification of particle images in order to obtain the washability analysis.

One of the important functions of the GUI is to deal with the user input, which can be by keystroke or by mouse action. User input is often referred to as an event. The main components of the implemented GUI include the graphical icons and the event-control subroutines. Figure 20 shows the layout of the GUI used for the development of this integrated image processing and analysis system. The main menu lets the user select the subroutines to be operated. The mass density analysis algorithm is implemented as one of the subroutines. As shown in Figure 21, parameters can be set to analyze multiple CT images for washability determination.

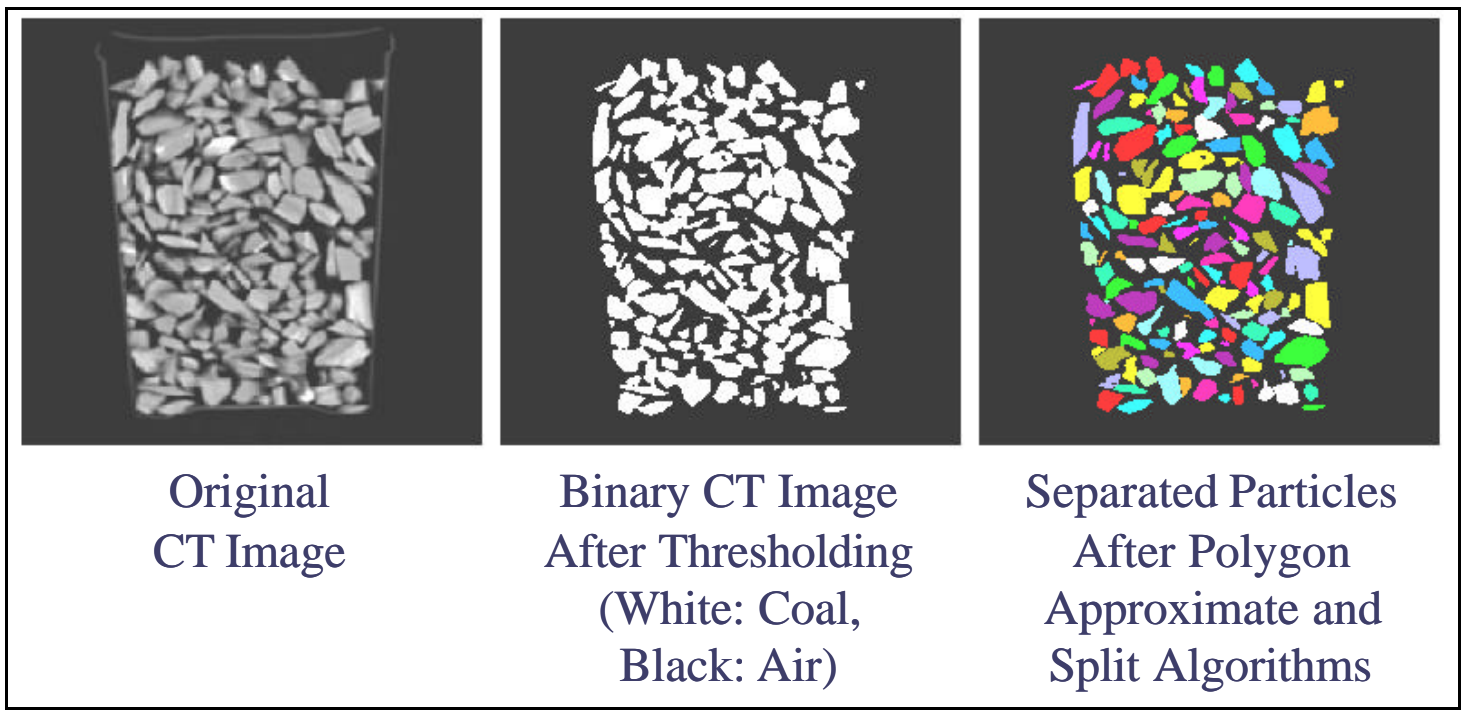

Figure 19. Image sequence showing the results for the separation of coal particles in contact using the algorithm for mass density analysis described in Figure 18. 


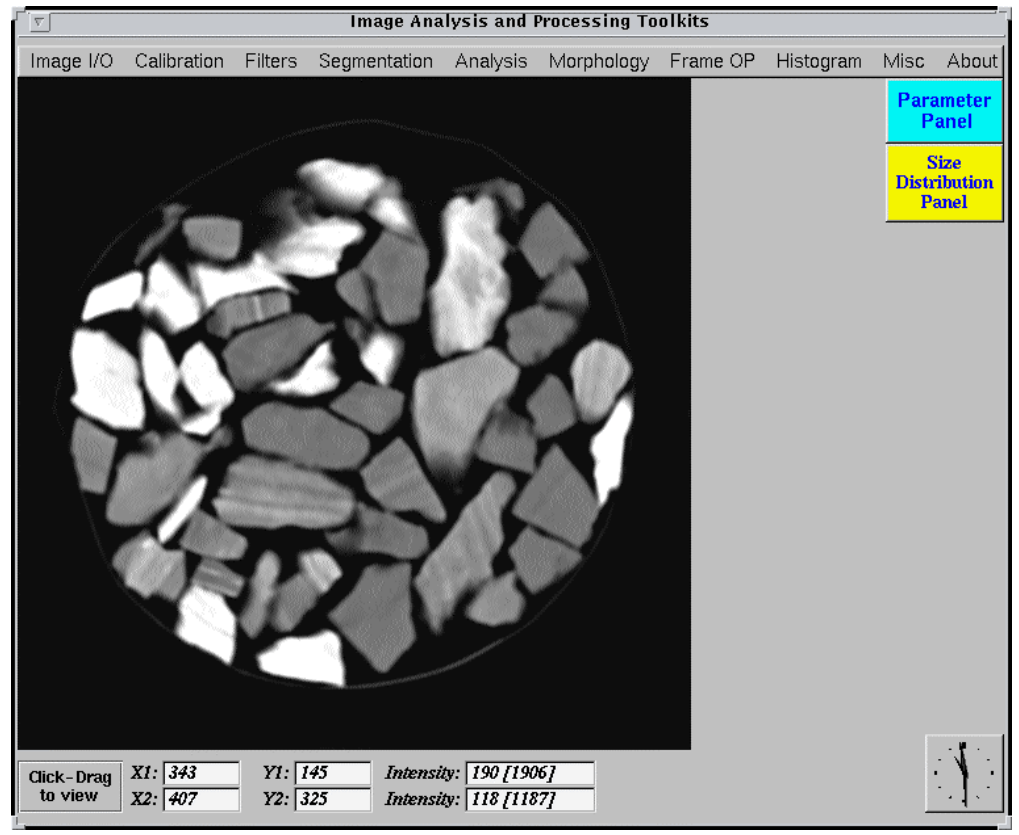

Figure 20. Layout of the graphical user interface (GUI) for the integrated image processing and analysis system to determine washability from x-ray CT images.

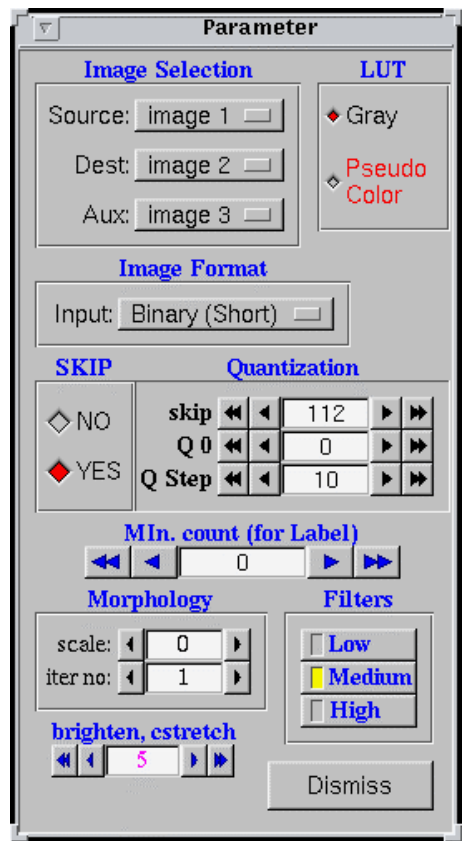

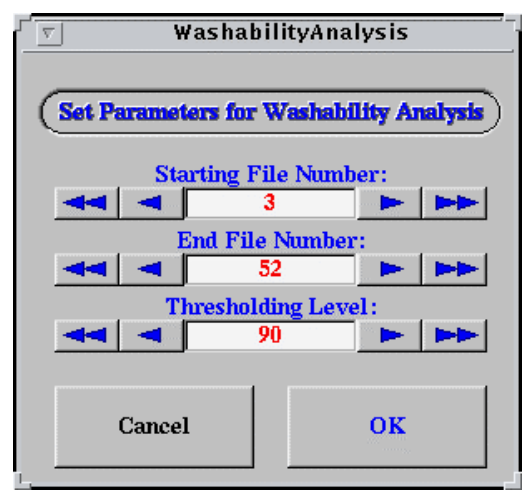

Figure 21. Parameter-window allows user to set the desired options (le ft) and subwindows used for setting parameters for washability analysis from multiple CT images (right). 


\section{Testing and Modification}

Experiments were designed to evaluate the CT scanner using coal samples under carefully controlled laboratory conditions. The test program is subdivided into four different test series, single-size/single-density, single-size/multiple-density, multiplesize/single-density, and multiple-size/multiple-density. Figure 22 shows the resulting images at different processing steps for the separation of the coal particles in contact for multiple-size/single-density samples and single-size/multiple-density samples using the mass density analysis algorithm.

Two samples, single-size/multiple-density $(25.4 \times 12.7 \mathrm{~mm}$ and $50.8 \times 25.4 \mathrm{~mm})$, were prepared for washability analysis using x-ray CT techniques. Using plastic containers as the sample chamber, two sets of sequential cross sectional images (150 and 124 slices) were collected. In these experiments each 2-D x-ray CT slice is $2 \mathrm{~mm}$ in thickness.
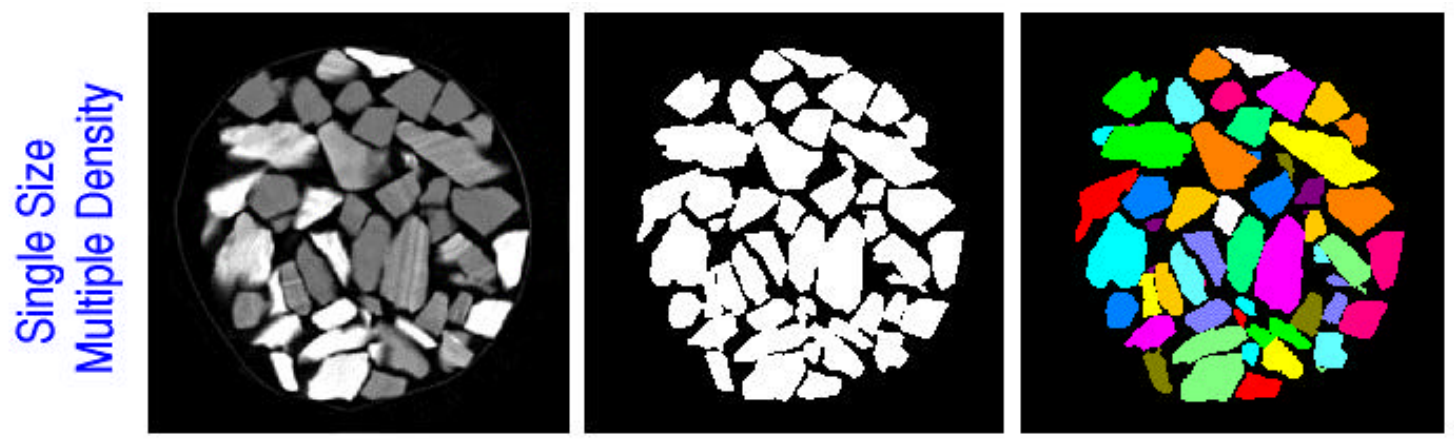

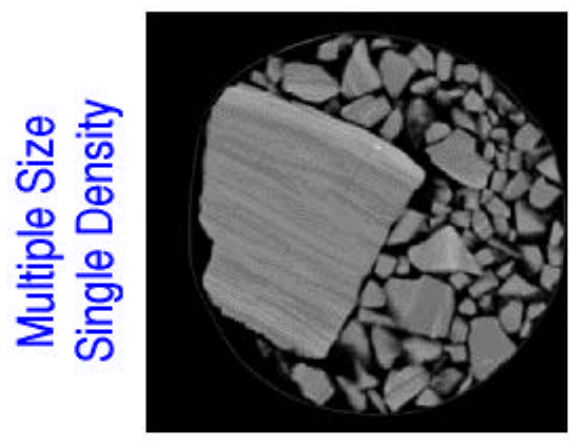

Original

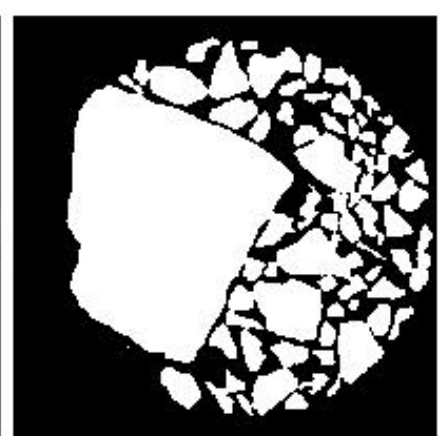

Segment

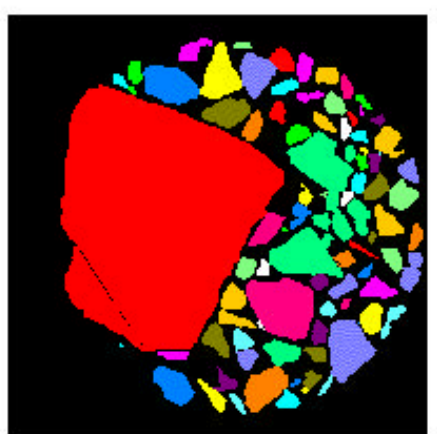

Labeled

Figure 22. Image sequence shows the results for the separation of multiple size/single density and single size/multiple density coal samples in contact using the algorithm for mass density analysis. 
Washability data for these carefully prepared samples are shown in Tables II and III, respectively. Washability curves for both samples using sink-float data are constructed and shown in Figures 23 and 24 respectively. In addition to the primary washability curve, three related curves, namely, specific gravity/yield curve, clean coal and reject curves for ash are also included for both coal samples.

Table II. Sink-float analyses for the Stockton coal sample $2(25.4$ x $12.7 \mathrm{~mm})$.

\begin{tabular}{|c|c|c|c|c|r|}
\hline \multicolumn{2}{|c|}{ Specific Gravity } & \multicolumn{2}{|c|}{ Individual Basis } & \multicolumn{2}{c|}{ Cumulative Basis } \\
\hline Sink & Float & Yield (\%) & Ash (\%) & Yield (\%) & Ash(\%) \\
\hline & 1.30 & 26.40 & 3.14 & 26.40 & 3.14 \\
1.30 & 1.40 & 21.10 & 10.10 & 47.50 & 6.23 \\
1.40 & 1.50 & 15.83 & 23.16 & 63.33 & 11.46 \\
1.50 & 1.60 & 6.59 & 29.06 & 69.92 & 12.22 \\
1.60 & 1.80 & 1.85 & 42.32 & 71.77 & 12.99 \\
1.80 & 2.10 & 1.85 & 59.09 & 73.62 & 14.15 \\
2.10 & & 26.38 & 86.48 & 100.00 & 33.23 \\
\hline & & 100.00 & & & \\
\hline
\end{tabular}

Table III. Sink-float analyses for the Stockton coal sample 3 (50.8 x $25.4 \mathrm{~mm})$.

\begin{tabular}{|c|c|r|r|r|r|}
\hline \multicolumn{2}{|c|}{ Specific Gravity } & \multicolumn{2}{|c|}{ Individual Basis } & \multicolumn{2}{c|}{ Cumulative Basis } \\
\hline Sink & Float & Yield (\%) & Ash (\%) & Yield (\%) & Ash(\%) \\
\hline & 130 & 7.161 & 7.89 & 7161 & 7.89 \\
1.30 & 1.40 & 19.46 & 10.73 & 41.07 & 6.60 \\
1.40 & 1.50 & 17.78 & 21.55 & 58.85 & 11.12 \\
1.50 & 1.60 & 5.39 & 28.32 & 64.24 & 12.56 \\
1.60 & 1.80 & 3.23 & 41.27 & 67.47 & 13.93 \\
2.10 & & 32.54 & 84.11 & 100.00 & 36.77 \\
\hline & & 100.00 & & & \\
\hline
\end{tabular}

Based on the 2-D x-ray CT images (slices) for these coal samples, Figures 25 and 26 illustrate the constructed specific gravity/yield curves for size fractions, $25.4 \times 12.7 \mathrm{~mm}$ and $50.8 \times 25.4 \mathrm{~mm}$, respectively. The specific gravity/yield curves for both samples using sink-float tests (Figures 23 and 24) are included for comparison. Good agreement is observed for both samples. 


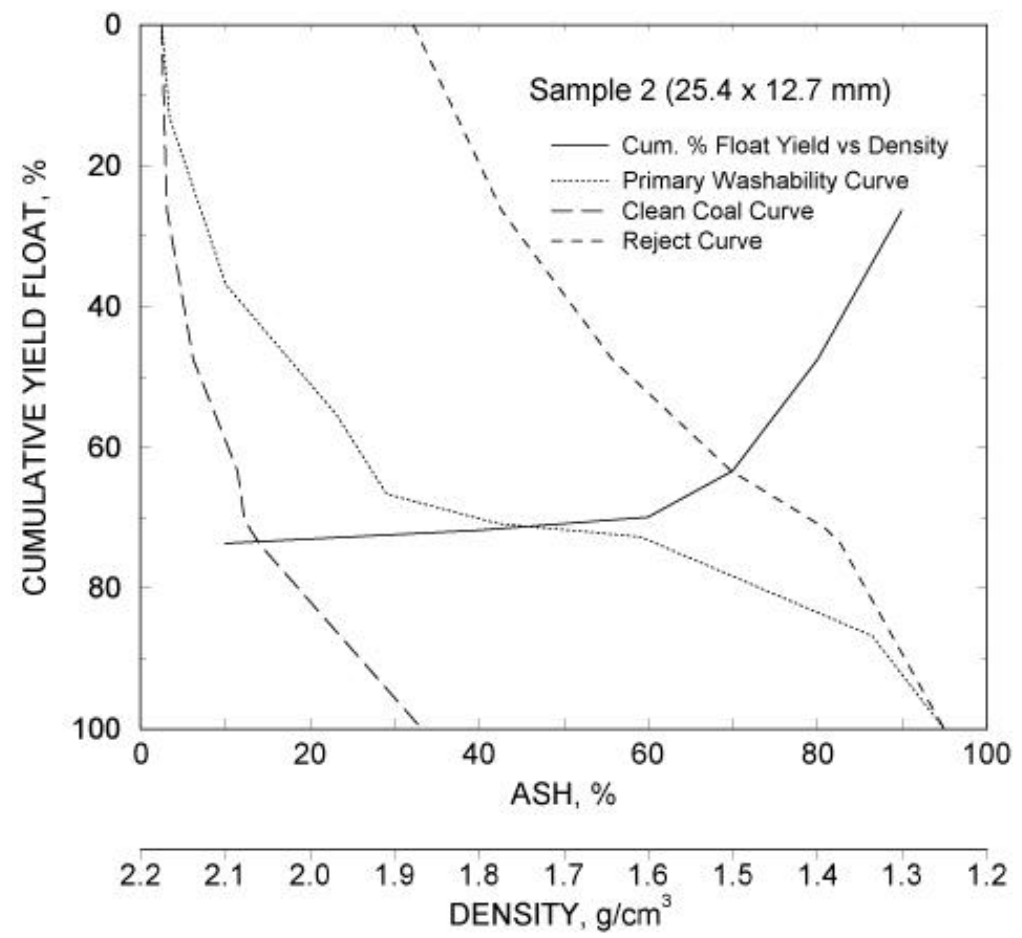

Figure 23. Sink-float washability curves for $1 \times 1 / 2$ inch $(25.4 \times 12.7 \mathrm{~mm})$ coal sample (sample 2). Data from Table II..

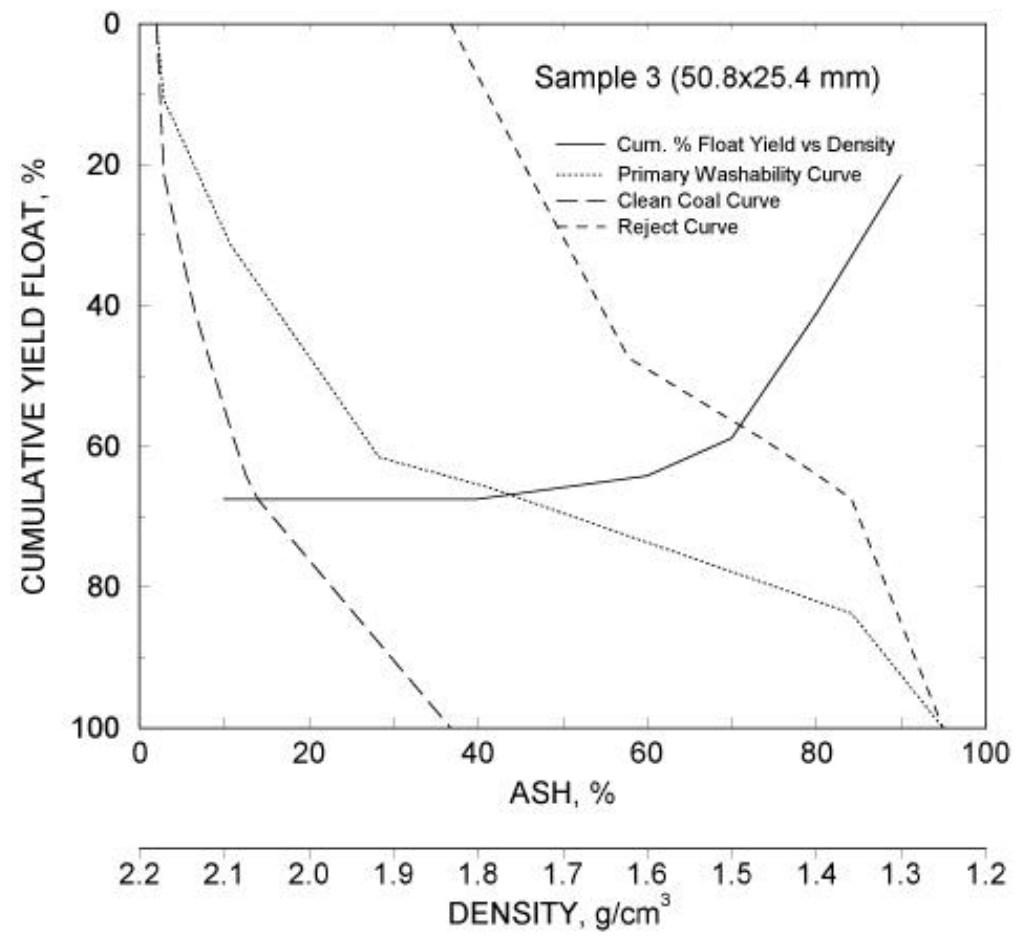

Figure 24. Sink-float washability curves for $2 \times 1$ inch $(50.4 \times 25.4 \mathrm{~mm})$ coal sample (sample 3). Data from Table III. 


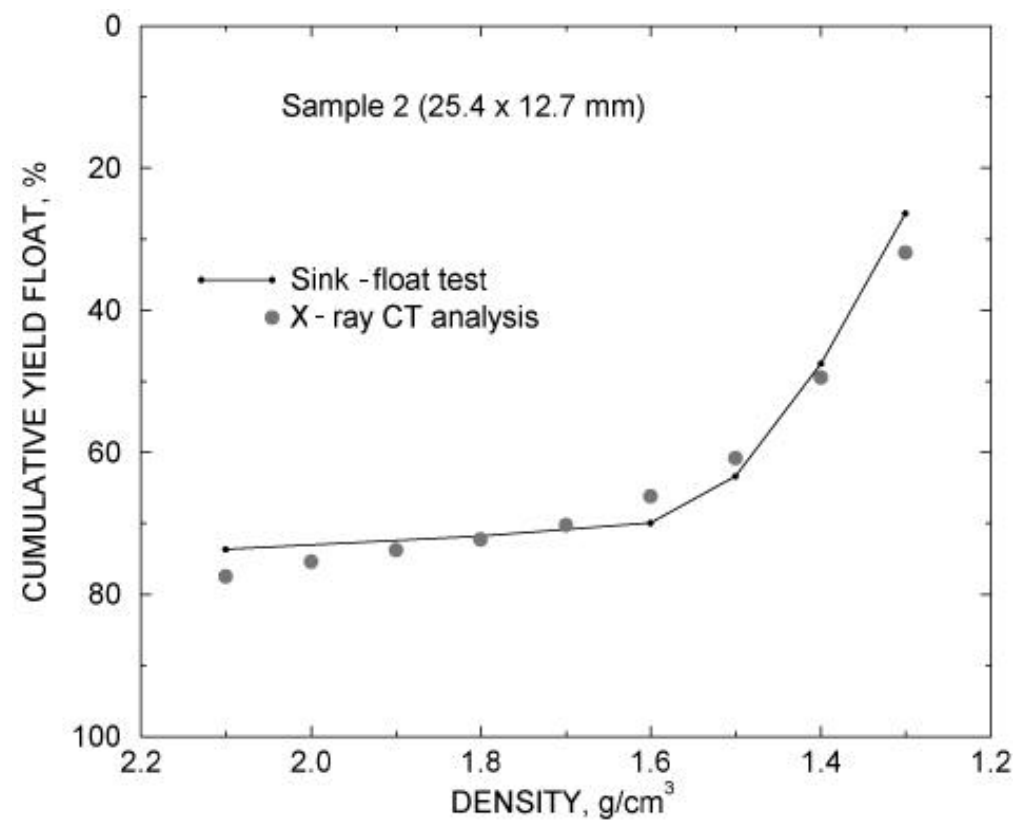

Figure 25. Comparison of specific gravity/yield curve for sample 2 as determined by sink-float test with the results from x-ray CT analysis.

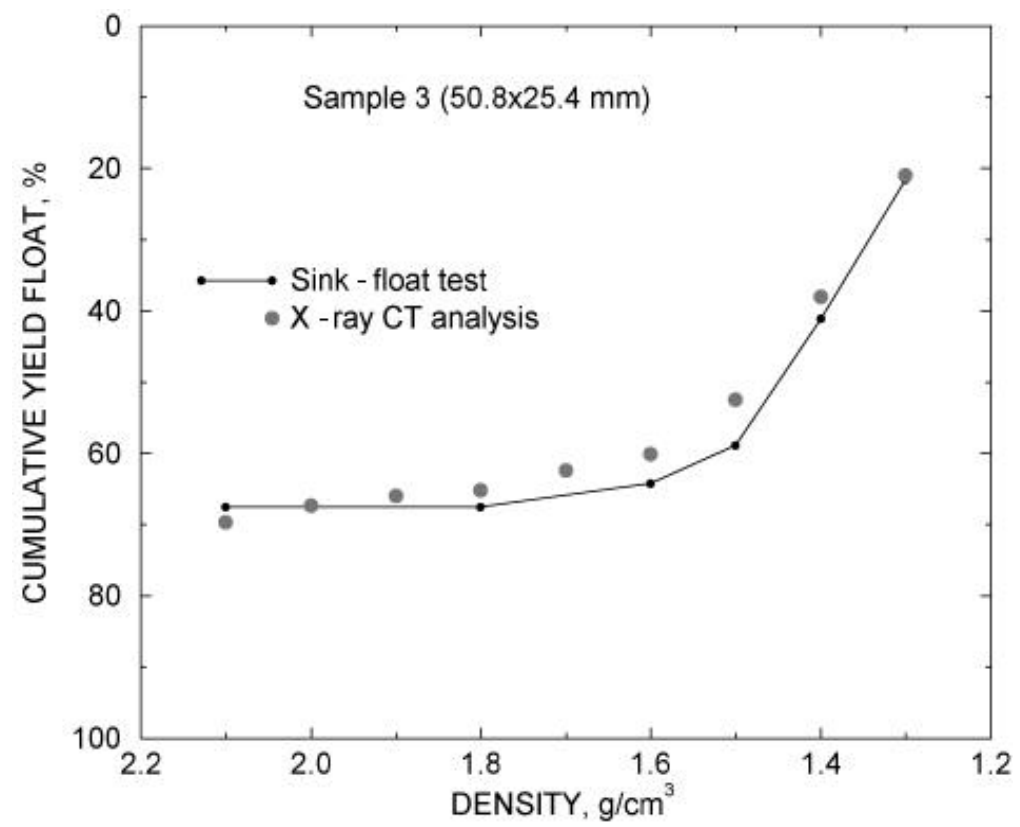

Figure 26. Comparison of specific gravity/yield curve for sample 3 as determined by sink-float test with the results from x-ray CT analysis. 


\section{$\underline{\text { Summary of Development Work }}$}

The development of the x-ray CT-based washability analyzer requires wellcharacterized test samples for use in calibration and testing. In this regard, samples of feed coal were collected, sized and subdivided into narrow specific gravity classes for use in the development and calibration of the CT analyzer. Approximately 40 size/density fractions were generated by this procedure. To use the CT measurement for coal washability analysis, it is necessary to do a calibration step with known density material or directly determine the density using duakenergy scans. Both methods were evaluated. In practice, full attenuation coefficient histograms of the sample composed of singlesize/single-density particles were characterized in detailed and used to calibrate the density scale. Two approaches (namely 3-D and 2-D mass density distribution analyses) were developed to facilitate the separation and classification the density distribution of the coal particle bed. The software package, Volume Slicer, was developed for displaying and managing the 3-D data sets. Volume Slicer allows the user to download the sequence of the original 2-D images and to examine the tomographic plane at different positions and from different view points (angles).

A methodology based on the finite mixture model and an appropriate image processing technique was developed to analyze the mass density distribution for the coal sample. In addition, an integrated software system with graphical user interface (GUI) was developed which allows the user to download the sequence of the original CT image slices. This system facilitates the separation and classification of particle images in order to obtain the washability analysis.

Two single-size/multiple-density samples were prepared to evaluate the washability analysis using the $\mathrm{x}$-ray $\mathrm{CT}$ technique. Using the algorithm for the mass density distribution analysis and a specially developed integrated software system, 150 and 124 2D CT images were analyzed. The results indicate that the specific gravity/yield curves can be constructed using the xray CT technique with good agreement with data obtained from independent sink-float tests. 


\section{Part II: Evaluation Under Simulated On-Line Conditions}

\section{$\underline{\text { Plant Sample Acquisition }}$}

Evaluation of the CT-based coal washability analyzer under simulated on-line conditions for the control of coarse coal cleaning circuits started in mid February 2000 and continued through mid July 2000. It was decided to collect composite samples on a weekly basis. The samples were obtained from the Powellton/Cedar Grove seam and were provided by an industrial mining operation in Boone County, West Virginia. Each sample consisted of about 110 pounds of 1-1/4 x 1/4-inch coal particles. After collection, the samples were divided into two representative splits. The first split was provided to Virginia Tech for analysis via traditional float-sink tests using heavy liquids. Four density fractions (i.e., 1.3, 1.5, 1.7 and 2.0 SG) were used for float-sink analysis. The other portion of the sample was shipped to the University of Utah for comparative analysis using the x-ray CT technique.

For CT analysis, two cylindrical sample containers were used for each coal sample (50-60 pounds). The size of sample container was about $184 \mathrm{~mm}$ in diameter and $600 \mathrm{~mm}$ in length (Figure 27). The wall of the sample container was a lightweight, non-metallic material (0.1 mm plastic).

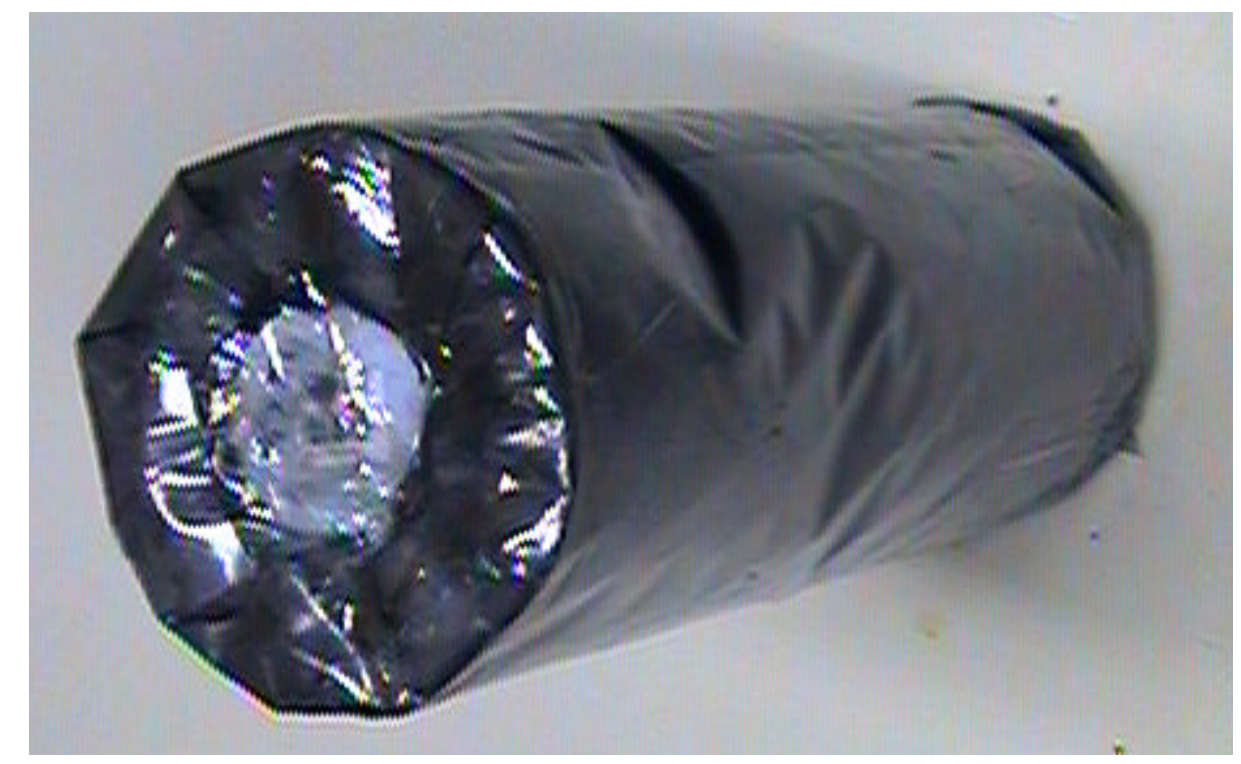

Figure 27. Cylindrical sample container with coal particles used for CT analysis. 


\section{$\underline{\text { On-line Considerations for Segmentation, Classification and Density Analysis }}$}

For the practical situation, based on image segmentation, usually only one threshold value between the air and coal phase is set to facilitate the particle segmentation. For coal particles with a higher density, the attenuation coefficient of the partially filled surface voxels is considered as coal phase because the attenuation coefficient has a higher value than the threshold setting. To accurately estimate the density class of a particular coal particle, consideration of the partially filled voxels for density calibration is necessary. In this regard, a calibration methodology is developed to correct the partially filled surface voxels for accurate estimation of washability curve.

Consider a polydispersed system of irregular coal particles intersected by a plane (as from a X-ray CT scanner) with a width of about 2-mm as shown in Figure 28. The particle edge effect, which generates the partially filled surface voxels, is evident. A successive subtraction process [14] can be applied to develop the coefficients required for the calibration of various densities. The successive subtraction process is as follows. When the number of sections (or voxels) of the same density is counted, allowance must be made for the fact that some of the sections (or voxels) will be derived from partially filled surface voxels of a coal particle of higher density. The number of these latter sections (or voxels) must be subtracted from the total number in order to obtain those sections (or voxels) due only to coal particle of that density range. Figure 29 shows the problem involved here. The sections from particles (voxel form) in the vertical columns have the same density class (measured voxel density $\rho_{\mathrm{s} 1}$ to $\rho_{\mathrm{s}}$ ), whereas the particle densities vary systematically between $\rho_{1}$ and $\rho_{5}$. The total number of voxels of one density class, for example, the lowest density class, can be express as:

$$
N_{v}(1)=N_{v}(1,1)+N_{v}(1,2)+N_{v}(1,3)+N_{v}(1,4)+N_{v}(1,5)
$$

This equation states simply that the total number of voxels of density $\rho_{\mathrm{s} 1}$ consists of the sum of the separate contributions of this voxel density from coal particles of the same density and all partially filled surface voxels of coal particles with higher density. It is 
noted that $N_{v}(i)$ is the measured quantity. Similar equations can be written for other density classes.

For x-ray CT-based coal washability analysis, it is desired to calculate the number of coal particles of density $\rho_{5}, \rho_{4}, \rho_{3}$, etc. In order to do so, the number of CT sliced

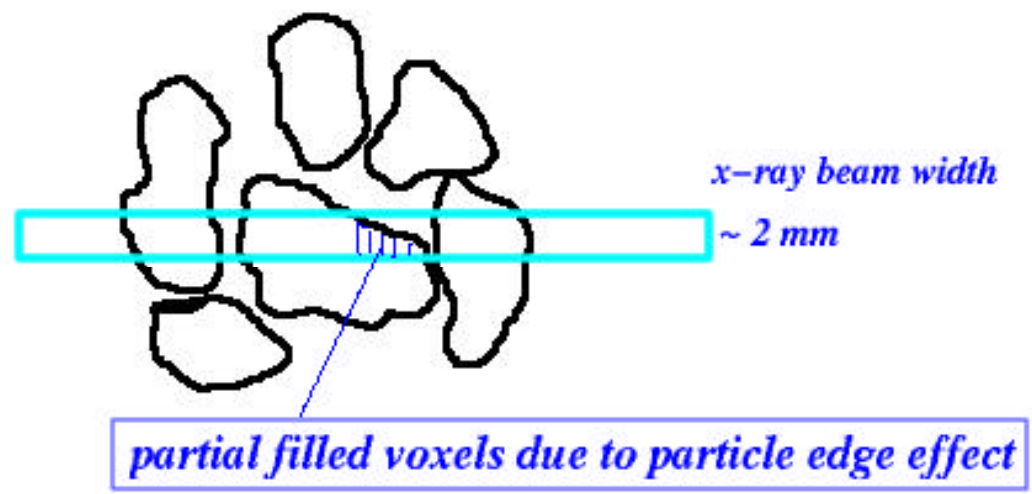

Figure 28. Intersection of polydispersed irregularly coal particles by x-ray sliced plane with a width of about $2 \mathrm{~mm}$.

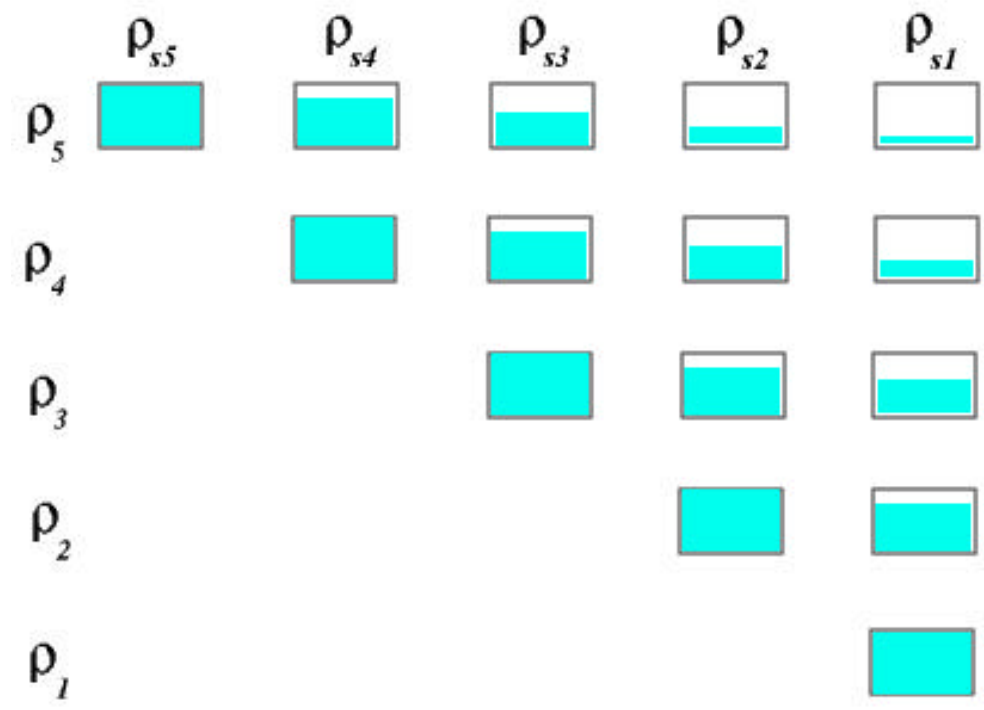

$$
\rho_{5}>\rho_{4}>\rho_{3}>\rho_{2}>\rho_{1}
$$

Figure 29. Schematic illustration of the contribution of voxels with density r1 to r5 (horizontal row as true density) to the total number of sections with density of rs1 to rs5 (vertical column as measured density). 
sections of density $\rho_{\mathrm{s} 5}, \rho_{\mathrm{s} 4}, \rho_{\mathrm{s} 3}$, etc. that arise only from the particle with higher density must be known. Nine gravity (density) classes were used in the x-ray CT washability tests: $<1.3,1.3 \times 1.4,1.4 \times 1.5,1.5 \times 1.6,1.6 x 1.7,1.7 \times 1.8,1.8 \times 1.9,1.9 x 2.0$, and $>2.0$. From the above discussion, the corresponding symbols for each density class are: $\rho_{\mathrm{s} 1}, \rho_{\mathrm{s} 2}, \ldots, \rho_{\mathrm{s} 9}$, respectively. The overall relationship between the known quantity (from sink-flow test), $N_{v}(i)$, and the measured quantity (from CT analysis), $N_{v}(i, i)$, becomes

$$
\left[\begin{array}{l}
N_{v}(1) \\
N_{v}(2) \\
N_{v}(3) \\
N_{v}(4) \\
N_{v}(5) \\
N_{v}(6) \\
N_{v}(7) \\
N_{v}(8) \\
N_{v}(9)
\end{array}\right]=\left[\begin{array}{ccccccccc}
1 & a_{1,2} & a_{1,3} & a_{1,4} & a_{1,5} & a_{1,6} & a_{1,7} & a_{1,8} & a_{1,9} \\
& 1 & a_{2,3} & a_{2,4} & a_{2,5} & a_{2,6} & a_{2,7} & a_{2,8} & a_{2,9} \\
& & 1 & a_{3,4} & a_{3,5} & a_{3,6} & a_{3,7} & a_{3,8} & a_{3,9} \\
& & & 1 & a_{4,5} & a_{4,6} & a_{4,7} & a_{4,8} & a_{4,9} \\
& & & & 1 & a_{5,6} & a_{5,7} & a_{5,8} & a_{5,9} \\
& & & & & 1 & a_{6,7} & a_{6,8} & a_{6,9} \\
& & 0 & & & & 1 & a_{7,8} & a_{7,9} \\
& & & & & & & 1 & a_{8,9} \\
& & & & & & & & a_{9,9}
\end{array}\right] \times\left[\begin{array}{c}
N_{v}(1,1) \\
N_{v}(2,2) \\
N_{v}(3,3) \\
N_{v}(4,4) \\
N_{v}(5,5) \\
N_{v}(6,6) \\
N_{v}(7,7) \\
N_{v}(8,8) \\
N_{v}(9,9)
\end{array}\right]
$$

From eq. (4) and (5), it is evident that:

$$
N_{v}(1,2)=a_{1,2} \times N_{v}(2,2), \text { etc. }
$$

where $N_{v}(i, j)$ is the number of voxels of density $\rho_{\mathrm{si}}$ obtained from particles of density $\rho_{\mathrm{j}}$ and $a_{i, j}$ is the probability of the partially filled surface voxels of particles with density $\rho_{\mathrm{j}}$

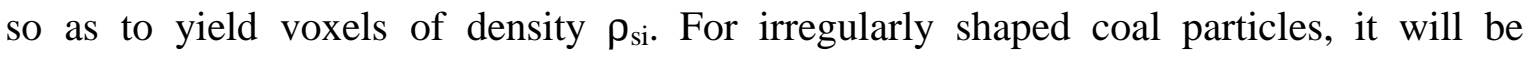
extremely difficult to derive an analytical form for $a_{i, j}$. An approximate value of $a_{i, j}$ can be determined statistically from $N_{v}(i, i)$ (sink-float test results) and $N_{v}(i)$ (CT analysis). Since nine gravity (density) classes were used for washability analysis, the mean densities of each class can be set as $1.25,1.35,1.45, \ldots ., 1.95$ and 2.05 , respectively. The number frequency distribution, $N_{v}(i)$, from sink-float test (density distribution by weight) can be determined. It is reasonable to assume that $a_{8,9}=a_{7,8}=a_{6,7}=a_{5,6}=\ldots=a_{1,2}$ and $a_{7,9}=a_{6,8}=\ldots=a_{1,3}$ etc. From the highest density class, $i=9, a_{9,9}$ can be calculated based on the known value of $N_{v}(9,9)$ and $N_{v}(9)$, and $a_{8,9}$ is simply determined by subtracting 
between known values of $N_{v}(i, i)$ and $N_{v}(i)$. This subtraction process is continued down to the lowest density class. It can be seen that each subtracted term depends on the previously calculated value of $N_{v}(i, i)$ and $N_{v}(i)$. In this manner, a kernel matrix $\underset{\underline{a}}{=}$ can be determined. Once $\underset{\underline{a}}{=}$ is known, the x-ray CT data for a packed bed of coal particles can be used to estimate the sink-float test results. Based on this correction procedure for partially filled surface voxels, the washability curve can be established with the use of the scaled attenuation coefficient histogram and density calibration curve (Figure 12). Since most of the image processing routines for particle separation and classification is eliminated using this approach, a significant reduction in processing time is achieved. For example, to process $100 \mathrm{CT}$ images, the time required for typical image processing routines for particle separation will be about 2500 seconds ( 25 second per image) compared to a total time of 30 second with this new approach.

\section{$\underline{\text { Simulated On-Line Tests }}$}

An overview of the float-sink data collected during the period between February and March is provided in Tables IV (mass distribution data) and V (ash distribution data). A total of 22 samples have been evaluated from this particular site. For each sample, the mass distributions were determined for the specific gravity classes of Float 1.3, $1.3 \times 1.5$, $1.5 \times 1.7,1.7 \times 2.0$ and Sink 2.0. Each fraction from the float-sink procedure was subjected to total ash analysis.

Figure 30 shows six sequential cross-sectioned x-ray CT scans $(5 \mathrm{~mm} / \mathrm{slice})$ for the sample taken from the plant site on February 19, 2000. Based on the scaled attenuation coefficient histograms of the 2-D x-ray CT images (slices) for these coal samples, the specific gravity/yield curves for selected samples were constructed as shown in Figures 31(a), (b) and (c). The specific gravity/yield curves for these samples using sink-float tests (Table IV) are include for comparison. As shown, the results indicate that the specific gravity/yield curves constructed using x-ray CT technique are in good agreement with the data obtained from independent sink-float tests. 
Table IV. Experimental mass distributions for plant samples subjected to float-sink tests.

\begin{tabular}{|c|c|c|c|c|c|c|c|c|}
\hline $\begin{array}{l}\text { Sample } \\
\text { Number }\end{array}$ & $\begin{array}{c}\text { Sample } \\
\text { Date }\end{array}$ & $\begin{array}{c}\% \text { of } \\
\text { Feed } \\
\text { Sample }\end{array}$ & $\begin{array}{c}\text { Mass } \\
\text { Flt } 1.3 \\
(\%)\end{array}$ & $\begin{array}{c}\text { Mass } \\
1.3 \times 1.5 \\
(\%)\end{array}$ & $\begin{array}{c}\text { Mass } \\
1.5 \times 1.7 \\
(\%)\end{array}$ & $\begin{array}{c}\text { Mass } \\
1.7 \times 2.0 \\
(\%)\end{array}$ & $\begin{array}{c}\text { Mass } \\
\text { Snk } 2.0 \\
(\%)\end{array}$ & $\begin{array}{c}\text { Mass } \\
\text { Feed } \\
(\%)\end{array}$ \\
\hline 1 & $2 / 19 / 00$ & 48.23 & 39.84 & 14.06 & 1.96 & 2.40 & 41.74 & 100.00 \\
\hline 2 & $2 / 26 / 00$ & 48.20 & 42.93 & 13.18 & 2.19 & 1.80 & 39.90 & 100.00 \\
\hline 3 & $3 / 4 / 00$ & 46.24 & 41.11 & 16.25 & 2.66 & 3.27 & 36.71 & 100.00 \\
\hline 4 & $3 / 11 / 00$ & 45.59 & 45.63 & 15.97 & 3.09 & 2.31 & 33.00 & 100.00 \\
\hline 5 & $3 / 18 / 00$ & 52.30 & 45.91 & 14.96 & 2.42 & 1.86 & 34.85 & 100.00 \\
\hline 6 & $3 / 25 / 00$ & 48.60 & 54.52 & 12.28 & 2.37 & 2.48 & 28.35 & 100.00 \\
\hline 7 & $4 / 1 / 00$ & 41.77 & 42.88 & 18.83 & 2.70 & 2.06 & 33.53 & 100.00 \\
\hline 8 & $4 / 8 / 00$ & 45.58 & 47.44 & 13.19 & 2.27 & 3.18 & 33.92 & 100.00 \\
\hline 9 & $4 / 15 / 00$ & 46.59 & 48.49 & 10.04 & 3.45 & 2.62 & 35.4 & 100.00 \\
\hline 10 & $4 / 22 / 00$ & 46.94 & 44.26 & 12.08 & 1.67 & 2.37 & 39.62 & 100.00 \\
\hline 11 & 4/29/00 & 47.82 & 42.71 & 13.95 & 1.69 & 2.46 & 39.19 & 100.00 \\
\hline 12 & $5 / 6 / 00$ & 45.12 & 40.98 & 17.03 & 2.18 & 2.90 & 36.91 & 100.00 \\
\hline 13 & $5 / 13 / 00$ & 45.93 & 46.08 & 10.44 & 1.75 & 1.88 & 39.85 & 100.00 \\
\hline 14 & $5 / 20 / 00$ & 47.63 & 45.8 & 11.64 & 2.01 & 2.51 & 38.04 & 100.00 \\
\hline 15 & $5 / 27 / 00$ & 45.07 & 49.46 & 12.92 & 2.75 & 1.65 & 33.22 & 100.00 \\
\hline 16 & $6 / 3 / 00$ & 42.61 & 47.37 & 12.54 & 2.6 & 2.26 & 35.23 & 100.00 \\
\hline 17 & $6 / 10 / 00$ & 40.68 & 42.93 & 16.7 & 2.51 & 2.79 & 35.07 & 100.00 \\
\hline 18 & $6 / 17 / 00$ & 47.8 & 39.66 & 16.15 & 2.59 & 2.31 & 39.29 & 100.00 \\
\hline 19 & $6 / 24 / 00$ & 48.81 & 41.76 & 15.4 & 2.64 & 2.89 & 37.31 & 100.00 \\
\hline 20 & $6 / 30 / 00$ & 43.21 & 45.70 & 14.11 & 3.34 & 2.85 & 34.00 & 100.00 \\
\hline 21 & $7 / 15 / 00$ & 44.97 & 42.53 & 13.32 & 2.96 & 2.52 & 38.99 & 100.00 \\
\hline 22 & $7 / 22 / 00$ & 44.17 & 48.47 & 12.99 & 1.98 & 2.42 & 34.14 & 100.00 \\
\hline Mean & --- & 46.08 & 44.84 & 14.00 & 2.43 & 2.45 & 36.28 & 100.00 \\
\hline Std Dev & --- & 2.64 & 3.59 & 2.21 & 0.49 & 0.43 & 3.15 & 0.00 \\
\hline Minimum & --- & 40.68 & 39.66 & 10.04 & 1.67 & 1.65 & 28.35 & 100.00 \\
\hline Maximum & --- & 52.30 & 54.52 & 18.83 & 3.45 & 3.27 & 41.74 & 100.00 \\
\hline Range & --- & 11.62 & 14.86 & 8.79 & 1.78 & 1.62 & 13.39 & 0.00 \\
\hline
\end{tabular}


Table V. Experimental ash distributions for plant samples subjected to float-sink tests.

\begin{tabular}{|c|c|c|c|c|c|c|c|c|}
\hline $\begin{array}{l}\text { Sample } \\
\text { Number }\end{array}$ & $\begin{array}{c}\text { Sample } \\
\text { Date }\end{array}$ & $\begin{array}{c}\% \text { of Feed } \\
\text { Sample }\end{array}$ & $\begin{array}{c}\text { Ash } \\
\text { Flt } 1.3 \\
(\%)\end{array}$ & $\begin{array}{c}\text { Ash } \\
1.3 \times 1.5 \\
(\%)\end{array}$ & \begin{tabular}{|c|} 
Ash \\
$1.5 \times 1.7$ \\
$(\%)$
\end{tabular} & $\begin{array}{c}\text { Ash } \\
1.7 \times 2.0 \\
(\%)\end{array}$ & $\begin{array}{c}\text { Ash } \\
\text { Snk 2.0 } \\
(\%)\end{array}$ & $\begin{array}{c}\text { Ash } \\
\text { Feed } \\
(\%)\end{array}$ \\
\hline 1 & $2 / 19 / 00$ & $\begin{array}{l}48.23 \\
-3 \times x\end{array}$ & 3.44 & 11.43 & 35.20 & 50.78 & 87.30 & 41.33 \\
\hline 2 & $2 / 26 / 00$ & 48.20 & 3.93 & 11.92 & 29.67 & 50.26 & 90.14 & 40.78 \\
\hline 3 & $3 / 4 / 00$ & 46.24 & 3.62 & 9.52 & 31.20 & 44.58 & 89.95 & 38.34 \\
\hline 4 & $3 / 11 / 00$ & 45.59 & 3.49 & 11.18 & 27.97 & 55.10 & 88.41 & 34.69 \\
\hline 5 & $3 / 18 / 00$ & .30 & 3.56 & 11.09 & 31.81 & 45.42 & $\begin{array}{l}88.43 \\
88 .\end{array}$ & 35.73 \\
\hline 6 & $3 / 25 / 00$ & 48.60 & 3.97 & 10.72 & 29.52 & 48.96 & 87.09 & 30.08 \\
\hline 7 & $4 / 1 / 00$ & 41.77 & 3.36 & 10.24 & 37.43 & 58.49 & 89.10 & 35.46 \\
\hline 8 & $4 / 8 / 00$ & 45.58 & 4.05 & 11.08 & 31.54 & 47.07 & 88.68 & 35.68 \\
\hline 9 & $4 / 15 / 00$ & 46.59 & 4.68 & 13.09 & 24.4 & 44.17 & 89.55 & 37.28 \\
\hline 10 & $4 / 22 / 00$ & 46.94 & 3.38 & 12.47 & 38 & 57.04 & 90.51 & 40.85 \\
\hline 11 & $4 / 29 / 00$ & & 3.43 & 10.58 & 33.87 & 55.43 & 89.94 & 40.12 \\
\hline 12 & $5 / 00$ & & 3.53 & 11.67 & 33.06 & 52.44 & 89.65 & 38.77 \\
\hline 13 & $5 / 13 / 00$ & 45.93 & 3.6 & 12.04 & 32.68 & 56.87 & 89.19 & 40.10 \\
\hline 14 & $5 / 20 / 00$ & 47.63 & 3.29 & 11.11 & 34.39 & 57.4 & 88.27 & 38.51 \\
\hline 15 & $5 / 27 / 00$ & & 3.28 & 11.64 & 29.32 & 53.37 & 85. & 33.34 \\
\hline 16 & $3 / 00$ & 42.61 & 3.43 & 12.16 & 36.31 & 50.78 & 89.67 & 36.83 \\
\hline 17 & $6 / 10 / 00$ & 40.68 & 3.59 & 10.38 & 33.92 & 53.61 & 90.83 & 37.48 \\
\hline 18 & $6 / 17 / 00$ & .8 & 3.22 & 10.09 & 35.54 & 55.07 & 90.76 & 40.76 \\
\hline 19 & $6 / 24 / 00$ & 48.81 & 3.61 & 11.94 & 39.63 & 52.37 & 91.59 & 40.08 \\
\hline 20 & $6 / 30 / 00$ & & 3.18 & 11.32 & 28.78 & 48.16 & 88.75 & 35.56 \\
\hline 21 & $7 / 15 / 00$ & 44.97 & 3.81 & 12.39 & 24.64 & 51.93 & 92.56 & 41.32 \\
\hline 22 & $7 / 22 / 00$ & 44.17 & 3.46 & 11.37 & 34.99 & 49.54 & 89.68 & 35.66 \\
\hline Mean & --- & 46.08 & 3.59 & 11.34 & 32.45 & 51.77 & 89.36 & 37.67 \\
\hline Std Dev & --- & 2.64 & 0.34 & 0.86 & 4.04 & 4.22 & 1.51 & 2.95 \\
\hline Minimum & --- & & 3.18 & 9.52 & 24.40 & 44.17 & 85.87 & 30.08 \\
\hline Maximum & --- & 52.30 & 4.68 & 13.09 & 39.63 & 58.49 & 92.56 & 41.33 \\
\hline Range & --- & 11.62 & 1.50 & 3.57 & 15.23 & 14.32 & 6.69 & 11.24 \\
\hline
\end{tabular}




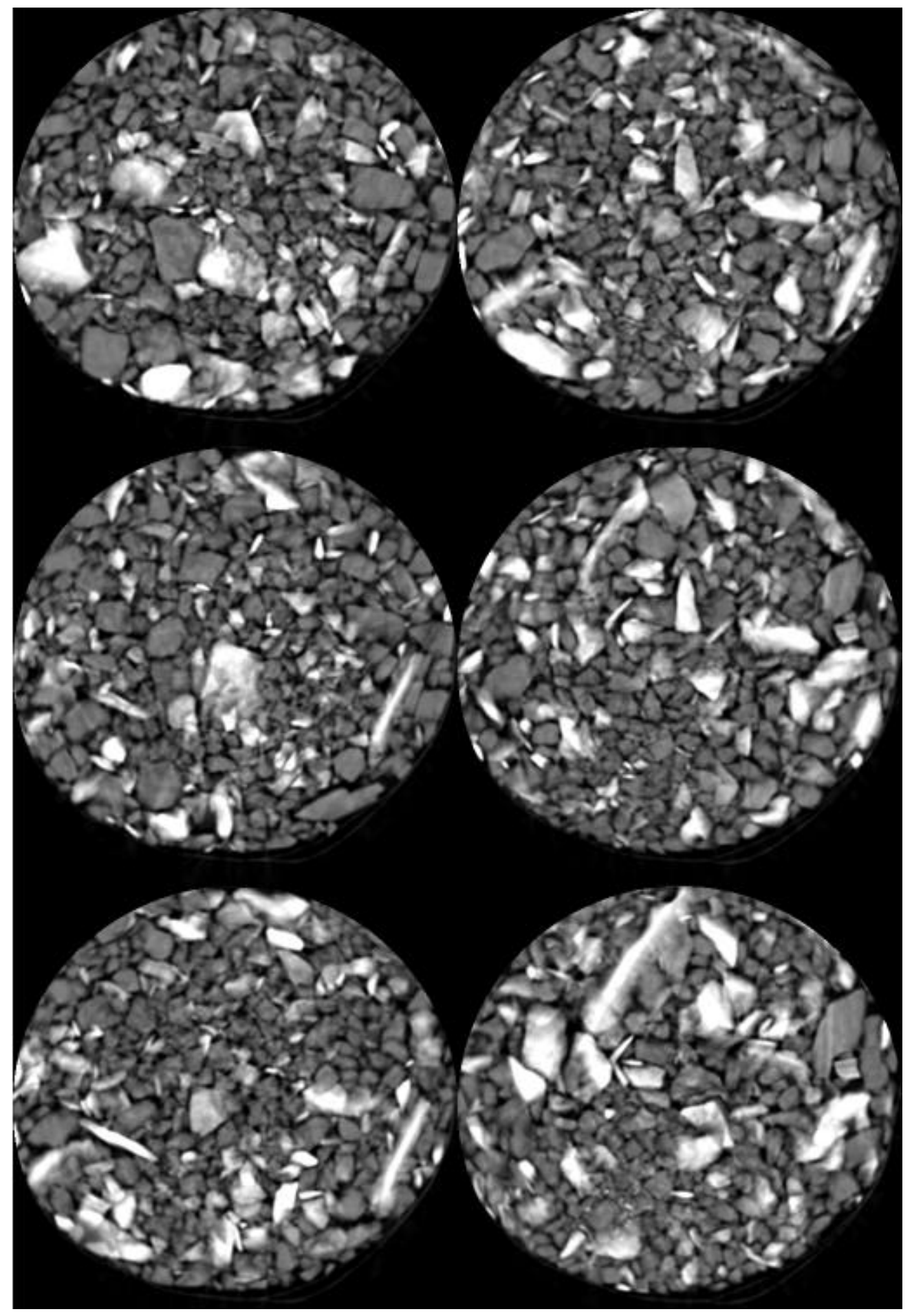

Figure 30. Sequential cross sections of $\mathrm{x}$-ray CT scans for a 1-1/4x1/4 inch coal sample at $5 \mathrm{~mm} / \mathrm{slice}$ (Plant sampling date of February 19, 2000). 

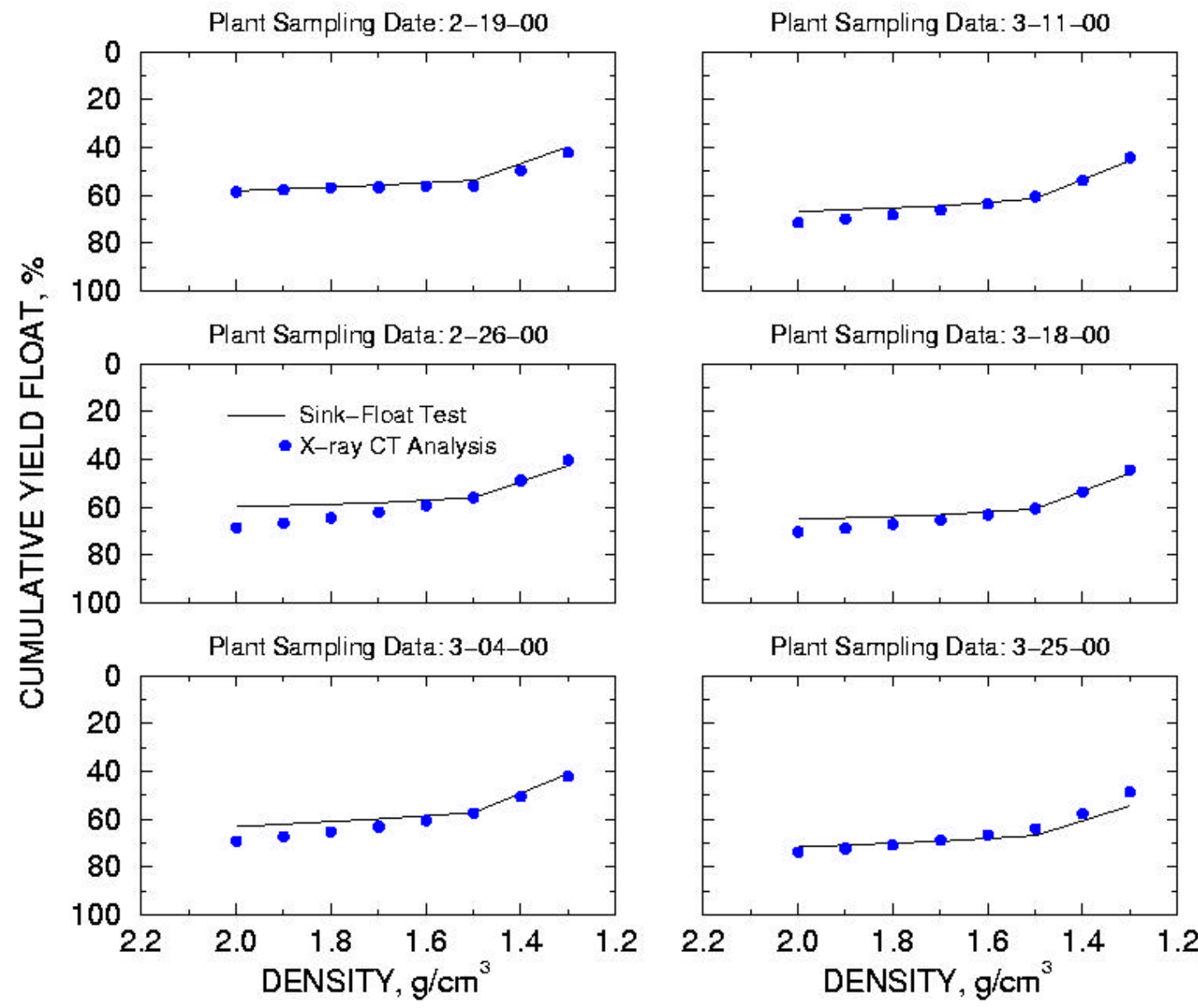

Plant Sampling Data: 3-25-00

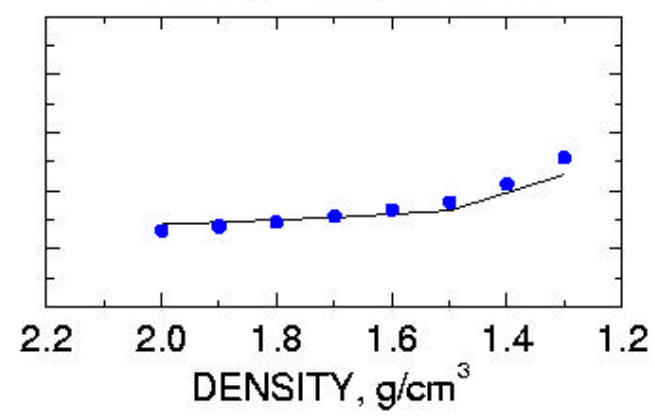

Figure 31(a). Comparisons of specific gravity/yield curve for coal samples (plant sampling data between $2 / 19$ and $3 / 25$ ) as determined by sink-float test with the results from $\mathrm{x}$-ray CT analysis ( $24 \mathrm{~kg}$ sample weight). 

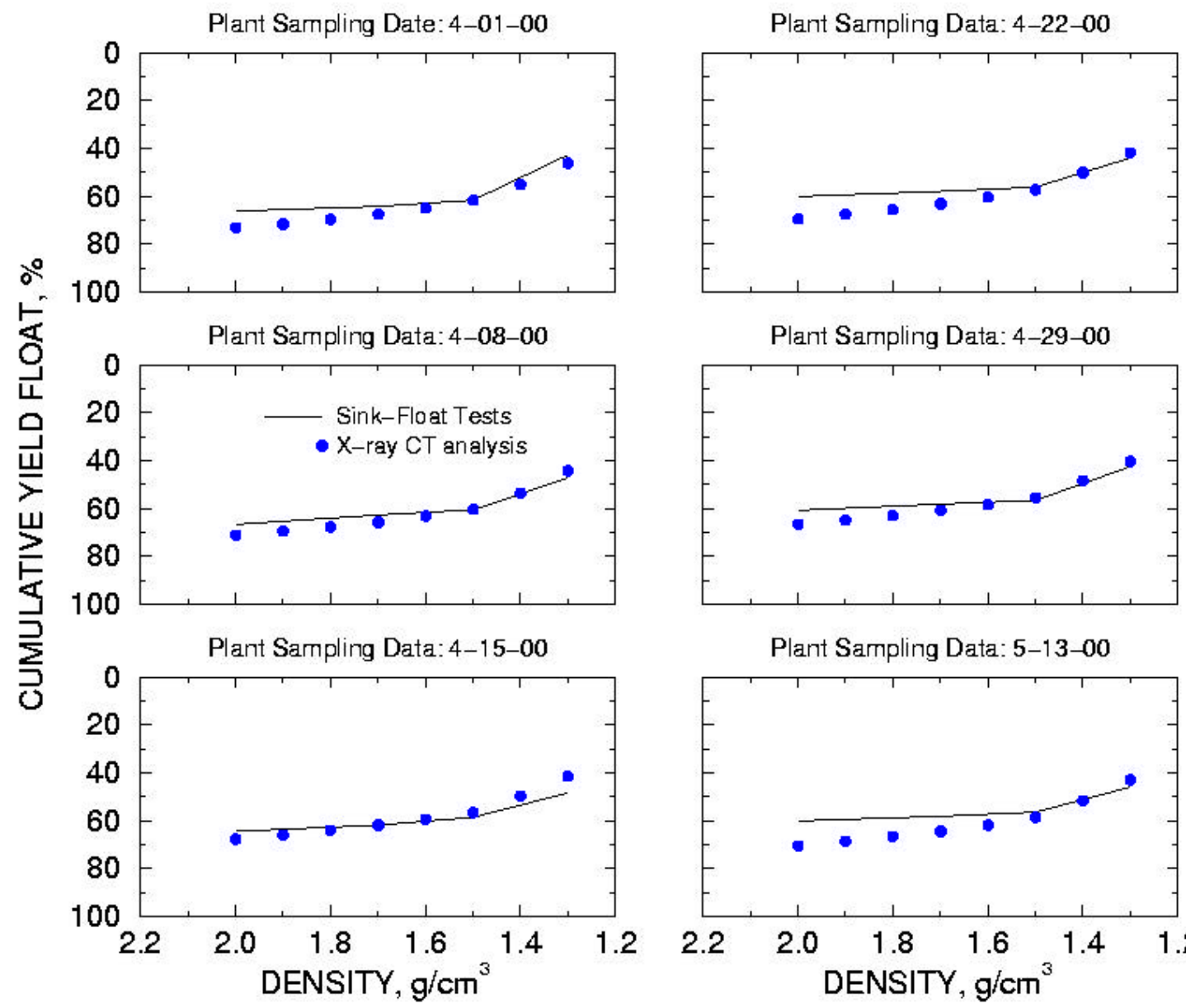

Plant Sampling Data: 4-29-00

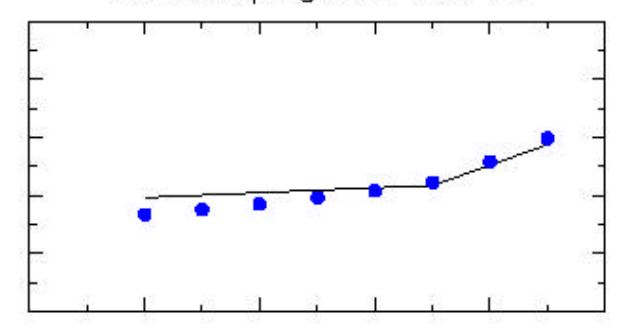

Plant Sampling Data: 5-13-00

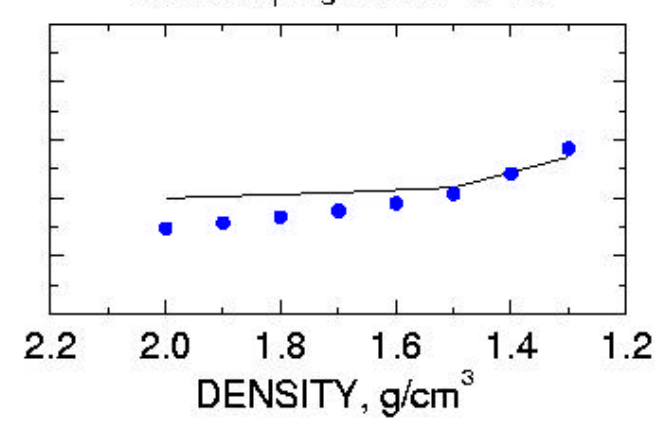

Figure 31(b). Comparisons of specific gravity/yield curve for coal samples (plant sampling data between 4/01 and 5/13) as determined by sink-float test with the results from $\mathrm{x}$-ray CT analysis ( $24 \mathrm{~kg}$ sample weight). 

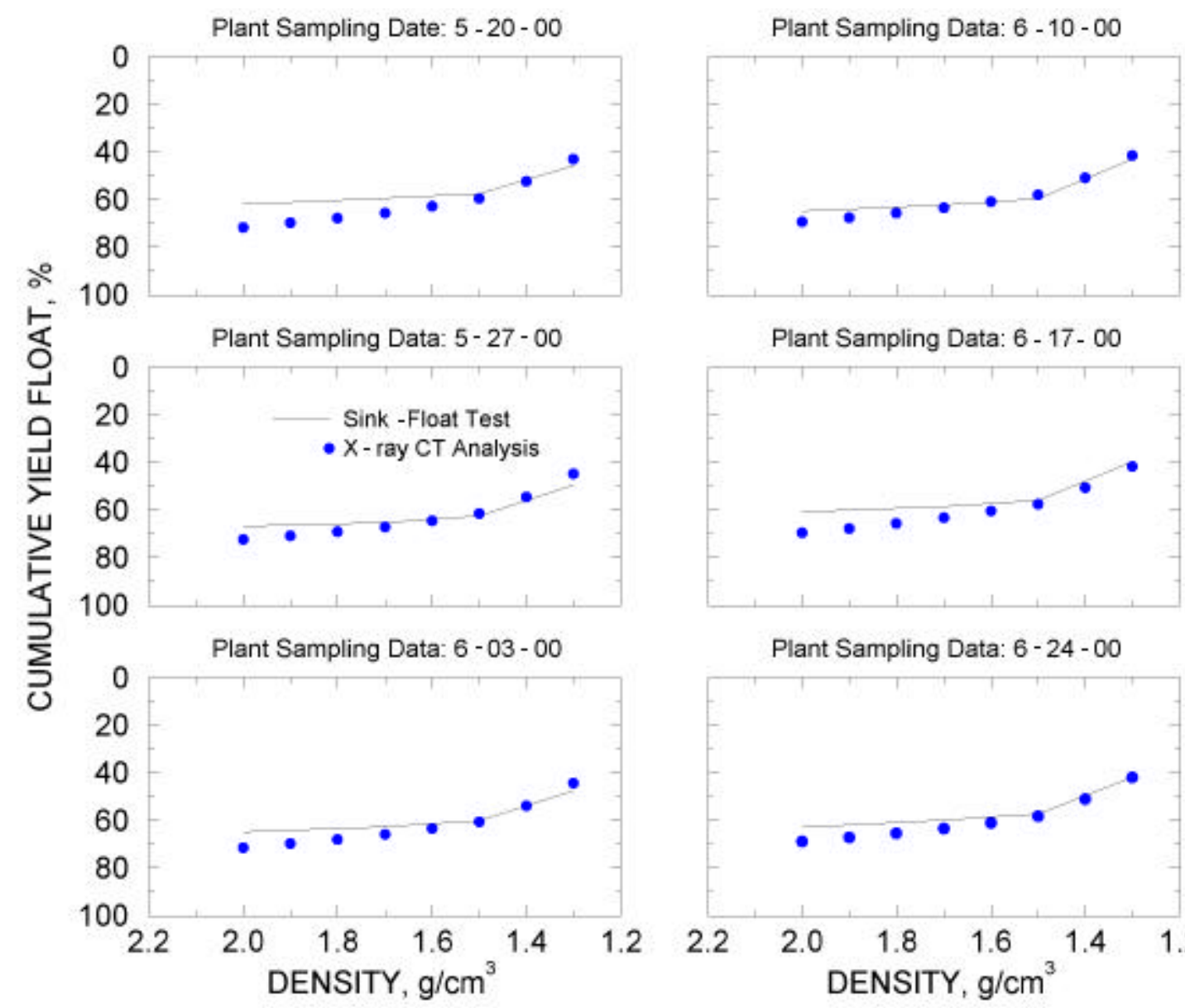

Plant Sampling Data: 6 - 17 - 00

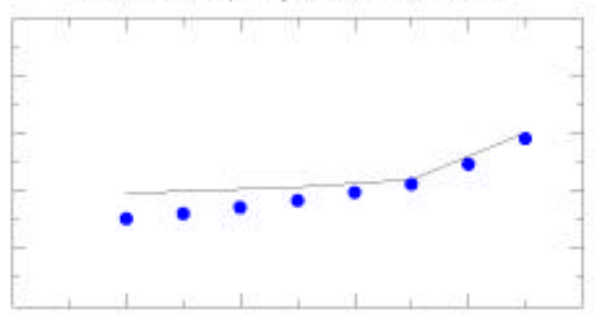

Plant Sampling Data: 6-24-00

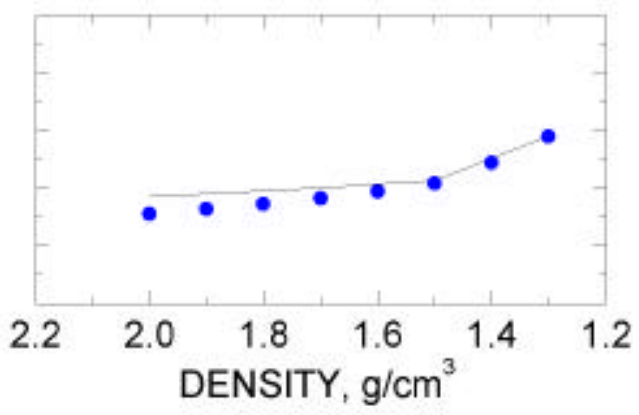

Figure 31(c). Comparisons of specific gravity/yield curve for coal samples (plant sampling data between $5 / 20$ and $6 / 24$ ) as determined by sink-float test with the results from $\mathrm{x}$-ray CT analysis ( $24 \mathrm{~kg}$ sample weight). 
As mentioned previously, for washability analysis using x-ray CT, two cylindrical sample containers were used for each coal sample. To evaluate the effect of sample weight required for analysis, washability measurements were made for each container separately for image distances of $5 \mathrm{~mm} / \mathrm{slice}$. Figure 32 illustrates the constructed yield/specific gravity curves for both containers. As expected a large variation (about 5\%) is observed for an insufficient amount of sample $(\sim 12 \mathrm{~kg})$.

Image frequency must be considered to evaluate the CT-base coal washability analyzer under the dynamic case (on-line condition). At what rate should CT slices be taken? What is the appropriate number of CT slices per unit of length? In this regard, image frequency, the number of CT slices needed to represent the entire coal particle population is analyzed in detail. As mentioned in result section of primary objective, two samples, 25.4 x $12.7 \mathrm{~mm}$ and $50.8 \times 25.4 \mathrm{~mm}$, were prepared for washability analysis by xray CT. Two sets of sequential cross sectional images (150 and 124 slices) were collected.

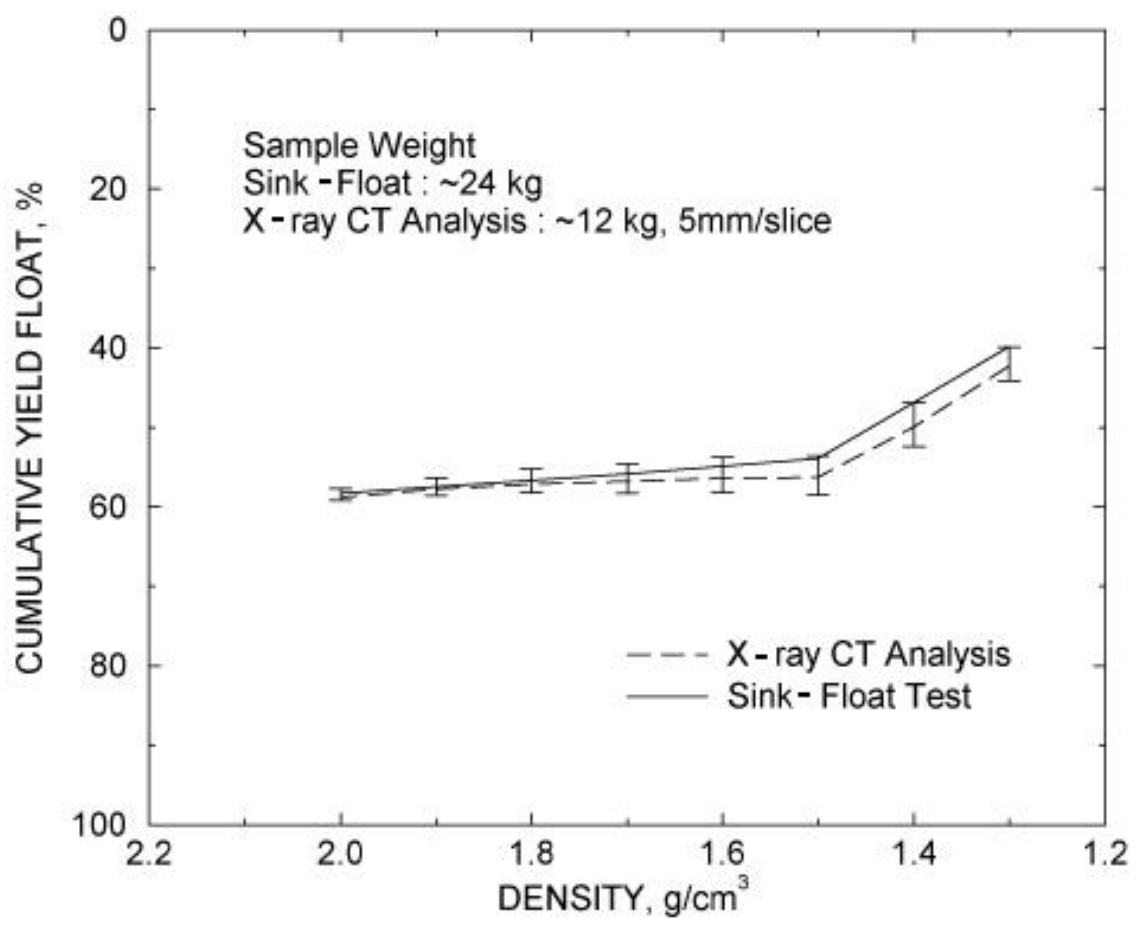

Figure 32. Effect of sample weight $(\sim 12 \mathrm{~kg})$ on specific gravity/yield curves for coal sample (2-19-00). Sink-float result (solid line) is included for comparison. 
In these experiments each 2-D CT slice was $2 \mathrm{~mm}$ in thickness. In this way the total coal particle population is scanned. CT washability measurements were made for image sample spacing of $4 \mathrm{~mm}, 6 \mathrm{~mm}, 8 \mathrm{~mm}, 10 \mathrm{~mm}, 20 \mathrm{~mm}$ and $30 \mathrm{~mm}$ for the total coal particle population. Thus of the total 150 slices for the $2 \times 1$ inch sample, an image sample spacing of $6 \mathrm{~mm}$ means that one out of every 3 images is analyzed.

Based on the above procedure, it is reasonable to use both the sink-float washability data and the CT measurement of the total population (image spacing of $2 \mathrm{~mm}$ ) as a reference to evaluate the number of scans required for analysis. Based on the 2-D CT images (slices) of these coal particle beds, Figures 33 and 34 illustrate the constructed

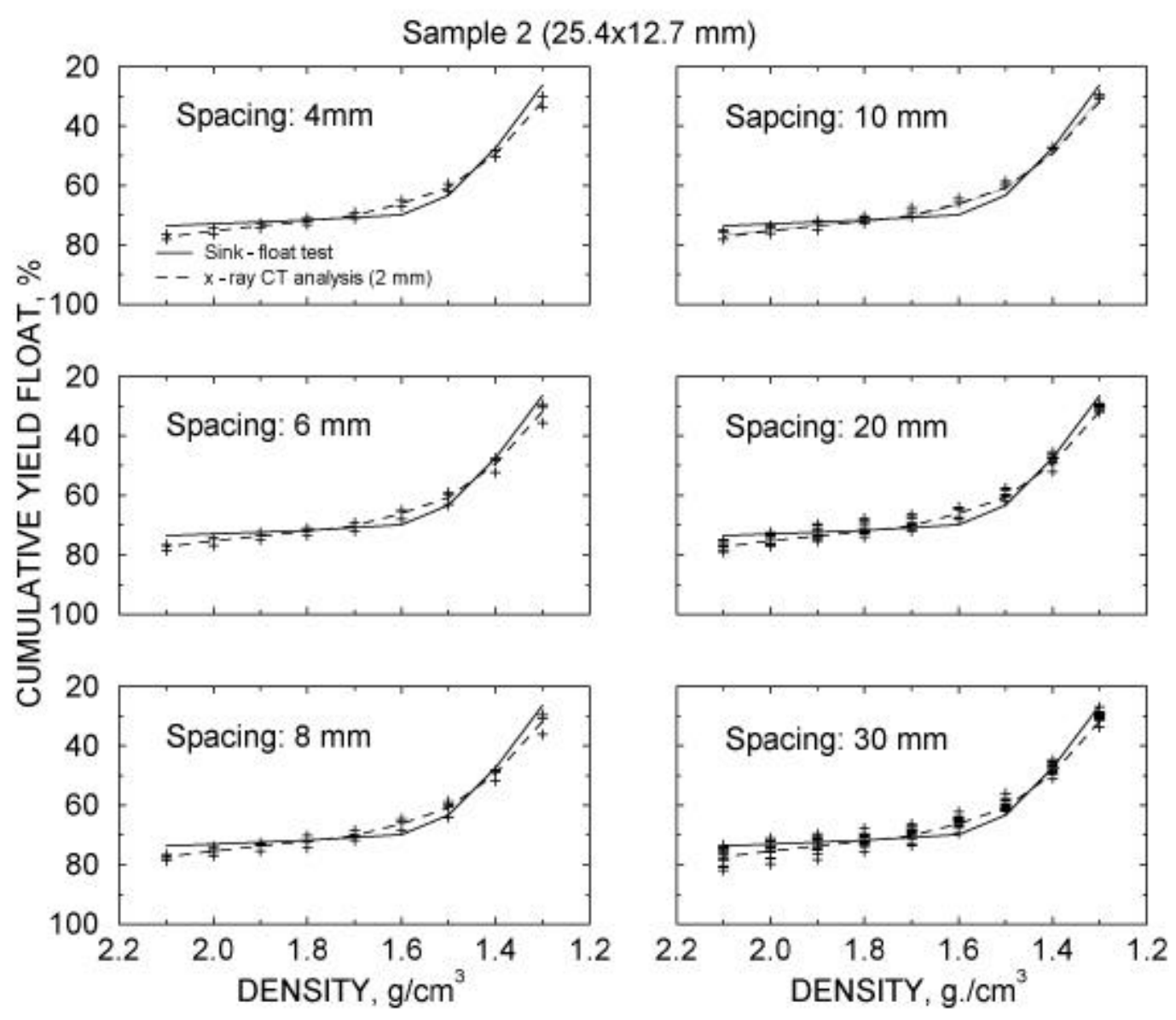

Figure 33. Comparisons of specific gravity/yield curves for sample $2(25.4 \times 12.7 \mathrm{~mm})$ for different image sample spacings. Sink-float results (solid line) and complete CT measurements at $2 \mathrm{~mm}$ (dash line) are included for comparison. 

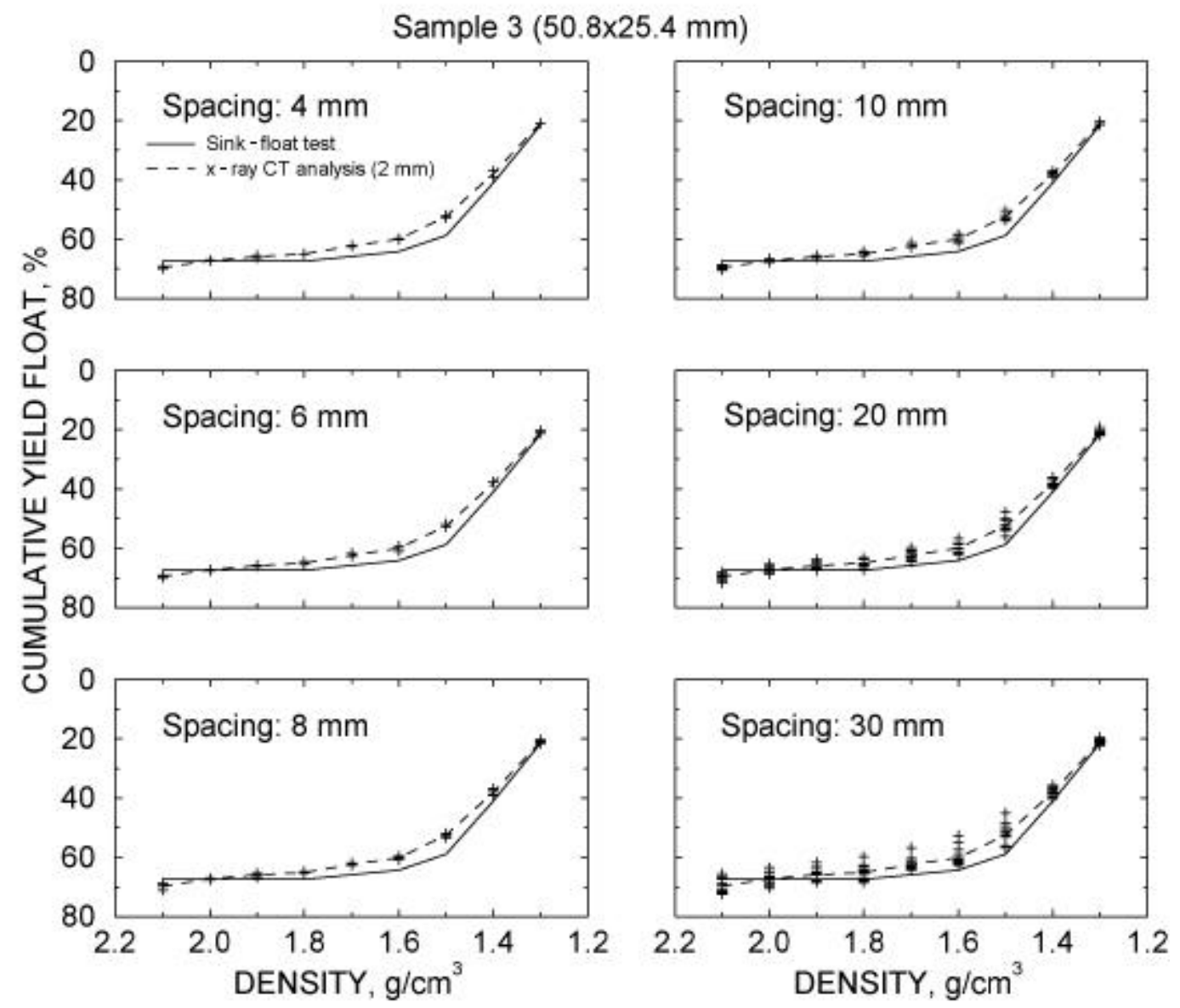

Figure 34. Comparisons of specific gravity/yield curves for sample $3(50.8 \times 25.4 \mathrm{~mm})$ for different image sample spacings. Sink-float results (solid line) and complete CT measurements at $2 \mathrm{~mm}$ (dash line) are included for comparison.

yield/specific gravity curves for different image sample spacing for both the $25.4 \times 12.7 \mathrm{~mm}$ and $50.8 \times 25.4 \mathrm{~mm}$ samples, respectively. Clearly the deviations for image sample spacing of less than $10 \mathrm{~mm}$ are not large but large variations of the results of $20 \mathrm{~mm}$ and $30 \mathrm{~mm}$ are observed as shown in Figures 33 and 34.

Figure 35 illustrates the constructed yield/specific gravity curves for image spacing of $10 \mathrm{~mm}$ for one of the sample for simulated on-line tests. Clearly the deviations for an image distance of $10 \mathrm{~mm} / \mathrm{slice}$ are not large compared with the effect of sample weight as shown in Figure 32. 


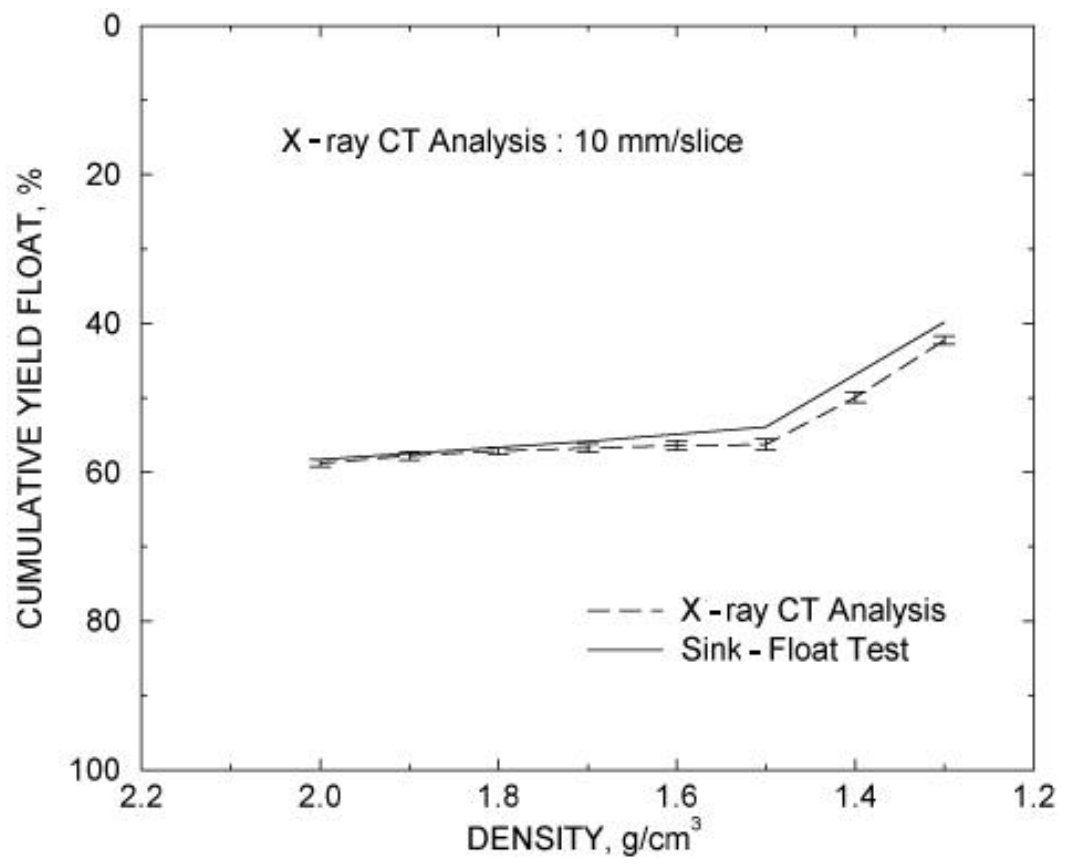

Figure 35. Effect of image spacing at $10 \mathrm{~mm}$ on specific gravity/yield curves for coal sample (2-19-00). Sink-float result (solid line) is included for comparison ( 24 kg sample weight).

\section{Plant Sampling for System Evaluation}

The feed to a coal preparation plant may be subject to significant variations in terms of size, quality and mineralogical association. Factors responsible for these variations include fluctuations in seam characteristics, modifications in mining practices and changes in the mix of coal entering the plant from multiple sections and/or mines. These disturbances make it difficult for plant operations to maintain a consistent coal quality and to maximize clean coal production. In order to examine the extent of these variations, samples were collected from the feed stream to an industrial coal preparation plant and subjected to washability (float-sink) analyses. The plant samples were taken daily and then combined to prepare a composite feed sample at the end of each four-week period. This procedure was continued for a period of about 13 months. 
Each field sample was sized at $6.35 \mathrm{~mm}(1 / 4 \mathrm{inch})$ and $1 \mathrm{~mm}$ (16 mesh). Due to the large amounts of material involved, a two-point float-sink procedure was used for each size fraction. This allowed three specific gravity fractions (i.e., float 1.35, 1.35 x 1.65 and sink 1.65) to be produced for each of the two coarser size fractions (i.e., plus $6.35 \mathrm{~mm}$ and $6.35 \mathrm{x} 1 \mathrm{~mm})$. Since the proposed CT unit is currently not capable of analyzing the minus $1 \mathrm{~mm}$ fraction, this size class was not evaluated as part of this study. A summary of the statistical analyses of the washability data is provided in Tables VI and VII.

Figure 36 shows the mass yield and ash content obtained for the plus 6.35-mm size fraction. As shown, the percentage of low-ash float 1.35 SG material in the composite feed samples varied substantially from a maximum of $41.4 \%$ to a minimum of $26.2 \%$ during the sampling campaign. Likewise, the percentage of high-ash $1.65 \mathrm{SG}$ sink material in the composite samples mirrored the data for the float $1.35 \mathrm{SG}$ fraction. The large variations in washability were surprising since each sample was prepared as a composite of approximately 20-25 individual daily samples taken over each four-week sampling period. As a result, the variations in washability for the individual samples are expected to exceed these average variations. Statistical analyses suggest that standard deviations for the individual daily samples would be in the order of $28.8 \%, 9.1 \%$ and $37.0 \%$ for the float $1.35,1.35 \times 1.65$ and sink $1.65 \mathrm{SG}$ classes, respectively. It is also interesting to note that the variations in the washability of the $6.35 \mathrm{x} 1 \mathrm{~mm}$ size fraction were less prominent (Figure 37). The standard deviations for these daily samples were estimated to be $14.9 \%, 4.0 \%$ and $12.5 \%$ for the float $1.35,1.35 \times 1.65$ and sink $1.65 \mathrm{SG}$ classes, respectively. The smaller variability may be attributed to the improved liberation of the finer material. 
Table VI . Statistical analysis of preparation plant feed data (plus $6.35 \mathrm{~mm}$ ).

\begin{tabular}{|c|c|c|c|c|c|c|c|c|}
\hline \multirow{2}{*}{$\begin{array}{l}\text { Statistical } \\
\text { Parameter }\end{array}$} & \multicolumn{3}{|c|}{ Mass (\%) } & \multicolumn{3}{|c|}{ Ash (\%) } & \multirow{2}{*}{\begin{tabular}{|c} 
Particle \\
Size \\
$(\%)$
\end{tabular}} & \multirow{2}{*}{$\begin{array}{c}\text { Feed } \\
\text { Ash } \\
(\%)\end{array}$} \\
\hline & Flt 1.35 & $\begin{array}{c}1.35 \times 1 . \\
65\end{array}$ & $\begin{array}{l}\text { Sink } \\
1.60 \\
\end{array}$ & Flt 1.35 & $\begin{array}{c}1.35 \times 1 . \\
65\end{array}$ & $\begin{array}{l}\text { Sink } \\
1.60\end{array}$ & & \\
\hline \multicolumn{9}{|l|}{ Sample Data: } \\
\hline Maximum & 41.43 & 10.48 & 69.71 & 4.63 & 26.88 & 89.77 & 53.34 & 62.39 \\
\hline Minimum & 26.23 & 3.64 & 48.09 & 3.15 & 17.76 & 77.72 & 21.85 & 41.68 \\
\hline Range & 15.20 & 6.84 & 21.62 & 1.48 & 9.12 & 12.05 & 31.49 & 20.71 \\
\hline Average & 33.66 & 6.30 & 60.04 & 3.60 & 21.94 & 82.49 & 37.43 & 52.31 \\
\hline Median & 33.39 & 6.07 & 60.11 & 3.49 & 21.98 & 81.04 & 37.96 & 51.11 \\
\hline Variance & 37.67 & 3.79 & 62.09 & 0.18 & 4.79 & 13.14 & 87.52 & 55.08 \\
\hline Std. Deviation & 6.14 & 1.95 & 7.88 & 0.42 & 2.19 & 3.63 & 9.36 & 7.42 \\
\hline \multicolumn{9}{|l|}{ Population Data: } \\
\hline Average & 33.66 & 6.30 & 60.04 & 3.60 & 21.94 & 82.49 & 37.43 & 52.31 \\
\hline Variance & 828.80 & 83.41 & 1366.01 & 3.97 & 105.30 & 289.10 & 1925.37 & 1211.82 \\
\hline Std. Deviation & 28.79 & 9.13 & 36.96 & 1.99 & 10.26 & 17.00 & 43.88 & 34.81 \\
\hline $95 \%$ C. Interval & 15.65 & 4.96 & 20.09 & 1.08 & 5.58 & 9.24 & 23.85 & 18.92 \\
\hline Lower Value & 18.01 & 1.34 & 39.95 & 2.52 & 16.36 & 73.24 & 13.58 & 33.39 \\
\hline Upper Value & 49.31 & 11.27 & 80.13 & 4.68 & 27.51 & 91.73 & 61.28 & 71.23 \\
\hline $90 \%$ C. Interval & 13.13 & 4.17 & 16.86 & 0.91 & 4.68 & 7.76 & 20.02 & 15.88 \\
\hline Lower Value & 20.53 & 2.14 & 43.18 & 2.69 & 17.25 & 74.73 & 17.41 & 36.43 \\
\hline Upper Value & 46.79 & 10.47 & 76.90 & 4.51 & 26.62 & 90.24 & 57.45 & 68.19 \\
\hline $80 \%$ C. Interval & 10.23 & 3.25 & 13.14 & 0.71 & 3.65 & 6.04 & 15.60 & 12.37 \\
\hline Lower Value & 23.43 & 3.06 & 46.90 & 2.89 & 18.29 & 76.44 & 21.84 & 39.94 \\
\hline Upper Value & 43.89 & 9.55 & 73.18 & 4.31 & 25.58 & 88.53 & 53.03 & 64.68 \\
\hline
\end{tabular}


Table VII. Statistical analysis of preparation plant feed data $(6.35 \times 1.00 \mathrm{~mm})$.

\begin{tabular}{|c|c|c|c|c|c|c|c|c|}
\hline \multirow{2}{*}{$\begin{array}{l}\text { Statistical } \\
\text { Parameter }\end{array}$} & \multicolumn{3}{|c|}{ Mass (\%) } & \multicolumn{3}{|c|}{$\operatorname{Ash}(\%)$} & \multirow{2}{*}{$\begin{array}{c}\text { Particle } \\
\text { Size } \\
(\%)\end{array}$} & \multirow{2}{*}{$\begin{array}{c}\text { Feed } \\
\text { Ash } \\
(\%) \\
\end{array}$} \\
\hline & Flt 1.35 & $\begin{array}{c}1.35 \times 1 \\
65\end{array}$ & $\begin{array}{l}\text { Sink } \\
1.60\end{array}$ & Flt 1.35 & $\begin{array}{c}1.35 \times 1 \\
65\end{array}$ & $\begin{array}{l}\text { Sink } \\
1.60\end{array}$ & & \\
\hline \multicolumn{9}{|l|}{ Sample Data: } \\
\hline Maximum & 71.86 & 7.34 & 32.78 & 3.46 & 22.31 & 83.46 & 48.43 & 29.46 \\
\hline Minimum & 60.19 & 4.89 & 23.25 & 2.53 & 16.99 & 77.79 & 30.57 & 21.48 \\
\hline Range & 11.67 & 2.45 & 9.53 & 0.93 & 5.32 & 5.67 & 17.86 & 7.98 \\
\hline Average & 63.83 & 6.29 & 29.88 & 2.88 & 18.82 & 80.65 & 39.67 & 27.12 \\
\hline Median & 63.02 & 6.52 & 30.94 & 2.80 & 18.59 & 80.93 & 36.83 & 28.18 \\
\hline Variance & 10.06 & 0.72 & 7.15 & 0.08 & 2.14 & 2.63 & 30.44 & 5.45 \\
\hline Std. Deviation & 3.17 & 0.85 & 2.67 & 0.28 & 1.46 & 1.62 & 5.52 & 2.33 \\
\hline \multicolumn{9}{|l|}{ Population Data: } \\
\hline Average & 63.83 & 6.29 & 29.88 & 2.88 & 18.82 & 80.65 & 39.67 & 27.12 \\
\hline Variance & 221.34 & 15.88 & 157.19 & 1.75 & 47.01 & 57.96 & 669.66 & 119.90 \\
\hline Std. Deviation & 14.88 & 3.99 & 12.54 & 1.32 & 6.86 & 7.61 & 25.88 & 10.95 \\
\hline $95 \%$ C. Interval & 8.09 & 2.17 & 6.82 & 0.72 & 3.73 & 4.14 & 14.07 & 5.95 \\
\hline Lower Value & 55.75 & 4.12 & 23.06 & 2.16 & 15.10 & 76.51 & 25.60 & 21.17 \\
\hline Upper Value & 71.92 & 8.46 & 36.69 & 3.60 & 22.55 & 84.79 & 53.74 & 33.07 \\
\hline $90 \%$ C. Interval & 6.79 & 1.82 & 5.72 & 0.60 & 3.13 & 3.47 & 11.81 & 5.00 \\
\hline Lower Value & 57.05 & 4.47 & 24.16 & 2.28 & 15.70 & 77.18 & 27.87 & 22.12 \\
\hline Upper Value & 70.62 & 8.11 & 35.60 & 3.48 & 21.95 & 84.12 & 51.48 & 32.11 \\
\hline $80 \%$ C. Interval & 5.29 & 1.42 & 4.46 & 0.47 & 2.44 & 2.71 & 9.20 & 3.89 \\
\hline Lower Value & 58.55 & 4.87 & 25.42 & 2.41 & 16.39 & 77.94 & 30.47 & 23.23 \\
\hline Upper Value & 69.12 & 7.71 & 34.33 & 3.35 & 21.26 & 83.36 & 48.87 & 31.01 \\
\hline
\end{tabular}



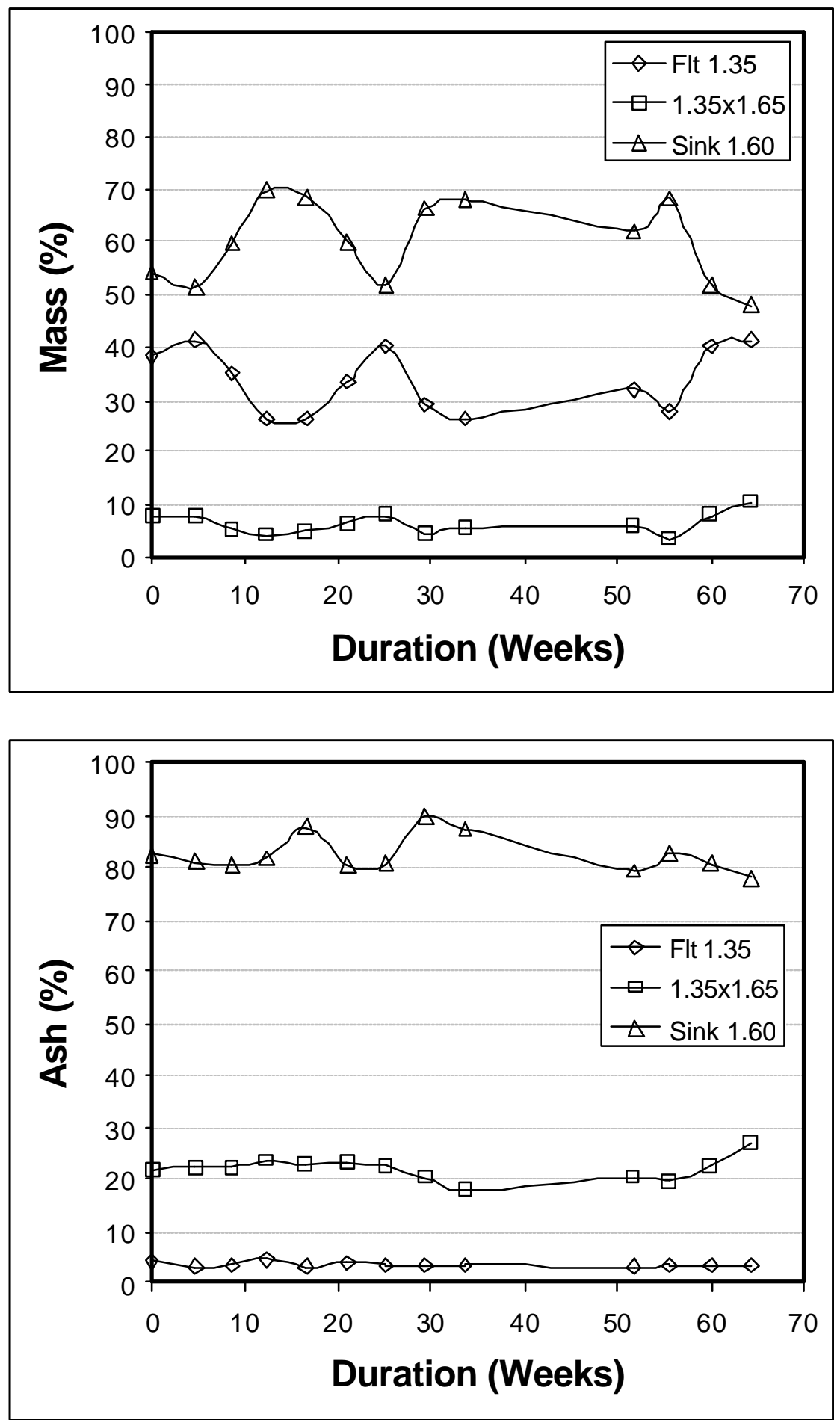

Figure 36. Variations in mass and ash for various SG classes (plus $6.35 \mathrm{~mm}$ feed). 

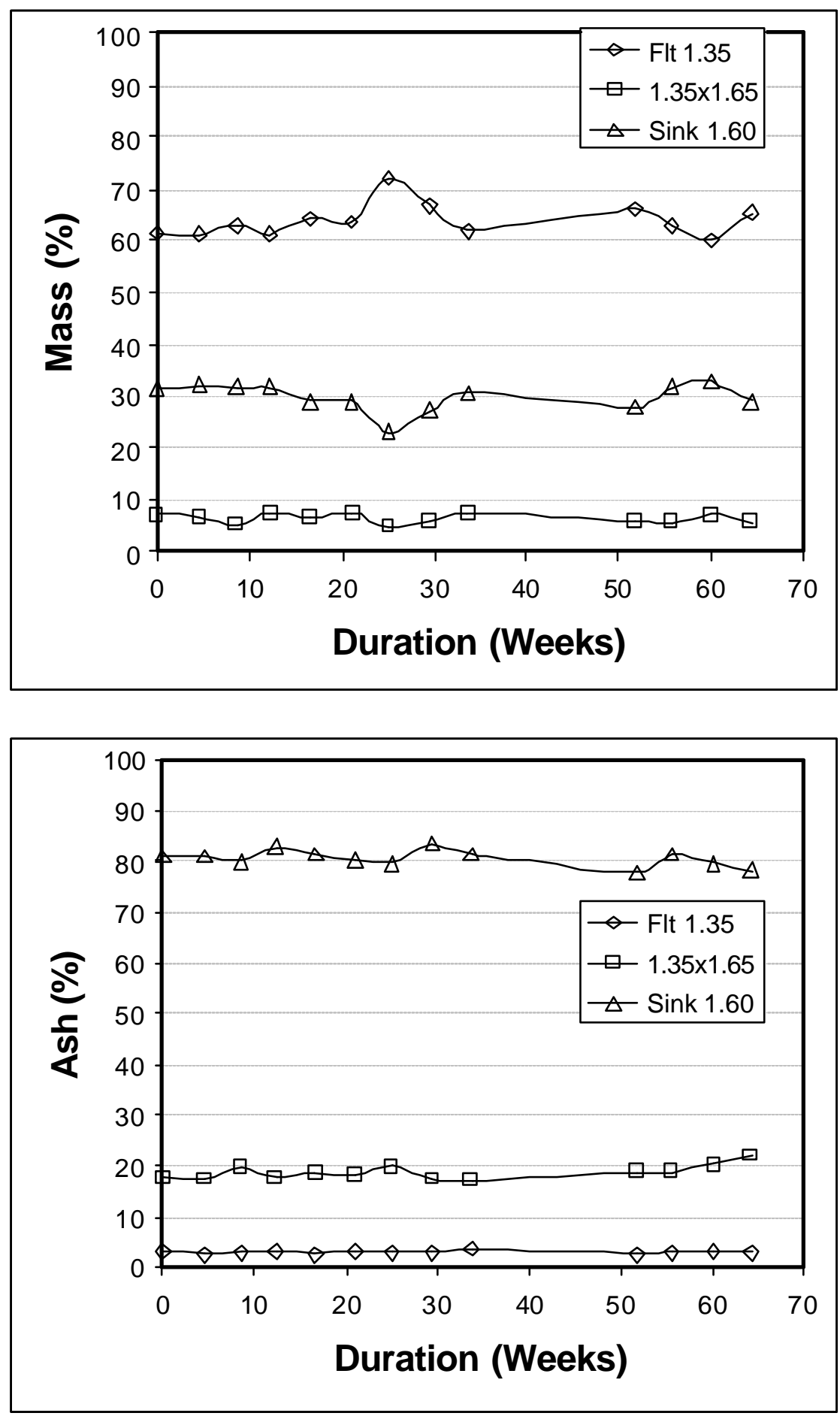

Figure 37. Variations in mass and ash for various $\mathrm{SG}$ classes $(6.35 \times 1.0 \mathrm{~mm}$ feed $)$. 


\section{$\underline{\text { Technical Justification for On-Line Washability Analysis }}$}

As indicated in the previous section of this report, the quality of cleaned products from coal preparation plants is often variable due to natural fluctuations in the washability characteristics of the plant feed. To combat this problem, many modern plants have installed on-line analyzers that provide feedback for the real-time control of product quality via the adjustment of the specific gravity of separation that is commonly referred to as the "cut-point". Unfortunately, this approach may actually lead to increased losses of saleable coal. This shortcoming is due to the fact that coal preparation plants incorporate several parallel cleaning circuits that are partitioned according to particle size. As such, the clean coal yield $(\mathrm{Y})$ and quality $(\mathrm{Q})$ for a plant consisting of $\mathrm{n}$ parallel circuits can be calculated from simple weighted averages using:

$$
\begin{gathered}
\mathrm{Y}=\sum_{\mathrm{i}=1}^{\mathrm{n}} \mathrm{S}_{\mathrm{i}} \mathrm{Y}_{\mathrm{i}} \\
\mathrm{Q}=\sum_{\mathrm{i}=1}^{\mathrm{n}} \mathrm{S}_{\mathrm{i}} \mathrm{Y}_{\mathrm{i}} \mathrm{Q}_{\mathrm{i}} / \sum_{\mathrm{i}=1}^{\mathrm{n}} \mathrm{S}_{\mathrm{i}} \mathrm{Y}_{\mathrm{i}}
\end{gathered}
$$

in which $\mathrm{S}_{\mathrm{i}}$ is the percentage of feed coal reporting to circuit $\mathrm{i}, \mathrm{Y}_{\mathrm{i}}$ is the clean coal yield from the separator in circuit $\mathrm{i}$, and $\mathrm{Q}_{\mathrm{i}}$ is the coal quality produced by the separator in circuit i. The overall plant yield $(\mathrm{Y})$ is normally limited by one or more constraints imposed on total product quality (Q). Consequently, most plant operators select circuit cut-points to ensure that the quality constraints are not exceeded in any given circuit, i.e., all circuits are set to produce the same quality. This objective is often difficult to achieve in practice due to natural fluctuations in the feed coal characteristics. To help alleviate this problem, a number of plants have installed on-line analyzers to provide instantaneous feedback regarding overall product quality. The control loops are generally configured to mimic the traditional operating philosophy of maintaining constant quality in all circuits. Circuit adjustments may be either manual (input by the operator) or automatic, depending on the level of control desired. Although this approach generally improves the consistency of the overall clean coal product, it does not ensure that the maximum plant yield has been achieved. 
The optimum operating points for different coal preparation circuits are those that maximize overall plant yield at a given clean coal quality. Depending on the liberation characteristics of the feed coal, this may or may not require identical product qualities for each circuit. A common method used to identify these optimum points is to sweep through all possible operating conditions for each circuit and to select the combination that provides the highest yield at the desired quality [15]. Obviously, this particular approach requires that the washability of the various feed coals be known at all points in time.

Another method for plant optimization is the concept of constant incremental quality. This concept, which has long been recognized in the coal preparation industry [16, $17,18]$, states that the clean coal yield for parallel operations is maximum when all circuits are operated at the same incremental quality. Incremental quality $\left(Q^{*}\right)$ may be conceptually defined as the quality of the last increment of mass added to a given product when the yield is increased by an infinitesimal amount. Mathematically, incremental quality $\left(\mathrm{Q}^{*}\right)$ is given by:

$$
\begin{gathered}
\mathrm{Y}(\mathrm{Q})+\Delta \mathrm{Y}\left(\mathrm{Q}^{*}\right)=(\mathrm{Y}+\Delta \mathrm{Y})(\mathrm{Q}+\Delta \mathrm{Q}) \\
\mathrm{Q}^{*}=\frac{(\mathrm{Y}+\Delta \mathrm{Y})(\mathrm{Q}+\Delta \mathrm{Q})-\mathrm{Y}(\mathrm{Q})}{\Delta \mathrm{Y}}=\mathrm{Y} \frac{\Delta \mathrm{Q}}{\Delta \mathrm{Y}}+\mathrm{Q}+\Delta \mathrm{Q} \approx \mathrm{Y} \frac{\Delta \mathrm{Q}}{\Delta \mathrm{Y}}+\mathrm{Q}
\end{gathered}
$$

in which $\Delta \mathrm{Y}$ and $\Delta \mathrm{Q}$ are the infinitesimal increases in the product yield (Y) and quality (Q), respectively [19].

The mathematical proof of the incremental quality concept is relatively straightforward for a simple two-circuit plant. According to Eq. [7], the combined yield quality can be determined from:

$$
\mathrm{Y}=\mathrm{S}_{1} \mathrm{Y}_{1}+\mathrm{S}_{2} \mathrm{Y}_{2}
$$

The expression for $\mathrm{Y}$ can be maximized by taking the derivative of $\mathrm{Y}$ with respect to $\mathrm{Y}_{1}$ and setting the result equal to zero. This gives: 


$$
\frac{\partial Y}{\partial Y_{1}}=S_{1}+S_{2} \frac{\partial Y_{2}}{\partial Y_{1}}=0 \quad \text { or } \quad \frac{\partial Y_{2}}{\partial Y_{1}}=-\frac{S_{1}}{S_{2}}
$$

Likewise, Eq. [8] can be used to determine a second governing expression for Y, i.e.:

$$
\mathrm{Y}=\mathrm{S}_{1} \mathrm{Y}_{1}+\mathrm{S}_{2} \mathrm{Y}_{2}
$$

This expression can be maximized by taking the derivative of $\mathrm{Y}$ with respect to $\mathrm{Y}_{2}$ and setting the result equal to zero. This gives:

$$
\begin{aligned}
\frac{\partial \mathrm{Y}}{\partial \mathrm{Y}_{2}}= & \frac{\mathrm{S}_{1}}{\mathrm{Q}}\left(\mathrm{Y}_{1} \frac{\partial \mathrm{Q}_{1}}{\partial \mathrm{Y}_{2}}+\mathrm{Q}_{1} \frac{\partial \mathrm{Y}_{1}}{\partial \mathrm{Y}_{2}}\right)+\frac{\mathrm{S}_{2}}{\mathrm{Q}}\left(\mathrm{Y}_{2} \frac{\partial \mathrm{Q}_{2}}{\partial \mathrm{Y}_{2}}+\mathrm{Q}_{2}\right)=0 \\
& -\frac{\mathrm{S}_{1}}{\mathrm{~S}_{2}}\left(\mathrm{Y}_{1} \frac{\partial \mathrm{Q}_{1}}{\partial \mathrm{Y}_{2}}+\mathrm{Q}_{1} \frac{\partial \mathrm{Y}_{1}}{\partial \mathrm{Y}_{2}}\right)=\mathrm{Y}_{2} \frac{\partial \mathrm{Q}_{2}}{\partial \mathrm{Y}_{2}}+\mathrm{Q}_{2}
\end{aligned}
$$

Substituting Eq. [12] gives:

$$
\mathrm{Y}_{1} \frac{\partial \mathrm{Q}_{1}}{\partial \mathrm{Y}_{1}}+\mathrm{Q}_{1}=\mathrm{Y}_{2} \frac{\partial \mathrm{Q}_{2}}{\partial \mathrm{Y}_{2}}+\mathrm{Q}_{2} \text { or } \mathrm{Q}_{1} *=\mathrm{Q}_{2} *
$$

Eq. [16] states that each circuit should be operated at the same incremental quality in order to maximize total plant yield (Y) at a fixed quality (Q). This condition is true for any number of parallel circuits and is independent of the size and washability characteristics of the feed coal. This finding dictates that plant-wide performance can only be optimized by maintaining constant incremental qualities in all parallel circuits at all times irrespective of variations in the characteristics of the feed coal. As such, this concept does not support the traditional plant control strategy that utilizes feedback from on-line "quality" analyzers to make real-time adjustments to circuit cut-points (see Figure 38a). While the traditional approach improves the consistency of the clean coal quality, it does not optimize plant yield. On the other hand, circuits operated under constant incremental quality will optimize yield, but will often generate clean coal products of highly variable quality. In many cases, the resultant variability will not be acceptable to downstream customers. 

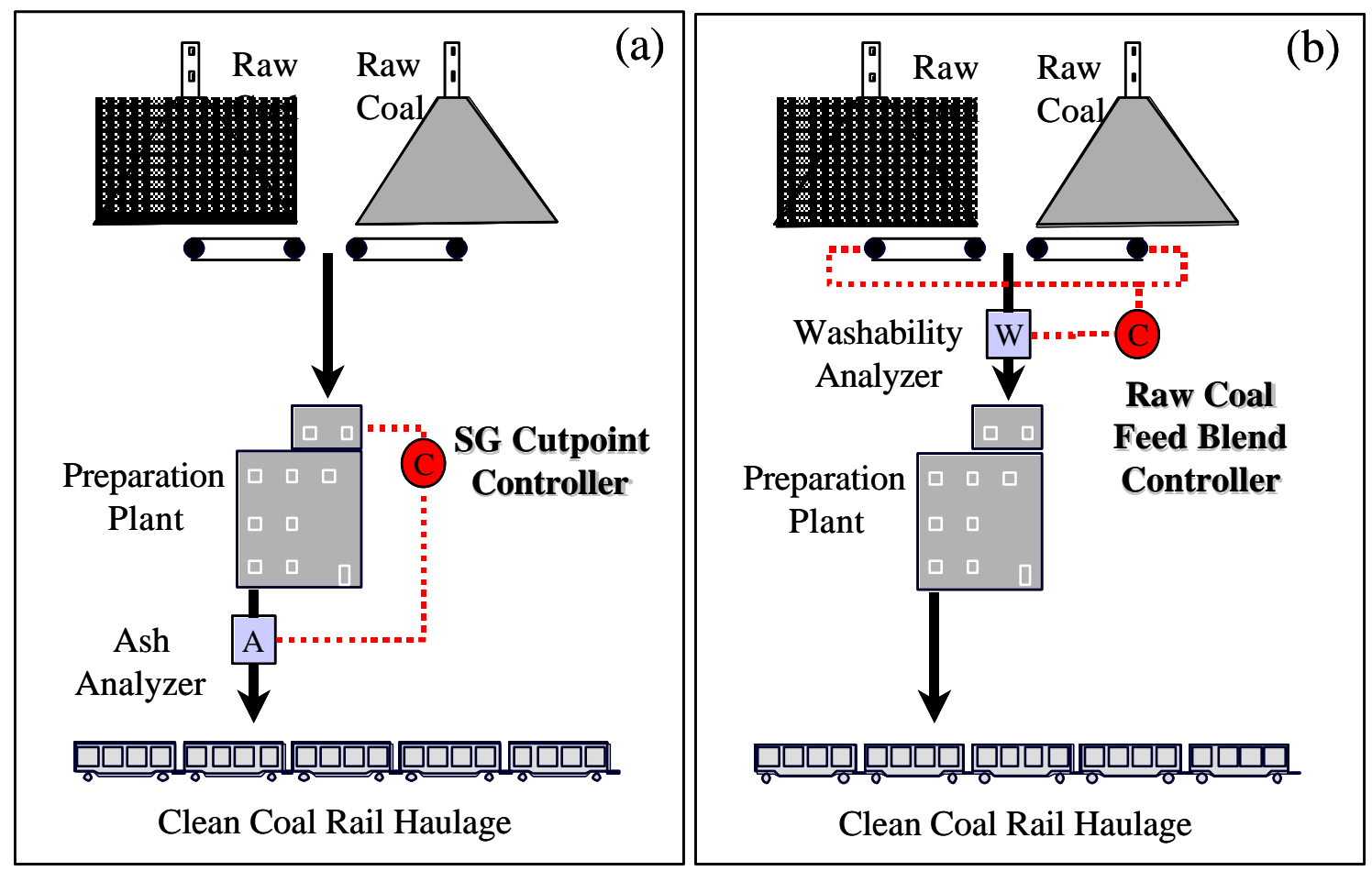

Figure 38. Alternative strategies for controlling clean coal quality by (a) the traditional approach involving manipulation of circuit specific gravity cut-points and (b) the measurement of feed coal washability and adjustment of feed coal blends.

An attractive solution to the variability problem is to blend the feed coals just prior to washing. In this control strategy, different feed coals are stored in separate feed stockpiles according to their washability characteristics (see Figure 38b). The on-line washability analyzer being developed in this project would be ideally suited for this type of application. Based on feedback from an on-line analyzer, different ratios of coal from the piles are then fed to the plant as required to maintain a constant clean coal quality for the overall plant. This approach allows the quality of the clean coal to be adjusted on-line while keeping the same incremental quality at all points in time. The added advantage of this approach is that the plant sees a relatively constant feed washability, which avoids overloading of individual circuits and allows overall plant capacity to be maximized. 
The only shortcoming of the proposed "washability-based" control strategy is that the potential exists for one of the stockpiles to be depleted if long-term changes in the coal washability occur. To overcome this problem, a supervisory control scheme may be used to adjust the plant cut-point. For example, if the "better" coal is completely consumed, the cut-point must be lowered and yield sacrificed to maintain a constant product quality. Alternatively, the system could be designed to issue an alarm to the plant operator who could choose to maintain the same cut-point and ship the lower quality coal to a different market. In any case, the goal of this particular control scheme is to absorb short-term changes in coal washability through variations in stockpile levels without requiring a change in circuit cut-points.

\section{$\underline{\text { Economic Justification for On-Line Washability Analysis }}$}

In order to evaluate the potential economic benefits of the proposed analyzer, a series of plant simulations were performed for the processing of the plus $6.35 \mathrm{~mm}$ and 6.25 x $1 \mathrm{~mm}$ size fractions. A combined plant feed rate of $750 \mathrm{tph}$ was assumed for these two sizes and a clean coal ash content of $5 \%$ was targeted. The simulations were performed using "poor" and "good" plant feeds determined from statistical analyses of the plant data described in the previous section of this report. A regression routine developed as part of this project was used to expand the washability data into classes between 1.2 SG and 2.2 $\mathrm{SG}$ in increments of $0.10 \mathrm{SG}$ units.

As expected, the simulation data showed that it was impossible to maintain a constant product ash content as the plant feed varied between good and poor washabilities. Therefore, simulations were performed to evaluate the effectiveness of a control system that employs a traditional on-line ash analyzer to maintain a constant product ash in all circuits. This control strategy allowed $309.8 \mathrm{tph}$ of blended clean coal to be produced at 5\% ash (see Table VIII). Simulation runs were also performed to determine the performance that may be achieved using a washability analyzer for plant control. In this case, 314.4 tph of clean coal were produced at $5 \%$ ash (see Table IX). The net difference between the "ash-based" and "washability-based" control schemes is about 4.6 tph of additional clean coal. For a metallurgical coal sold at $\$ 36.50 /$ ton, this represents in excess 
of $\$ 1$ million in revenues annually (i.e., Revenue $=4.6$ ton $/ \mathrm{hr} \times \$ 36.50 /$ ton $\times 6000 \mathrm{hrs} / \mathrm{yr}=$ $\$ 1,007,400 / y r)$. Therefore, a large financial incentive exists for the development of the proposed on-line washability analyzer and washability-based control system.

Table VIII. Simulation of a control system utilizing a traditional ash analyzer.

\begin{tabular}{ccclccc}
\hline & \multicolumn{2}{c}{ Plus 6.25 mm } & \multicolumn{2}{c}{$6.25 \mathrm{~mm} \times 16 \mathrm{M}$} & \multicolumn{2}{c}{ Overall Product } \\
\hline Coal & Clean & Ash & Clean & Ash & Clean & Ash \\
Feed & $(\mathrm{tph})$ & $(\%)$ & $(\mathrm{tph})$ & $(\%)$ & $(\mathrm{tph})$ & $(\%)$ \\
\hline Poor & 75.5 & 5.00 & 197.2 & 5.00 & 272.8 & 5.00 \\
Good & 124.2 & 5.00 & 222.6 & 5.00 & 346.8 & 5.00 \\
\hline Blend & 99.9 & 5.00 & 209.9 & 5.00 & $\mathbf{3 0 9 . 8}$ & $\mathbf{5 . 0 0}$ \\
\hline
\end{tabular}

Table IX. Simulation of a control system utilizing a washability analyzer.

\begin{tabular}{ccclccc}
\hline & \multicolumn{2}{c}{ Plus 6.25 mm } & \multicolumn{2}{c}{$6.25 \mathrm{~mm} \times 16 \mathrm{M}$} & \multicolumn{2}{c}{ Overall Product } \\
\hline Coal & Clean & Ash & Clean & Ash & Clean & Ash \\
Feed & $(\mathrm{tph})$ & $(\%)$ & $(\mathrm{tph})$ & $(\%)$ & $(\mathrm{tph})$ & $(\%)$ \\
\hline Poor & 74.8 & 4.82 & 190.2 & 3.85 & 265.1 & 4.12 \\
Good & 137.6 & 6.29 & 226.1 & 5.25 & 363.7 & 5.64 \\
\hline Blend & 106.2 & 5.77 & 208.1 & 4.61 & $\mathbf{3 1 4 . 4}$ & $\mathbf{5 . 0 0}$ \\
\hline
\end{tabular}




\section{SUMMARY AND CONCLUSIONS}

\section{Part I: Development of CT-Based On-Line Coal Washability Analyzer}

The development of the x-ray CT-based washability analyzer requires wellcharacterized test samples for use in calibration and testing. In this regard, samples of feed coal were collected, sized and subdivided into narrow specific gravity classes for use in the development and calibration of the $\mathrm{CT}$ analyzer. Approximately 40 size/density fractions were generated by this procedure. To use the CT measurement for coal washability analysis, it is necessary to do a calibration step with known density material or directly determine the density using dualenergy scans. Both methods were evaluated. In practice, full attenuation coefficient histograms of the sample composed of single-size/singledensity particles were characterized in detailed and used to calibrate the density scale. Two approaches (namely 3-D and 2-D mass density distribution analyses) were developed to facilitate the separation and classification the density distribution of the coal particle bed. The software package, Volume Slicer, was developed for displaying and managing the 3-D data sets. Volume Slicer allows the user to download the sequence of the original 2-D images and to examine the tomographic plane at different positions and from different view points (angles).

A methodology based on the finite mixture model and an appropriate image processing technique was developed to analyze the mass density distribution for the coal sample. In addition, an integrated software system with graphical user interface (GUI) was developed which allows the user to download the sequence of the original CT image slices. This system facilitates the separation and classification of particle images in order to obtain the washability analysis.

Two single-size/multiple-density samples were prepared to evaluate the washability analysis using the $\mathrm{x}$-ray $\mathrm{CT}$ technique. Using the algorithm for the mass density distribution analysis and a specially developed integrated software system, 150 and 124 2D $\mathrm{CT}$ images were analyzed. The results indicate that the specific gravity/yield curves can be 
constructed using the xray CT technique with good agreement with data obtained from independent sink-float tests.

\section{Part II: Evaluation Under Simulated On-Line Conditions}

A methodology based on the finite mixture model and an appropriate successive subtraction technique is discussed for development of the X-ray CT-based washability analyzer. In summary, full attenuation coefficient histograms of the coal sample from x-ray CT analysis is used to calibrate the density scale and to obtain the mass density distribution for the coal sample.

The performance of the on-line washability analyzer has been evaluated under simulated plant conditions and data has been used to assess the accuracy of the unit for monitoring plant organic efficiency. Composite samples were collected on a weekly basis starting mid February 2000 and running through mid July 2000. Preliminary results of this sampling campaign are presented. Plant site samples were prepared to evaluate the washability analysis using the x-ray CT technique. Using the newly developed methodology for the mass density distribution analysis, scaled attenuation coefficient histograms of the 2D CT images of these samples were analyzed. The results indicate that specific gravity/yield curves can be constructed using the x-ray CT technique and that these results are in good agreement with the data obtained from independent sink-float tests.

Potential applications of the on-line washability analyzer were evaluated. According to a theoretical principle known as the incremental quality concept, a plant limited by an upper constraint on clean coal quality will produce maximum total yield when (i) all parallel circuits are operated at the same incremental quality and (ii) the incremental quality is held constant throughout the entire duration of a given production cycle. As such, this concept supports the on-line measurement of feed coal washability and subsequent blending of feed coals prior to cleaning in order to maximize coal recovery at a given quality level. This concept does not support the traditional approach to plant control that involves the realtime adjustment of specific gravity cut-points based on online measurements of product quality. A plant that raises and lowers specific gravity cut- 
points to maintain constant quality in response to changes in feed washability will always produce less clean coal than a plant that maintains the same cut-points and is fed a relatively constant washability. Data obtained from a case study indicate that additional revenues in excess of $\$ 1$ million annually are possible through the implementation of a control system based on feed blending in conjunction with on- line washability analysis. 


\section{REFERENCES}

1. J. W. Leonard, (ed.), Coal Preparation, 4th Ed., AIME, New York, 1979.

2. G. Norton, The Economic Role of Coal Preparation in the Production and Utilization of Coal for the Market, Internal Publication, Norton-Hambleton Consultants, Inc., 3135 Professional Drive, Ann Arbor, MI., 1979.

3. G. T. Herman, Image Reconstruction From Projections: The Fundamentals of Computerized Tomography, Academic Press, New York, 1980.

4. W. F. Banholzer, C. L. Spiro, P. G. Kosky and D. H. Maylotte, Direct Imaging of Time-Averaged Flow Patterns in a Fluidized Reactor Using X-ray Computed Tomography, Ind. Eng. Chem. Res., 26, 763-767 (1987).

5. B. P. Flannery, H. W. Deckman, W. G. Roberg and K. L. D'Amico, ThreeDimensional X-ray Microtomography, Science, 237, 1439-1444 (1987).

6. B. P. Flannery and W. G. Roberg, Observations: Strategies for Three-Dimensional Synchrotron Microtomography, J. Appl. Phys, 62 (12), 4668-4674 (1987).

7. D. H. Maylotte, P. G. Krosky, C. L. Spiro, E. J. Lamby and A. Davis, Computed Tomography of Coals, DOE Quarterly Technique Progress Report. No. 5-10, Contract DE-AC21-82MC19210, 1984.

8. C. L. Spiro, D. S. Holmes, J. Lobos and D. H. Maylotte, Use the X-ray Computed Tomography to Examine Microbial Desulfurization of Lump Coal, Energy and Fuels, 1, 76-79 (1987).

9. C. L. Lin, J. D. Miller, A. B. Cortes and R. Galery, Coal Washability Analysis by Xray Computed Tomography, Coal Preparation, 9, 107-119 (1991).

10. S. L. Wellington and H. J. Vinegar, X-ray Cmputerized Tomography, J. of Petroleum Technology, 8, 885-898 (1987).

11. E. C. McCullough, Photon Attenuation in Computed Tomography, Medical Physics, 2, 307-320 (1975).

12. J. D. Miller, C. L. Lin and A. B. Cortes, A Review of X-ray Computed Tomography and Its Applications in Mineral Processing, Mineral Processing and Extractive Metallurgy Reviews, 7, 1-18 (1990). 
13. D. H. Titterington, A. F. M. Smith and U. E. Makov, Statistical Analysis of Finite Mixture Distribution, John Wiley \& Sons, New York, 1985.

14. W. Wang, Computer Vision for Rock Aggregates, Doctoral Thesis, Royal Institute of Technology, Stockholm, Sweden, 1997.

15. Peng, F.F. and Luckie, P.T., 1991. Process Control - Part I: Separation Evaluation, Coal Preparation, J. Leonard (Ed.), 5th Ed., SME, Littleton, Colorado, 659-716.

16. Mayer, F.W., 1950. A New Washing Curve. Gluckauf, 86: 498-509.

17. Dell, C.C., 1956. The Mayer Curve, Colliery Guardian, Vol. 33, pp. 412-414.

18. Rayner, J.G., 1987. Direct Determination of Washing Parameters to Maximize Yield at a Given Ash, Bull. Proc. Australia Inst. Mining and Metallurgy, 292(8): 67-70.

19. Abbott, J., 1982. The Optimisation of Process Parameters to Maximise the Profitability from a Three-Component Blend, 1st Australian Coal Preparation Conf., April 6-10, Newcastle, Australia, 87-105. 
Appendix A

Float-Sink Data

Stockton Coal Seam 
Table A-1. Particle size distribution for the Stockton coal sample.

\begin{tabular}{|c|c|c|c|c|c|c|c|}
\hline \multicolumn{2}{|c|}{ Particle Size } & \multicolumn{3}{c|}{ Individual Basis } & \multicolumn{3}{c|}{ Cumulative Basis } \\
\hline Passing & Retain & Mass (\%) & Ash (\%) & Unit & Mass (\%) & unit & Ash(\%) \\
\hline & $2 "$ & 9.47 & 46.11 & 436.7 & 9.47 & 436.7 & 46.11 \\
$2 "$ & $1 "$ & 17.21 & 34.01 & 585.3 & 26.68 & 1022.0 & 38.30 \\
$1 "$ & $1 / 2 "$ & 21.10 & 31.45 & 663.6 & 47.78 & 1685.6 & 35.28 \\
$1 / 2 "$ & $3 / 8 "$ & 8.80 & 30.78 & 270.9 & 56.58 & 1956.4 & 34.58 \\
$3 / 8 "$ & $1 / 4 "$ & 8.92 & 32.45 & 289.5 & 65.50 & 2245.9 & 34.29 \\
$1 / 4 "$ & $14 \mathrm{M}$ & 20.89 & 31.19 & 651.6 & 86.39 & 2897.4 & 33.54 \\
$14 \mathrm{M}$ & $28 \mathrm{M}$ & 3.83 & 29.84 & 114.3 & 90.22 & 3011.7 & 33.38 \\
$28 \mathrm{M}$ & $60 \mathrm{M}$ & 3.08 & 27.67 & 85.2 & 93.30 & 3097.0 & 33.19 \\
$60 \mathrm{M}$ & $100 \mathrm{M}$ & 1.15 & 26.95 & 31.0 & 94.45 & 3127.9 & 33.12 \\
$100 \mathrm{M}$ & $325 \mathrm{M}$ & 1.51 & 25.02 & 37.8 & 95.96 & 3165.7 & 32.99 \\
$325 \mathrm{M}$ & & 4.04 & 48.57 & 196.2 & 100.0 & 3362.0 & 33.62 \\
\hline & & 100.00 & & & & & \\
\hline
\end{tabular}

Table A-2. Float-sink analyses for the Stockton coal sample (plus 2 inch).

\begin{tabular}{|c|c|c|c|c|c|c|c|}
\hline \multicolumn{2}{|c|}{ Snecific Gravitv } & \multicolumn{3}{|c|}{ Individual Basis } & \multicolumn{3}{c|}{ Cumulative Basis } \\
\hline Sink & Float & Mass (\%) & Ash (\%) & Unit & Mass(\%) & unit & Ash(\%) \\
\hline \multirow{3}{*}{1.30} & 1.30 & 14.81 & 3.63 & 53.8 & 14.81 & 53.8 & 3.63 \\
1.40 & 1.40 & 11.71 & 9.58 & 112.2 & 26.52 & 165.9 & 6.26 \\
1.50 & 1.50 & 12.23 & 20.71 & 253.3 & 38.75 & 419.2 & 10.82 \\
1.60 & 1.60 & 4.14 & 27.24 & 112.8 & 42.89 & 532.0 & 12.40 \\
1.70 & 1.70 & 3.27 & 35.17 & 115.0 & 46.16 & 647.0 & 14.02 \\
1.80 & 1.90 & 3.58 & 43.08 & 154.2 & 49.74 & 801.2 & 16.11 \\
1.90 & 2.00 & 4.44 & 57.50 & 255.3 & 57.53 & 1230.2 & 21.38 \\
2.00 & 2.10 & 1.13 & 62.10 & 70.2 & 58.66 & 1330.3 & 22.17 \\
2.10 & & 41.34 & 80.10 & 3311.3 & 100.0 & 4611.7 & 46.12 \\
\hline & & 100.00 & & & & & \\
\hline
\end{tabular}


Table A-3. Float-sink analyses for the Stockton coal sample (2 x 1 inch).

\begin{tabular}{|c|c|c|c|c|c|c|c|}
\hline \multicolumn{2}{|c|}{ Snecific Gravitv } & \multicolumn{3}{|c|}{ Individual Basis } & \multicolumn{3}{c|}{ Cumulative Basis } \\
\hline Sink & Float & Mass (\%) & Ash (\%) & Unit & Mass(\%) & unit & Ash(\%) \\
\hline & 1.30 & 17.81 & 2.89 & 51.5 & 17.81 & 51.5 & 2.89 \\
1.30 & 1.40 & 19.51 & 10.73 & 209.3 & 37.32 & 260.8 & 6.99 \\
1.40 & 1.50 & 19.61 & 21.55 & 422.6 & 56.93 & 683.4 & 12.00 \\
1.50 & 1.60 & 7.77 & 28.32 & 220.0 & 64.70 & 903.5 & 13.96 \\
1.60 & 1.70 & 2.55 & 37.71 & 96.2 & 67.25 & 999.6 & 14.86 \\
1.70 & 1.80 & 3.47 & 43.90 & 152.3 & 70.72 & 1151.9 & 16.29 \\
1.80 & 1.90 & 2.70 & 51.53 & 139.1 & 73.42 & 1291.1 & 17.58 \\
1.90 & 2.00 & 2.25 & 56.16 & 126.4 & 75.67 & 1417.4 & 18.73 \\
2.00 & 2.10 & 2.93 & 62.71 & 183.7 & 78.60 & 1601.2 & 20.37 \\
2.10 & & 21.40 & 84.11 & 1800.0 & 100.0 & 3401.1 & 34.01 \\
\hline & & 100.00 & & & & & \\
\hline
\end{tabular}

Table A-4. Float-sink analyses for the Stockton coal sample (1 x 1/2 inch).

\begin{tabular}{|c|c|c|c|c|c|c|c|}
\hline \multicolumn{2}{|c|}{ Snecific Gravitv } & \multicolumn{3}{|c|}{ Individual Basis } & \multicolumn{3}{c|}{ Cumulative Basis } \\
\hline Sink & Float & Mass (\%) & Ash (\%) & Unit & Mass(\%) & unit & Ash(\%) \\
\hline & 1.30 & 22.72 & 3.14 & 71.3 & 22.72 & 71.3 & 3.14 \\
1.30 & 1.40 & 20.01 & 10.10 & 202.1 & 42.73 & 273.4 & 6.40 \\
1.40 & 1.50 & 18.85 & 23.16 & 436.6 & 61.58 & 710.0 & 11.53 \\
1.50 & 1.60 & 8.19 & 29.06 & 238.0 & 69.77 & 948.0 & 13.59 \\
1.60 & 1.70 & 3.04 & 38.29 & 116.4 & 72.18 & 1064.4 & 14.62 \\
1.70 & 1.80 & 2.43 & 47.36 & 115.1 & 75.24 & 1179.5 & 15.68 \\
1.80 & 1.90 & 2.07 & 52.61 & 108.9 & 77.31 & 1288.4 & 16.67 \\
1.90 & 2.00 & 1.65 & 59.87 & 98.8 & 78.96 & 1387.2 & 17.57 \\
2.00 & 2.10 & 2.79 & 63.43 & 179.8 & 81.75 & 1566.9 & 19.17 \\
2.10 & & 18.25 & 86.48 & 1578.3 & 100.0 & 3145.2 & 31.45 \\
\hline & & 100.00 & & & & & \\
\hline
\end{tabular}


Table A-5. Float-sink analyses for the Stockton coal sample (1/2 x 3/8 inch).

\begin{tabular}{|c|c|c|c|c|c|c|c|}
\hline \multicolumn{2}{|c|}{ Snecific Gravitv } & \multicolumn{3}{|c|}{ Individual Basis } & \multicolumn{3}{c|}{ Cumulative Basis } \\
\hline Sink & Float & Mass (\%) & Ash (\%) & Unit & Mass(\%) & unit & Ash(\%) \\
\hline & 1.30 & 21.30 & 3.24 & 69.0 & 21.30 & 69.0 & 3.24 \\
1.30 & 1.40 & 20.01 & 10.87 & 217.5 & 41.31 & 286.5 & 6.94 \\
1.40 & 1.50 & 18.90 & 21.87 & 413.3 & 60.21 & 699.9 & 11.62 \\
1.50 & 1.60 & 10.74 & 29.77 & 319.7 & 70.95 & 1019.6 & 14.37 \\
1.60 & 1.70 & 3.36 & 39.64 & 133.2 & 74.31 & 1152.8 & 15.51 \\
1.70 & 1.80 & 2.58 & 46.73 & 120.6 & 76.89 & 1273.3 & 16.56 \\
1.80 & 1.90 & 2.14 & 54.97 & 117.6 & 79.03 & 1391.0 & 17.60 \\
1.90 & 2.00 & 1.79 & 60.62 & 108.5 & 80.82 & 1499.5 & 18.55 \\
2.00 & 2.10 & 3.24 & 65.91 & 213.5 & 84.06 & 1713.0 & 20.38 \\
2.10 & & 15.94 & 85.67 & 1365.6 & 100.0 & 3078.6 & 30.79 \\
\hline & & 100.00 & & & & & \\
\hline
\end{tabular}

Table A-6. Float-sink analyses for the Stockton coal sample ( $3 / 8$ x 1/4 inch).

\begin{tabular}{|c|c|c|c|c|c|c|c|}
\hline \multicolumn{2}{|c|}{ Snecific Gravitv } & \multicolumn{3}{|c|}{ Individual Basis } & \multicolumn{3}{c|}{ Cumulative Basis } \\
\hline Sink & Float & Mass (\%) & Ash (\%) & Unit & Mass(\%) & unit & Ash(\%) \\
\hline & 1.30 & 21.95 & 2.84 & 62.3 & 21.95 & 62.3 & 2.84 \\
1.30 & 1.40 & 24.14 & 10.39 & 250.8 & 46.09 & 313.2 & 6.79 \\
1.40 & 1.50 & 13.35 & 23.10 & 308.4 & 59.44 & 621.5 & 10.46 \\
1.50 & 1.60 & 9.14 & 30.92 & 282.6 & 68.58 & 904.1 & 13.18 \\
1.60 & 1.70 & 2.77 & 39.31 & 108.9 & 71.35 & 1013.0 & 14.20 \\
1.70 & 1.80 & 2.21 & 49.12 & 108.6 & 73.56 & 1121.6 & 15.25 \\
1.80 & 1.90 & 1.73 & 54.48 & 94.3 & 75.29 & 1215.8 & 16.15 \\
1.90 & 2.00 & 1.27 & 58.58 & 74.4 & 76.56 & 1290.2 & 16.85 \\
2.00 & 2.10 & 2.41 & 65.39 & 157.6 & 78.97 & 1447.8 & 18.33 \\
2.10 & & 21.03 & 85.39 & 1795.8 & 100.0 & 3243.6 & 32.44 \\
\hline & & 100.00 & & & & & \\
\hline
\end{tabular}

